\title{
THE DISPOSAL of
}

\section{RADIOACTIVE WASTE ON LAND}

DATA LIBRARY

Woods Hole Oceanographic Institution

Report of the

Committee on Waste Disposal of the

Division of Earth Sciences

April 1957 


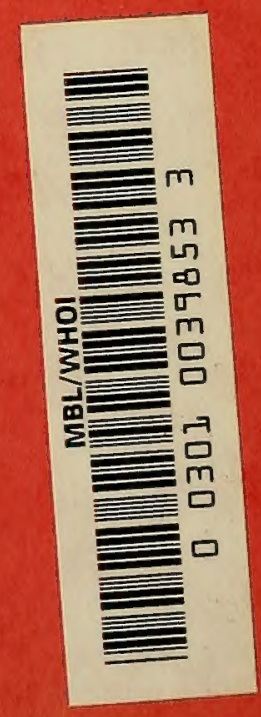




$$
\begin{gathered}
\text { Report of the } \\
\text { Committee on waste Disposal } \\
\text { of the } \\
\text { Division of Earth Sciences }
\end{gathered}
$$

Committee Members

Harry H. Hess, Chairman

John N. Adkins William B. Heroy

William E. Benson M. King Hubbert

John C. Frye Richard J. Russell

Charles V. Theis

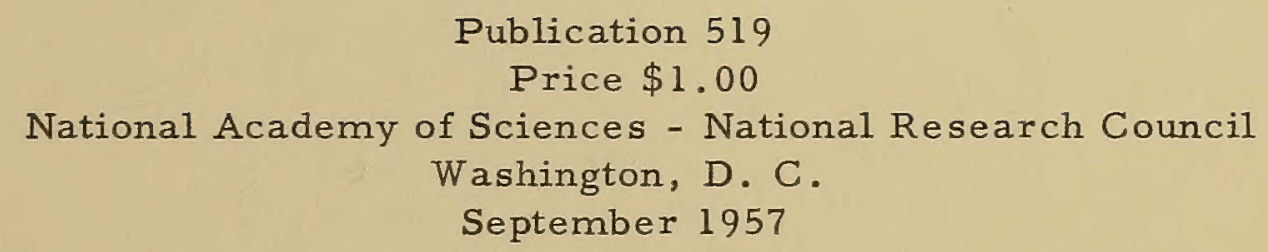


Library of Congress catalog card number: 57-60047 


\section{CONTENTS}

\section{Page}

Abstract

Report

Appendices

A - History of the Committee .............. 8

B - Proceedings of the Princeton Conference ...... 12

C - Committee on Deep Disposal ........... 82

D - Committee on Shallow Disposal .......... 91

E - Participants in the Conference ........... 104

F - Disposal of Radioactive Waste in Salt Cavities,... report by W. B. Heroy ............ 108 



\title{
NATIONAL ACADEMY OF SCIENCES - NATIONAL RESEARCH COUNCIL DIVISION OF EARTH SCIENCES \\ COMMITTEE ON WASTE DISPOSAL
}

\section{REPORT ON DISPOSAL OF RADIOACTIVE WASTE ON LAND}

\begin{abstract}
A committee of geologists and geophysicists was established by the National Academy of Sciences-National Research Council at the request of the Atomic Energy Commission to consider the possibilities of disposing of high level radioactive wastes in quantity within the continental limits of the United States. The group was charged with assembling the existing geologic information pertinent to disposal, delineating the unanswered problems associated with the disposal schemes proposed, and point out areas of research and development meriting first attention; the committee is to serve as continuing adviser on the geological and geophysical aspects of disposal and the research and development program.
\end{abstract}

The Committee with the cooperation of the Johns Hopkins University organized a conference at Princeton in September 1955. After the Princeton Conference members of the committee inspected disposal installations and made individual studies. Two years' consideration of the disposal problems leads to certain general conclusions. Wastes may be disposed of safely at many sites in the United States but, conversely, there are many large areas in which it is unlikely that disposal sites can be found, for example, the Atlantic Seaboard. The research to ascertain feasibility of disposal has for the most part not yet been done. Disposal in cavities mined in salt beds and salt domes is suggested as the possibility promising the most practical immediate solution of the problem. Disposal could be greatly simplified if the waste could be gotten into solid form of relatively insoluble character. In the future the injection of large volumes of dilute liquid waste into porous rock strata at depths in excess of 5,000 feet may become feasible but means of rendering the waste solutions compatible with the mineral and fluid components of the rock must first be developed. The main difficulties to the injection method recognized at present are to prevent clogging of pore space as the solutions are pumped into the rock and the prediction or control of the rate and direction of movement.

This initial report is presented in advance of research and development having been done to determine many scientific, engineering and economic factors, and, in the absence of essential data, represents considered judgments subject to verification. 
The Committee on Waste Disposal was set up at the request of the Atomic Energy Commission to study the possibilities of disposing of radioactive waste materials on land and to indicate what research was needed to determine feasibility.

In September 1955 a conference was held at Princeton which included representatives of AEC, members of the Department of Sanitary Engineering of Johns Hopkins, representatives of the U. S. Geological Survey, industry and many individual scientists competent in relevant fields. Informed opinions were rendered at the conference on the questions asked by AEC so the present general report can be a brief summary of the main conclusions. The factual data resulting from the conference are included in this report as appendices.

As an outgrowth of the conferences (the preliminary ones at Johns Hopkins and the comprehensive one at Princeton) numerous reports have been made by individuals and committees dealing with the waste problem. In particular the summary by Drs. Hatch and Lieberman for the NAS-NRC "Study Group on Dispersal and Disposal of Radioactive Wastes" covers in adequate form much of what might have been included in a report of the present committee.

The Conference and the subsequent studies of the Committee made it obvious that there is no specific answer to such a question as "How shall we dispose of radioactive waste?" On the other hand, given a specific geographic site and specific type of waste, a specific answer as to feasibility and cost of waste disposal becomes possible. It is then a chemical engineering, geological and economic investigation with definite parameters for which a definite answer or series of answers can be sought.

The Committee has considered the complex and varied problems of waste disposal on land and can express considered opinions on various of the problems and the research needed to deal with the problems. The Committee has in no sense done the research so that such expressions of opinion as are contained herein are predicated on the assumption that the research will be done before any final conclusion is reached on any type of waste disposal. 
Unlike the disposal of any other type of waste, the hazard related to radioactive waste is so great that no element of doubt should be allowed to exist regarding safety. Stringent rules must be set up and a system of inspection and monitoring instituted. Safe disposal means that the waste shall not come in contact with any living thing. Considering half-lives of the isotopes in waste this means for 600 years if $\mathrm{Cs}^{137}$ and $\mathrm{Sr}^{90}$ are present or for about one-tenth as many years if these two isotopes are removed.

The Committee has heard a number of descriptions of the waste disposal operations at Hanford and Oak Ridge and several committee members have visited the Oak Ridge Installation. Some questions exist at this time in the minds of most members concerning the long-term safety of waste disposal as practiced on these sites if continued for the indefinite future. A great deal of work has been done at each of them by competent men, but it is not possible to say exactly what may happen to the waste and how its component elements may disperse. The above statements should in no sense be regarded as criticism of officials responsible for the operation of these installations. They were constructed during the exigencies of a war so that plant location with respect to waste disposal could not be an over-riding consideration. They are in isolated localities far from population centers so that the hazard has been minimized in this respect, and in addition, continuing control is being maintained by the operators.

The Committee is convinced that radioactive waste can be disposed of safely in a variety of ways and at a large number of sites in the United States. It may require several years of research and pilot testing before the first such disposal system can be put into operation. Until such time storage in tanks will be required for waste.

The cost of safe waste disposal will probably be relatively high until a great deal of research has been done and experience gained. Transportation costs have to be added to over-all disposal custs. For this reason site selection for any chemical processing plant where large quantities of highly radioactive waste will be produced, must be based on availability of a disposal area within economic transportation distance. Economic balance will exist between length of cooling time in tanks at the site of waste production vs. cost of transportation in shielded carriers - - the thickness of the shielding required being dependent on cooling time. 
It will not be possible to dispose safely of large quantities of high-level waste in many large sections of the country. This circumstance may dictate that it will not be economically feasible to place those types of power reactors or other nuclear facilities which produce liquid wastes in large quantity in such unfavorable sections of the country. We have on several occasions been asked such questions as "Where can waste be disposed of within 25 miles of Tarrytown, New York?" The answer almost certainly is that waste cannot be disposed of safely anywhere near this site. We stress that the necessary geologic investigation of any proposed site must be completed and the decision as to a safe disposal means established before authorization for construction is given. Unfortunately such an investigation might take several years and cause embarrassing delays in the issuing of permits for construction. This situation can only be handled by starting investigation now of a large number of potential future sites as well as the complementary laboratory investigations of disposal methods.

With the example of Tarrytown mentioned above it might be remarked that the probability of finding a safe ultimate disposal means at the Savannah River plant appears equally gloomy. This only serves to emphasize the need for consideration of disposal before a site is chosen.

A discussion of the various possibilities for waste disposal may be found in Appendices C and D, the Reports of the Committees for "deep" and "shallow" disposal, respectively.

The most promising method of disposal of high level waste at the present time seems to be in salt deposits (see Appendix F by Heroy). The great advantage here is that no water can pass through salt. Fractures are self-sealing. Abandoned salt mines or cavities especially mined to hold waste are, in essence, long-enduring tanks . The possibility of making cavities in salt by pumping in water and removing brine is not favored (except for waste in solid form) unless the size and shape of such a cavity can be accurately controlled. The major element of potential risk in disposal in salt is that the cavity will collapse, structurally, in time. Salt is a weak material and will flow. Hence research is needed on size and shape of openings which can be relied upon to be structurally stable. The cavities should be at relatively shallow depth to avoid high confining pressures. Salt beds and mines are abundantly available along the south side of the Great Lakes from New York to Michigan and also in the form of salt domes along much of the Gulf Coast. Smaller salt deposits are 
available at a number of other sites.

The second most promising method seems to be in forming a silicate brick or slag which would hold all elements of the waste in virtually insoluble blocks. These could be stored in sheds on the surface in arid areas or in dry mines.

Separation of the $\mathrm{Cs}$ and $\mathrm{Sr}$ isotopes from the waste and their storage in small packages or surface tanks would of course greatly simplify the general problem of waste disposal. Research on the feasibility of such separation should be pushed.

Finally, disposal of waste in porous media such as sandstones at comparatively great depth may eventually be possible. Unlike oil, the waste would be denser than the normal saline water contained in such beds provided the heat generated by radioactive decay after emplacement is not sufficient to reverse the density relationship. Instead of concentrating in and being immobilized in tops of anticlines it would sink to floors of synclines. Deep synclines with closure would be preferred as disposal structures inasmuch as they would largely immobilize the waste if it was not allowed to become too hot. The great difficulty with this potential method is that the character of the waste fluid would have to be drastically changed to permit it to disperse in the porous medium without clogging the pore space. If Acid aluminum nitrate wastes would almost certainly form a gel-like substance if pumped into a sandstone. Extraction of the radioactive elements from the much larger bulk of aluminum nitrate appears at present to be a prohibitively expensive process. If processes were changed to produce waste without this unfavorable character deep disposal would become much more reasonable. The possibility that great dilution of aluminum nitrate waste fluid might alleviate pore space clogging should be investigated though it does not seem likely that the problem will be solved in this way. Folded rocks containing. porous beds in which suitable structures could be located are widely distributed in the United States.

The above remarks indicate the most promising avenues on which research should be pressed. Besides these, it is necessary to train a number of geologists in the attributes of the wastes and the possible solution of the problems of their disposal. Geological investigation of a large number of potential sites for processing plants

I/ Edwin Roedder (USGS) (1956) Disposal of high aluminum radioactive waste solutions by injection into aquifers. 
or reactors producing liquid waste should be undertaken without delay. The question should not be phrased: "How can we dispose of waste at $\mathrm{X}$ site?" but should be: "Can or cannot waste be disposed of at $\mathrm{X}$ site?" The possibility of the negative answer should always be considered.

\section{SPECIFIC RECOMMENDATIONS ON DISPOSAL}

1. Storage in tanks is at present the safest and possibly the most economical method of containing waste.

2. Disposal in salt is the most promising method for the near future. Research should be pushed immediately on the structural problem of stability vs. size of cavities at a given depth; on the thermal problem - getting rid of the heat or keeping it down to acceptable levels - and on the economics of such disposal. (Appendix F by Heroy)

3. Next most promising seems to be stabilization of the waste in a slag or ceramic material forming a relatively insoluble product. This could be placed in dry mines, surface sheds or large cavities in salt.

4. Disposal of waste in porous beds interstratified with impermeable beds in a synclinal structure is a possibility for the more distant future. This is of particular interest for disposal of the large volumes of waste to be expected in the future. Very difficult and complex problems have to be solved before it will become feasible. The reaction of the waste with connate waters or constituents of the rocks soluble in the waste solution will have to be studied. The composition of the rocks and the connate waters are both variable as will be the composition of the waste solutions so that an almost infinite variety of circumstances result. In general acid aluminous waste would almost certainly tend to form precipitates which would clog pore spaces. The problem would have to be solved first for a given bed at a given site for a given waste solution at a given dilution.

5. The removal of $\mathrm{Cs}^{137}$ and $\mathrm{Sr}^{90}$ from the waste would make disposal somewhat easier for the waste free of these isotopes but does not change qualitatively the recommendations made in the report.

6. In the complex relations between (a) storage time of waste for cooling, (b) transportation cost in shielded carriers and (c) dis tance to disposal site, the last of these factors must be considered 
before location of any plant producing large quantities of waste, remembering that there are large sectors of the country where disposal is not possible.

7. Continuing disposal of certain / large volume $T$ low level waste in the vadose water zone, above the water table, is of limited application and probably involves unacceptable long term risks.

\section{GENERAL RECOMMENDATIONS ON COROLLARY PROBLEMS}

1. The movement of gross quantities of fluids through porous media is reasonably well understood by hydrologists and geologists, but whether this is accomplished by forward movement of the whole fluid mass at low velocity or whether the transfer is accomplished by rapid flow in "ribbons", is not known. In deep disposal of waste in porous media it will in many cases be essential to know which of these conditions exists. This will be a difficult problem to solve.

2. The education of a considerable number of geologists and hydrologists in the characteristics of radioactive wastes and its disposal problems is going to be necessary. 


\author{
APPENDIX A \\ HISTORY OF \\ COMMITTEE ON DISPOSAL OF RADIOACTIVE WASTE ON LAND
}

Following discussions between representatives of the Atomic Energy Commission and the National Academy of Sciences - National Research Council, contract number AT(30-1)-1788 was signed on February 28, 1955. The scope of the agreement was stated as follows :

1. The Contractor shall furnish personnel, facilities, and equipment, and do all things necessary for the purpose of conducting a program of research pertinent to the methods of disposing of radioactive waste materials in geologic structures. The work shall consist of the following:

a. Setting up a Steering Committee of leading scientists who will prepare and arrange for conferences on disposal methods;

b. Conducting the conferences;

c. Reporting to the Commission on the proceedings and comments of these conferences;

d. Evaluating all suggestions and research to date on disposal methods that involve land surface or underground sites, including the surface and underground water on the continents but excluding the oceans.

e. Recommending programs of research that should be carried out.

The Steering Committee appointed in March 1955 consisted of Harry H. Hess, Chairman, John N. Adkins, John C. Frye, M. King Hubbert, Chester R. Longwell, Richard J. Russell, and Charles V. Theis. In the fall of 1955, Dr. Longwell resigned because of the difficulties in attending committee meetings from his location in California, and William E. Benson and William B. Heroy were appointed. 
At the first meeting of the Steering Committee, held April 15, 1955, at Ames Hall of the Johns Hopkins University, seven members of the Committee met with eight members of the Sanitary Engineering Department and one representative of the Reactor Development Division, AEC. The entire problem was described and the previous general studies of disposal reviewed: a conference had been held in August 1954 at Woods Hole to explore with oceanographers the possibility of disposal in the oceans, and another had been held in Washington in November 1954 with geologists to consider underground disposal.

At the November 1954 conference the following plan was proposed anticipating the signing of a contract with AEC: a steering committee was to secure a proper definition of the problem (including as much technological data as was possible within the restrictions of security classification) and conduct two conferences with the guidance and assistance of the AEC and Hopkins group. The first meeting would have as its objective the generation of ideas and cataloging of suggestions for underground disposal of wastes, and the second would be to appraise critically the ideas, documenting the advantages and disadvantages, arranging the suggestions in order of apparent feasibility, and indicating the lines of research needed to arrive at reliable answers to the more pressing problems. The willingness of the Hopkins group to perform staff functions for the Committee was stated especially as regards compiling the unclassified technological data. The AEC relationships were summarized, and the desirability of the Committee visiting Oak Ridge was discussed. The minutes of this meeting were prepared by the Hopkins group.

During the summer of 1955 arrangements were made to hold the first conference at the Graduate School of Princeton University, Princeton, N. J., on September 10-12. Participants were selected and invited, and those who accepted the invitation were sent a digest of the essential data entitled "Radioactive wastes in the atomic energy industry" compiled by A. B. Joseph and J. M. Morgan, Jr., of the Hopkins group. The "graybook" summarized the information generally available up to March 31, 1955 on the kinds of waste, treatment and disposal methods, and the projected magnitudes of high level wastes and their disposal problems.

The Princeton Conference was attended by 65 persons representing many scientific and engineering disciplines, active in a variety of capacities in universities, research institutions, private 
companies, and government scientific agencies. The participants are listed in Appendix E.

During the afternoon and evening of September 10th, the conferees heard and discussed eleven informal talks which presented in considerable detail the various technological, economic, and theoretical problems of waste disposal. During and after the Geneva Conference on the Peaceful Uses of Atomic Energy (July 1955) a great deal of heretofore classified information was released: the Princeton Conference benefited from the unexpected availability of data on chemical processing and nature of waste solutions pertinent to the conference topic. After the conclusion of the eleventh talk on the morning of September $11 \mathrm{th}$, a lengthy period of general discussion and review followed. Two committees were then appointed to examine carefully the waste problem from two points of view; see Appendix B, page 75. The committees worked independently through the balance of the morning, the afternoon and evening of September 11th. The conference reconvened on September 12 th and heard summary reports from the Chairman of each committee. (See Appendix B, pages 76-81.) The Committee reports are given in Appendices C and D. This completed the work of the conference and it was adjourned at 11:30 a.m.

The conference deliberations were recorded by the stenotypist, Miss Jean Burleigh, and by a tape recorder provided by the Hopkins groups and operated by Mr. A. B. Joseph. The edited condensation is presented in Appendix B. The minutes of the Committee meetings were prepared by volunteers and are given in Appendices $C$ and $D$.

The Steering Committee met on September 12th to consider the next steps to take in the light of the results of the conference. It was decided that it was not necessary to hold a second conference because the first had succeeded in both generating and evaluating ideas as well as could be expected within the limitations of existing knowledge -- significant improvements on the ideas expressed could be made only by direct investigation, not by additional exchanges of opinions. Until the deliberations of the Conference were available, the Committee could do little to document the suggestions or prepare a report: the preparation of proceedings from the stenotype record was given first priority, and the manner in which the talks were to be edited, verified by the speakers, and distributed to the Committee was outlined. 
The next meeting of the Steering Committee was held in New Orleans on November 9, 1955. By that time the proceedings were complete with one exception. (See Appendix B, page 27). The consensus of the Committee was arrived at on the main points to be embodied in the report, and general premises on which it was to be based.

Some members of the Committee made independent inquiries on such topics as (a) the distribution, location, and annual increments to mine workings in salt deposits, (b) economics and technology of power transmission, (c) engineering procedures in oil field injection, (d) hydrology of deep aquifers, and (e) effect of carbonate wallrock on simulated waste solution. It was found generally that a great deal more specific information is available than was presented at the Conference but that the additional data do not simplify the problems nor point to possible solutions that had not been mentioned heretofore. The utilization of cavities in salt deposits for storage and disposal of wastes aroused considerable interest at the Conference so the location of the main salt mines and distribution of the principal salt deposits were documented by Mr. Heroy along with his study of the production and availability of mine workings in salt.

In this period the name "Steering Committee" became inappropriate, so the Division of Earth Sciences referred to the group at the Committee on Waste Disposal. Members of the Committee visited the AEC installations at Oak Ridge and Brookhaven, as follows:

Oak Ridge - Feb. 15-16, 1956: W. E. Benson, W. B. Heroy, M. K. Hubbert, R. J. Russell, C. V. Theis, and W. R. Thurston, Secretary.

Brookhaven - March 29, 1956: R. J.Russell and W. R. Thurston, Secretary; April 19, 1956: J. N. Adkins, W.E. Benson, W. B. Heroy, and M. K. Hubbert. 
NATIONAL ACADEMY OF SCIENCES - NATIONAL RESEARCH COUNCIL DIVISION OF EARTH SCIENCES

PROCEEDINGS of the PRINCETON CONFERENCE

$$
\text { on }
$$

DISPOSAL OF RADIOACTIVE WASTE PRODUCTS

Edited condensation from the record of the stenotype reporter.

September $10-12,1955$

Graduate College, Princeton University

Princeton, New Jersey 


\section{CONTENTS}

September 10, 1955

Page

\section{Afternoon Session}

R. J. Russell

- Opening remarks.............. 14

H. H. Hess

- Remarks .................... 14

A. E. Gorman

- Address and discussion .......... 15

Charles Renn

- Address and discussion ......... 18

J. T. Christy

- Address and discussion ......... 22

F. L. Culler, Jr. - Address and discussion ......... 32

\section{Evening Session}

H. H. Hess

- Remarks .................. 34

J. A. Lieberman

- Address and discussion .......... 34

A. M. Piper

- Address and discussion ......... 40

R. J. Morton

- Address and discussion ......... 50

E. G. Struxness

- Address and discussion

September 11, 1955

Sunday Morning Session

E. G. Struxness - Continuation of address and discussion .............. 58

General Discussion ......................... 64

Appointment of Committees .................. 75

September 12,1955

\section{Monday Morning Session}

Reports of Committees:

M. K. Hubbert ...................... 76

J. C. Frye ......................... 78

H. H. Hess - Closing remarks .............. 81 
14.

PROCEEDINGS OF THE PRINCETON CONFERENCE
ON THE DISPOSAL OF RADIOACTIVE WASTE PRODUCTS

SATURDAY AFTERNOON SESSION

September 10, 1955

The Conference on Disposal of Radioactive Waste Products convened in the Commons Room of the Graduate College, Princeton University, at 2 o'clock.

DR. RICHARD J. RUSSELL: On behalf of the Division of Earth Sciences of the National Academy of Sciences - National Research Council, I am happy to welcome you to this Conference and to see this meeting so well attended. We have been working with people at Johns Hopkins and with people from the A.E.C. since last November to prepare for this conference and plan for another one. We have called together a heterogeneous group of people from many different fields and disciplines with a cumulative total of a tremendous amount of experience.

The main objective in this Conference, as far as the Division of Earth Sciences is concerned, is to generate and list ideas for the underground disposal of high level wastes. That is our mission.

The ground rules have changed from time to time on the problem, and it has been very difficult for those associated with it to keep up with developments in the chemical processing which determine the nature of the materials we have to deal with. We have had the feeling several times that the problem has shifted completely from one area over to another; we believe that in this conference you will get a hint of the varied nature of the problems before us.

The preparation of this conference and the organization of the report which we will submit under the contract with the A.E.C., is under the direction of Harry Hess, who has served as Chairman of the Steering Committee, and who will preside at these meetings.

...Dr. H. H. Hess assumed the Chair ...

CHAIRMAN HESS: I would like to welcome you here on behalf of Princeton University. I am very happy, as Chairman of the Steering 
Committee, to see how many of you responded to our request to participate in this conference. I know it is a serious matter to leave your normal activities and devote several days to our problem, and I am delighted to see that so many of you have come.

The problem we have to deal with is a very complex one. This first day will be spent determining what the components are: they change rather rapidly; the whole problem has changed since our first meeting of last spring. We will have to get the necessary background to know what sort of a problem we are dealing with, and I hope before the meeting is over there will be some specific suggestions that can be looked into and that will lead at least in the direction of the solution or several solutions, however it may develop.

Mr. Gorman, of the A.E.C., has agreed to make the introductory remarks describing the Reactor Division's concept of the problem.

Mr. Gorman!

Mr.A. E. Gorman,

Reactor Development Division

U.S. Atomic Energy Commission,

Building $\mathrm{T} 5$,

1901 Constitution Avenue,

Washington 25, D. C.

MR. GORMAN: On behalf of the Reactor Division of the A.E.C., I want to take this occasion to thank you all for giving us your time and valuable assistance to discuss one of our acute problems, and also to thank the University for its courtesy in providing such excellent accommodations for us.

The Reactor Division is sponsoring the contracts with the National Academy of Sciences and Johns Hopkins University to evaluate problems connected with the disposal of high and low level radioactive wastes.

At this conference we are confining our attention to disposal of the high level wastes, which in A.E.C. we feel is a real serious problem. Because atomic energy work was begun during the war period, our plants were established in more or less distant and isolated places, and as problems of waste disposal arose they were not too difficult to take care of because of this isolation. Now, however, 
under the rapid growth of opportunities under the Atomic Energy Act of 1954 for privately-owned competitive industries to enter the field of atomic energy, some real problems are being posed. It seems inevitable that the industry will move toward more populated areas.

Our discussions with representatives of industry make it evident that they envision building reactors and fuel processing plants near their markets. When a new industry moves into a community which is already well integrated and well organized, it finds that its predecessors have certain established rights. The new industry wants to be a good neighbor. In the field of atomic energy we have to face the problem that the established regulatory agencies (which could take almost any industry and its waste problems in its stride), are not familiar with radiation as a contaminant, nor with the materials and the technology of the industry. Obviously, if the industry is to grow in a healthy way, it must be a "good neighbor," and that means having harmonious relations with the rest of the community and the regulatory agencies.

The group at Johns Hopkins University and the A.E.C. staff have been struggling with this waste problem for a number of years. To some extent, because of our geographically isolated locations, it has been possible "to sweep the problem under the rug," so to speak. But those of us who are close to it are convinced that we must face up to the fact that we are confronted by a real problem. I am sure that when you hear the details of the situation from those who follow me on today's program you also will be convinced.

When we tried to evaluate the problem in the early phases of the atomic energy program, we called upon the U. S. Geological Survey, the Weather Bureau, and many other governmental agencies, and many universities for assistance, but the problem of the disposal of high level waste is a long way from being resolved. It is one which causes deep concern because of the danger of contaminating local water supply, or having an unfavorable affect on natural resources. The volumes of waste are large but they are not excessive, compared with other industries. The main concern is the fact that some of the constituents of the wastes have long half-lives which require that the waste be kept under control for many, many years.

In addition to the consideration of safety there is also the question of cost. The handling of waste in our installations is costing tens of millions of dollars a year. The magnitude of this itam is such that 
it could be a serious deterrent to the development of a competitive industry, therefore, it merits a good deal of attention. In effect, in A.E.C. we feel it is our responsibility to find economical solutions before we can expect an industry to be developed, and to do so, we know we need a lot of help.

The problem has really two major categories: 1) where and how can we put wastes into the ground economically and under conditions which will not jeopardize the rights of others, especially in populated areas; and 2) what can we do with the large volume of wastes that have been and are yet to be produced at our production plants, particularly those which are being accumulated in underground tanks at the Hanford Works in the State of Washington. Almost every year appropriations must be made to build more and larger tanks, but this cannot go on forever. At least, we hope it will not go on forever. We are looking to this group for more rational schemes directed toward disposal to the ground.

Some of our difficulties have been described to the oceanographers and marine biologists in meetings which Dr. Renn will review. They have given us good advice: much of that advice indicates that we ought to consider further means of underground disposal. (Laughter) It seems to us, purely on the basis of economics, that ground disposal should be much cheaper than ocean disposal.

After the representatives of our contractor and our operations and field officers have briefed you on the character of the wastes and the current and foreseeable problems, we hope you will be able to make recommendations to us as to what methods have hope of being reasonably effective, and what type of research and development should be carried out in order to evaluate these potentialities.

The problem is extremely complex. It takes team work over a wide spectrum in order to put the problem before you in the proper light so that you may evaluate all aspects. If you can indicate to us the directions in which we should encourage research and development, we would be in a sound position to go to our budget people and ask for appropriations to study those approaches that have some probability of yielding positive solutions.

It is no ordinary responsibility to take part in the early phases of the growth of a new industry. Looking backward we know of the mistakes that many industries made in assuming that disposal of 
18.

wastes was simply a backdoor problem that anybody could handle. But in this new atomic energy industry hazards are magnified greatly by the unique potentialities of the wastes.

We have great hopes that as a result of your deliberations we can start an evaluation of the problem that will lead to final and economic disposal of high level radioactive wastes. By final, I mean returning those wastes to nature in some place where they can be held for very, very long periods of time without jeopardy to our environment or property. We know that we can extract from some of these wastes certain long half-life radioisotopes, but if this is done, you still have to keep a reasonable control over the use and storage of these materials. So the problem cannot be evaded by simply milking the wastes of their highly objectionable constituents.

I think, Dr. Hess, that is about all I want to say by way of introduction, because I know all of you are anxious to get down to the meat of the problem which those who follow me will be able to present to you.

CHAIRMAN HESS: Dr. Renn, of Johns Hopkins will continue the introduction.

Dr. Charles Renn, Department of Sanitary Engineering \& Water Resources, Johns Hopkins University, Baltimore 18, Md.

DR. CHARLES RENN: Five points were made at the most recent conference on ocean disposal of radioactive wastes which I think will interest you. This meeting was held on June 22-24, at Woods Hole, Massachusetts.

First, it is important to define the problem in terms of the volumes and characteristics of the different wastes so that the oceanographer can consider the variety of ways of disposing of materials in the seas.

For example, the coastal waters above the middle Atlantic continental shelf exchange, roughly, in a year and a half. This provides a relatively long growth interval for any crop to be in contact with wastes; there is a substantial hazarc to commercial fisheries if the waste material is released even in dilute form over the continental shelf. 
That brings up the question of dilution. A popular idea is that dilution is easy to obtain if you have large masses of water. However, the larger the masses of water; the more unpredictable the mechanism of dilution becomes. According to some evidence, saline wastes dumped in the ocean will move as thin horizontal layers thousands of times as rapidly as on the vertical plane, so that concentration of high order will be maintained over this horizontal band. There is a great hazard of isotopic movement and concentration along these bands. Those who are familiar with the dilution of industrial waste in larger rivers and harbors know the tendency of these wastes to move in narrow and uncontrolled streams, particularly along the edges. It takes a special circumstance to make available for dilution the full volume of a large mass of water. There are large gaps in our knowledge of the mixing mechanisms in oceanic masses.

The question of sequestering waste in the ocean came up. Where it is important to note the value of detailed knowledge of the ocean floor and of the water column. We have in the last ten years acquired a very extensive history of the vertical stratification of water, but there are very few areas where the stations have been sufficiently close together, and the measurements made with sufficient precision to accurately bound the water mass and determine the rate of water exchange. The measurements are close together in the study of the Carribean deeps, and include recent, very precise measurements. These deeps have some ideal characteristics. The deep is bounded by a natural escarpment, and has a single entrance and exit. It allows the oceanographer to assay the rate at which water enters and leaves the area. There is possibility of confinement, and it should be possible to predict the rate of eventual exchange within this confined mass.

A special hazard had to be considered: when the heat content of possible waste loads was examined, the thermal stability of this area was found to be -- as far as we know -- very close to the limit required for containment. It will require a more careful analysis of the situation to be certain whether we can introduce the heat at the bottom of the stratified water or not.

A very important point was brought up in the discussion of the tendency of planktonic organisms and their predators to concentrate the more active and troublesome fractions of waste. For example, the long-life elements are taken up quite appreciably by filter-feeding plankton. We simply don't know what the rate of concentration beyond 
the planktonic forms would be. Presumably, at each stage of production we would gain concentrations of activity where initial concentrations are high, and lose where initial concentrations are low. This represents a very considerable gap in our knowledge of the course of events following dilution and dispersion of dissolved and suspended wastes in the ocean. But this is not an insoluble problem. The oceanographer and the marine ecologist can make approximations to determine theoretical standards for the allowable concentration of isotopes. This would force the ecologist to examine all the important variables that enter into the marine environment.

The geologists presented an interesting discussion of ground water: it was suggested that it might be possible to enter some artesian aquifer that discharged at sea on the edge of the continental shelf. This would make it possible to introduce waste off the shelf into deep water without large disturbances. It would be much more convenient than transport by ocean vessel.

The question of packaged waste was considered. A common concept that many specialists in the field of atomic waste disposal have, and which has been considered at one time or another, is that packaged waste can be dumped in the deep, and that it will sink in the bottom oozes. A careful survey of such dumping ground would be required. The ideal condition a naturally enclosed area in which there is a deep bed of mud. Oceanographic and marine geological research indicates that suitable pockets of mud exist not far from shore on the Atlantic shelf, these would not involve deep sea operations, but might affect commercial fisheries, for example, those in the Gulf of Maine.

The oceanographers are not in agreement on rates of exchange between surface and deep waters. One group represents the view that the deep waters are roughly 2000 years old. The supporting data depend largely on carbon 14 measurements which are not wholly consistent. Another group contends that the rate of turnover of the deep is much more rapid, that the data from the oxygen distribution pattern and thermal stratification indicates relatively rapid movement.

This is a summary of the thinking in the field. We were very happy indeed to find that the oceanographers had seriously worked over the material that was presented as raw data, and that a large amount of diligent work had been done. They discussed the problems vigorously, and generated well developed philosophics on the waste disposal prohlem. 
DR. M. KING HUBBERT: Mr. Chairman, I would like to refer to the "graybook" of March 31, 1955. In view of the oceanographic discussions, I would like to comment on one statement that struck my attention: it was stated that if wastes were put in the deep water that they would have to be monitored by periodic observations, but that no major cable company would guarantee a cable two miles long for more than one or two trips.

That statement struck me as being odd, and I checked with the Schlumberger Company, who regularly lower things on cables down oil wells as much as four miles deep, and I asked them what the life of a cable is, and they said they are good for about 200 round-trips.

DR. RENN: I am glad you brought that up, Dr. Hubbert, because one of the points made by a small group of men was this: that the situation as far as monitoring is concerned has improved greatly. First of all, plastics have been developed which have low adsorption characteristics for fission products. Methods of signalling that permit a high degree of leakage have been developed, so that deep water systems would not become vulnerable to small leaks of sea water. Instrumentation is improving rapidly and the present emphasis is on increasing the sensitivity of the equipment. The conditions for handling sampling gear at sea differ from those of oil well logging. The weights are greater, and there are sudden strains due to ship and boom heaving, with the newer signal systems, longer effective life of cables is possible, however.

CHAIRMAN HESS: Are there any other questions you would like to bring up while Dr. Renn is still here?

DR. TRUMAN P. KOHMAN: I would like to ask a little more about getting material into the ocean flom coastal installations. Were you referring to underwater?

DR. RENN: This point was discussed more in detail by Dr. Ewing. He offered it purely as a possibility. The question under discussion at that time was how to get the waste across the continental shelf and out into deep ocean. His suggestion was simply that there must exist a number of strata which incline seaward, below the surface of the continental shelf, and intercepting the continental slope. The density of the introduced waste being higher than salt water, it would force the stream ahead and would eventually seep out below the edge of the shelf. 
DR. KOHMAN: In other words, there are no such existing rivers that flow underground in the sea against the more dense salt water, but the idea is they would create one?

DR. RENN: No, the implication was that these structures do exist. For example, in the Chesapeake Bay we have artesian springs, and the picture I get is that such inclined strata probably exist and break through the sloping faces of the shelf.

\section{CHAIRMAN HESS: Are there any other questions?}

If not, Dr. Christy, of Hanford, will tell us some of the problems they have out there in waste disposal.

I have to apologize to Dr. Christy. He did not know he was coming to discuss these problems until a few days ago, and he didn't know he was going to be a speaker until lunchtime.

Dr. Joseph T. Christy, Hanford.

DR. JOSEPH T. CHRISTY: Hanford is the name of an Atomic Energy Commission site in the northwestern part of this country, on the Columbia River in southeastern Washington. A schematic breakdown of the operations will permit the presentation of a generalized view of the plants, within the limitations of security classifications.

The Columbia River forms one boundary of our site, and the reactors are along the river. The major radioactive waste problem at Hanford does not involve the waters of the Columbia River which is tapped for flow through the reactors, and is returned to the river to dissipate heat generated in the reactor. The radioactivity is negligible because the water is not recirculated and there is no concentration of activity; furthermore, there is no significant contamination by fuel elements from rupture. The major waste problems are in the chemical separations plants.

Early Hanford consisted of reactors and three major chemical processing plants, of which only two were operated initially. A fourth plant was not completed except for waste tanks, and the third plant became a stand-by. At each one of these plants, separate storage facilities were provided for many thousands of gallons of waste. Essentially all of the waste from the initial plants was stored, because 
no other safe disposal method was known. In time, under an accelerated program, storage space was exhausted so another set of tanks was installed. Included in initial wastes was a considerable amount of material for which there was use and which required recovery. The stand-by plant was re-equipped and placed into operation and the waste from most of the tanks was processed. In the chemical processing for recovery the waste fed to the recovery plant was added to, resulting in more waste to store.

The handling of radioactive wastes at Hanford involved stored quantities measured in many millions of gallons, in underground tank farms separated from two to six miles, and extensive transfer pipe shielding. In initial plant operation, there were several types of waste to handle: a) a high level waste from which a valuable constituent was recovered by reprocessing; b) an intermediate waste, active enough to necessitate storing; and c) a low level waste which, after being passed through a series of tanks arranged in a "cascade" system, could be fed into a cribbed excavation and allowed to seep into the ground; by this arrangement, most of the radioactivity of the low level waste is concentrated in sediments that fall out in the tanks. The radioactive material appears to adhere to certain types of solids. If the initial solution is of relatively low activity it can be disposed of through cribs in the ground. A plant producing this type of waste is still operating and the waste is being handled essentially in this fashion. The high-level waste is being reprocessed after storage in tanks for a period of a year and a half to two years. After recovery, nickel ferrocyanide is used as a scavenging agent on the resultant wastes to remove two major fission products, cesium 137 and strontium 90 . The nickel ferrocyanide is added to the waste before it leaves the plant. The nickel ferrocyanide forms a precipitate, and the presence of the phosphate ion aids in soil retention for cribbing the supernatant. The low level supernatant is allowed to seep into the ground but tanks are required to hold the sludges. The intermediate-type waste has been concentrated in the past by evaporation but the ferrocyanide treatment has proved effective and is now being used in lieu of evaporation.

DR. DAVID T. GRIGGS: Was the reason for the evaporation because the sludge settled and put the water on top?

DR. CHRISTY: The evaporator was actually a concentrator. All the evaporator would do is evaporate, the "overheads" were cribbed and the "bottoms" were transferred to storage tanks. The same 
results can be gotten by the simple addition of some small quantities of a cheap chemical, eliminating the costs of steam and manpower in evaporation.

DR. T.P. KOHMAN: Does the ferrocyanide combine?

DR. CHRISTY: The nickel ferrocyanide forms "floc" and promotes sedimentation.

DR. KOHMAN: Is the nickel salt added separately?

DR. CHRISTY: The nickel and the salt are added separately.

DR. H.C. THOMAS: Are you at liberty to say what the relative values of these wastes are?

DR. CHRISTY: This is the sort of thing I would rather not comment on.

DR. KOHMAN: Was this precipitation method the result of a hundred different tests?

DR. CHRISTY: No. The original compound developed in the laboratory was copper ferrocyanide. Hanford optimized the technique, and learned that nickel was a lot better than copper. More is being learned. It has been found that calcium nitrate added to the mixture gives more efficient clean-up of liquors.

MR. WILLIAM LINDSEY: I think, while Hanford had a very low water table, the waste was permitted to overflow and the soil held all other fission products.

This precipitation only retains some fission-products. Some fission products flow over the tops of the tanks and into the soil. This would be a serious matter except for the soil conditions at Hanford which permitted it. As time went by, this process proved to have quite a few limitations, one being the fact that we couldn't recover the desired element. So another plant was built and is being operated today, which we will call the S plant. This plant had a tank farm and quite recently another large farm had to be added. (Mr. Gorman mentioned tens of millions of dollars in tanks.)

DR. CHRISTY: The thermal heat generated by the radioactive decay of fission products is used to some degree successfully to 
self-concentrate currently the Hanford wastes. Heat, however, builds up in the accumulated sludges of these huge tanks and there is periodic burping. This burping creates pressurized conditions which must be taken into account in future tank construction. Burping is being controlled by agitation. There is an agitation system in the development stage, which, combined with stronger vessels, shows promise of being able to control the burping.

I might point out that waste storage tanks are all underground, and that they are concrete tanks, mild steel lined and capped.

Another new process has been developed and a new plant built which permits recovery of the desired elements without secondary processing; this greatly reduces the quantity of wastes produced. This improvement makes it possible to be optimistic about developing a self-concentration program.

I want to emphasize this point: the new process gives better recovery and lessens the quantity of waste but it does not eliminate the disposal problem; the difficulties and expenses of storage are still great.

DR. J.W. WATKINS: Was it your statement that this waste shouldn't be processed for around three years without the addition of nickel ferrocyanide?

DR. CHRISTY: We were discussing a process which is in use today but is becoming obsolete. The waste from one particular process has to be aged, mainly so that the recovery process will work. This process was developed for an aged waste, and then it was found that the nickel ferrocyanide could be used on this particular waste after recovery. With these other (unaged) wastes it appears that self-concentration will be the answer.

MR. WILLIAM B. HEROY: Your diagram shows a waste line from one plant feeding into another plant; as one plant becomes obsolete does the other automatically become obsolete?

DR. CHRISTY: After recovery is complete the subject plant will be obsolete?

MR. HEROY: In the series of tanks where the overflow from one cascades into the next, what happens to the sludge of precipitated 
26.

ferroycanide? Does that just accumulate in the bottom of the tank?

DR. CHRISTY: That is correct.

DR. R. H. WILHELM: On self-evaporation what type of waste do you get in the distillate, the "overhead?"

DR. CHRISTY: It is essentially water.

DR. T. P. KOHMAN: Does the uranium get into one of those three wastes?

DR. CHRISTY: An insignificant amount.

DR. KOHMAN: But not the bulk of the uranium?

DR. CHRISTY: No, not the bulk.

DR. KOHMAN: Is the amount of nickel ferrocyanide sufficient to carry out all of the strontium?

DR. CHRISTY: I would say, essentially all. Nickel ferrocyanide is a highly efficient scavenging agent.

DR. KOHMAN: There is always aluminum.

DR. CHRISTY: This is something I didn't mention. Coating wastes in the early days used to be added to the intermediate wastes. When this process was developed, the coating wastes were diverted into separate tanks so that it wouldn't interfere with the chemistry which makes this process possible. Today there is no alternative but to store the coating wastes.

DR. KOHMAN: Fission products too?

DR. CHRISTY: Fission products too. So we have to store all our jackets or coating wastes.

DR. H. C. THOMAS: Isn't it like the Irishman building a hole to put the dirt into. Now what are you going to do with all the nickel ferrocyanide?

DR. CHRISTY: That is a part of the problem being considered by this group, I understand. 
DR. DAVID T. GRIGGS: I would like to ask a question about costs. We are given in the Johns Hopkins report a cost of 35 cents to $\$ 2$ a gallon for waste of this general type. Of course, you named a great variety of waste, and I wonder if we could have a cost on the last two that you talked about.

\section{DR. CHRISTY: Nickel ferrocyanide?}

DR. GRIGGS: Nickel ferrocyanide, and then you spoke of a new plant.

DR. CHRISTY:- On the cost of tank installation, the more tanks that are built the lower are the unit cost. There are also ways to increase the capacity of the tanks, and in doing this, the cost is reduced as the tank design and the number of tanks are constructed are optimized.

DR. GRIGGS: Then I ask about concentration. You talked about a new process that results in greater concentration.

DR. CHRISTY: I don't have with me the cost of the essential material which would be needed for the nickel ferrocyanide. But on storage, unit volume waste storage costs are down in the range of 20 cents a gallon. However, when you self-concentrate as is the current development, condensor equipment and cribs are added costs. So I would say there is some increase in that 20 cents a gallon which would be possibly five to ten cents.

DR. GRIGGS: On the other hand, you have less gallons to store because you have concentrated it.

DR. CHRISTY: That is right.

DR. GRIGGS: Could you say what final waste storage costs will be per gallon using self-concentration and nickel ferrocyanide.

DR. CHRISTY: I would like to repeat that both of these developments are in their infancy, and anything said will be very preliminary. But I would guess that something on the order of 25 to 35 cents per waste space gallon will be the cost by utilizin self-concentration. There is yet to be developed an ideal way of agitating the sludges in these huge tanks, so we can't calculate what the final cost will be. 
DR. GRIGGS: This seems to be a small cost compared to the one given in the Johns Hopkins report.

DR. CHRISTY: This looks like a most promising development.

DR. GRIGGS: Suppose all the radioactive products in the stored material had completed their disintegration, what would be the recoverable value per gallon for the aluminum nitrate and other salts if you could simply mine these deposits as though they were natural deposits? Is it desirable to dispose of the waste so they could be recovered at a later date?

DR. TRUMAN P. KOHMAN: First of all, you couldn't possibly wait for all the radioactive materials to decay. Sometimes it is millions of years. But I think there are some elements for which it might be worthwhile to mine these deposits. There are two other elements besides plutonium -- technetium and neptunium.

DR. CHRISTY: The mining operation undertaken recently to recover an element from the sludge proved to be difficult and hazardous. These underground tanks had to be entered with remote equipment such as pumps to sluice out that material to transfer it to another tank, and it is a difficult operation. Only the extremely high value of the element involved made it economically possible to support the operation. The mining of anything in these tanks became more difficult as time passes because it develops into fairly solid material.

Our hope is to make use of the nickel ferrocyanide treatment and make self-concentration fully effective so that eventually we won't have to be too concerned about how long these tanks will last. It is felt that a slurry will be produced, then a semi-solid mass in each vessel, and then, if tank space is again required, the supernatant above the sludge may be treated with something which should not be difficult for the chemists to come up with, something which would give a result similar to nickel ferrocyanide.

DR. J. W. WATKINS: Can you tell us anymore about the characteristics of cribs and units that prevent contamination of the river?

DR. CHRISTY: The cribs are rather simple. They started out to be just a hole in the ground below surface. Our ground water table is quite deep - on the order of 350 feet - - and these cribs were constructed close to the surface. The top was just a timbered structure, 
so that the waste was pumped into the crib and seeped into the soil. Considerable safety factors have been added to limit activity seepage. Over a hundred wells were drilled for monitoring plants, soil, and the underground regions.

The cribs under construction are filled with rock, and gravel of varying sizes, and then a waterproof paper covered with a topping of soil. The waste is discharged into the central zone. The rock and gravel fill is simply a cheap way to maintain a cavern; timbering is costlier.

CHAIRMAN HESS: Are there two long-life elements going into the cribs in any appreciable amount?

DR. CHRISTY: No, not in any appreciable amount.

MR. LINDSEY: I would like to elucidate this a little more. Those fission products that do go overboard have this column of soil, 250 or 300 feet high, to filter through before they get to the water table, and the tests that we have run indicate that this soil has very good absorption properties for picking out all the elements remaining. The crib is used until the monitoring picks up the first trace of the first salt coming through in the water table; the use of that crib is then discontinued. In some cases a concrete cap is put on top of the crib area so no surface water can percolate down through this column of soil to absorb fission products.

At Hanford we have a deep column of soil with excellent absorption qualities and we can dispose therefore of large quantities of low level waste as a routine procedure. What we need now is a process which will dispose of the high level wastes, and that will remove the elements that have long life, and remove those that are not absorbed readily by the soil.

DR. HENRY C. THOMAS: Have any studies been made of the distribution of the absorbed elements under the crib? To do this, would you have to sample every six feet and determine the change in the composition of the material?

MR. LINDSEY: I would like Mr. Lieberman to answer that.

MR. JOSEPH A. LIEBERMAN: There has been a little of that done. We are dealing only with the low level waste from which the 
30.

cesium and strontium has not been removed completely. The ferrocynide method is excellent, it is relatively new, and is more effective with cesium and strontium than other methods. The process and procedure used in disposing of the supernatants containing the rest of the fission products is based on laboratory experiments: soil columns are made up to simulate the soil profile and then the actual waste is passed through; from this is determined how much waste can be passed through the column before a contaminant will "break through" at the specific deposits under consideration. Strontium is usually the critical element. Let's say five column volumes of this waste are in the laboratory column out in the field. We will put in the equivalent say, of two columns of waste. (These are not necessarily the figures or proportions actually used.) I understand there is some strontium put in the ground in Hanford, however, no strontium has been detected in the ground water. If, by chance, some contaminant passed through the exchange columns and down to ground water, its half-life must have been short and by the time it traveled to the Columbia River its effectiveness must have disappeared.

To answer your question specifically, there is laboratory information on the point you make, but in the field, it is very difficult to get comparable data. It is more a case of detecting activity at different levels rather than getting the spectrum. Ruthenium is expected to be at the bottom, strontium close to the top, and the others appear between; this distribution has been established as a result of laboratory work.

DR. DAVID T. GRIGGS: There has been mention of longer life elements: does that refer to the fission products that were mentioned?

DR. CHRISTY: Consider plutonium.

DR. GRIGGS: Are there any longer life fission products?

DR. CHRISTY: Plutonium is of most concern.

DR. GRIGGS: Will that information be available?

DR. CULLER: Sure. There are a lot of them. The list is quite long.

DR. CHRISTY: Other chemicals present in these wastes, in addition to the fission products, are the following: 


$$
\begin{array}{ll}
\mathrm{Na}_{2} \mathrm{U}_{2} \mathrm{O}_{7} & \mathrm{Na}_{2} \mathrm{CrO}_{4} \\
\mathrm{Na}_{2} \mathrm{CO}_{2} & \mathrm{NaAlO}_{2} \\
\mathrm{NaNO} & \mathrm{NaOH} \\
\mathrm{Fe}(\mathrm{OH})_{3} & \mathrm{NaNO}_{2} \\
\mathrm{Na}_{2} \mathrm{SO}_{4} & \mathrm{NaSiO}_{3}
\end{array}
$$

DR. A. RODGER DENISON: You mentioned solids in some of these wastes. Do all the wastes have solids as they go into the tanks?

DR. CHRISTY: Yes, they do.

DR. MURRAY HAWKINS: Are these Type 1 wastes you are talking about?

DR. CHRISTY: Certain of these will be found in each of the wastes that we have. For example, some will in the coating wastes, some in the first cycle, second cycle, and third cycle and some in the wastes from the new plants.

CHAIRMAN HESS: Are there any further questions?

DR. J. W. WATKINS: I would like to ask if you are not concerned with technetium because of the low energy.

MR. J.A. LIEBERMAN: I don't know that I can answer that question specifically; maybe some of the other men can give a hand. As a biological hazard it is of much lower magnitude than strontium or cesium. Whether it has intrinsic value as an element I don't know; I think there has been some mention of recovering it for its value. But from the biological standpoint, to my knowledge it has never been given as a neuclid to be concerned about.

DR. H. C. THOMAS: I was just looking in the book to see if I can find it. I don't believe that there is any biological hazard given with it.

DR. T. P. KOHMAN: Because of its long half-life, its activity is quite low. It forms a minor fraction of the total fission product activity.

CHAIRMAN HESS: Are there any other questions?

DR. L. B. RILEY: What is the rate of heat production from the nickel sludge, the high level sludge? Is it 1 to $3 \mathrm{Btu} / \mathrm{hr} /$ gallon given 
in the handbook? And how does heat output vary with the half-life or with the life of radioactivity? Is it maximum at the start and does it fall off with time?

DR. CHRISTY: The heat follows the same trend as the radiation. It declines along the same curve, essentially.

MR. W. LINDSEY: Regarding the heat figures: the high level wastes that we allow to boil, will continue to boil for a period, of roughly ten years before the heat generation falls to a point where heat losses to the ground will stop the boiling - - and the boiling is fairly brisk.

CHAIRMAN HESS: Are there any further questions?

We have one more speaker this afternoon, but we have gone for an hour and a half. Let's take a ten-minute breather and come back.

... Recess ...

CHAIRMAN HESS: I would like to call on Dr. Culler of Oak Ridge, as our next speaker.

Dr. Floyd L. Culler, Jr., Director

Chemical Technology Division

Oak Ridge National Laboratory

P. O. Box P

Oak Ridge, Tenn.

(Dr. Culler presented an informal review of principles and processes involved in reactors and chemical processing. The types of reactors and fuel purification processes are numerous and yield a varied assortment of waste solutions, each with somewhat different disposal characteristics. The relationship between the predicted optimum sizes of power reactors and fuel processing plants suggests that the most economical arrangement would be for one chemical plant to process the material from 5 - 15 reactors; this would localize the principal production of waste but require wellshielded transportation of fuel elements.)

(The information given by Dr. Culler has been covered in the references given below, and in the works referred to in bibliographies contained in these references.) 
Culler, F. L., Jr., The nature and magnitude of radioactive wastes as influenced by types of reactors and fuel processing - present and prospective, ORNL Central Files Number 56-5-2, May 4, 1956, Oak Ridge, Tenn.

Report of the Committee on the Disposal and Dispersal of Atomic Wastes to be published by the NAS-NRC as one of its series of scientific and technical monographs.

Culler, F.L., Jr., and Bruce, F. R., The processing of uranium-aluminum fuel elements, International Conference on the Peaceful Uses of Atomic Energy, A/CONF .8/P/541 USA 20 July 1955.

Zeitlin, H. R., Arnold, E. D., and Ullmann, J.W., Processing requirements, buildup of fission product activity, and liquid radiochemical waste volumes in a predicted nuclear power economy, ORNL Central Files Number 56-1-162, January 30, 1956, Oak Ridge, Tenn. 


\section{SATURDAY EVENING SESSION}

September 10, 1955

The meeting reconvened at eight o'clock, Dr. Hess presiding.

CHAIRMAN HESS: We start the evening session with a good many people, judging from what I have heard since the last session, who are doubtful whether we have very much of a problem or any problem at all. Many of the things that seemed to be problems have disappeared as the chemical processing of wastes has improved.

Dr. Lieberman of the AEC is the next speaker and he will point out what problems we really have to solve here and how serious they are.

Dr. Joseph A. Lieberman

Sanitary Engineer

Atomic Energy Commission

Washington $25, \mathrm{D}$. C.

DR. LIEBERMAN: I certainly hope that I can disabuse you of the idea that we have any solution that will solve immediately the problems of waste disposal. We feel hopeful that improvements in technology will, as the nuclear industry develops, reduce the complexity of the problem, perhaps through following some of the approaches already described or perhaps along lines on which research is just starting. The whole problem is divisible into two major categories, one of immediate concern, lasting at least five, ten, or maybe more years, and the other, a longer range problem subject to much estimating of future power requirements and production, much speculation about the proportion of power we will be getting from nuclear fission, and much debate about what kind of reactors will be the best.

The amount of fission products produced is a rather simple arithmetical calculation. When a gram of uranium fissions, 24,000 kilowatt hours, or one megawatt day, of heat energy are produced and about one gram of fission products result. The total quantity of fission products accumulated at any time depends on the output of energy being produced by nuclear fission, how long the nuclear reactors have been operating, and other factors related to chemical processing of nuclear fuels. Mr. Davis, Director of the Reactor Division, has estimated 
that by 1980 there would be 175,000 megawatts of electrical energy produced by nuclear fission. There are other estimates based on other assumptions. The basic data for calculation given in the "graybook", prepared by the Hopkins group, are probably as good as we can get. Obviously, the quantities change as processes change, but from what we now know, it looks as though we have to consider the fission product wastes of the immediate future with activity concentrations ranging in the hundreds of curies per gallon. The heat content is of the order of 1 to $3 \mathrm{BTU}$ 's per gallon-hour. In Idaho there are waste tanks where, roughly, 100,000 gallons of high level wastes are stored, and a cooling system must be provided capable of removing something like 300,000 BTU's per hour. That is just for the first tank. If we can't do anything else with these wastes, we have to plan for the time when we may have to build additional tanks to contain wastes that will continue to be produced.

We are still building tanks, and as far as anyone can see, more will have to be built. These tanks are physical structures and have a finite life. A tank manufacturer may guarantee the integrity of the tank for ten years, maybe twenty, maybe fifty years but there is a limit and things can go wrong. If we put these fission products in a tank and since they have an effective half-life reckoned in terms of hundreds of years, we or the people that come after us have to be concerned about that tank and its environment for a long time. In other words, as presently practiced, tank storage of high-level wastes is not actually disposing of these materials.

As sanitary engineers familiar with experiences in other industries, we know that things don't always go the way the flow sheets indicate they should. Day-to-day operations of a plant are sometimes affected by practices that do not enter into consideration of the laboratory procedures. It is not a case of anything being overlooked; it is merely that many steps and stages do not exist in the laboratory that are essential parts of industrial operation.

One thing that should be emphasized has to do with the utilization of the fission products. I think it is worth pointing out, that, to my knowledge, there has been no practical fabrication of fission product sources. Much has been and is being done in the laboratories by many people on the effect of radiations on foods, in chemical reactions, cold sterilization of antibiotics, and all sorts of possible uses; all this work is extremely important. If we find ways of extracting and utilizing radioactive cesium and strontium, we merely postpone the date of disposal of these two fission products. After being used they 
36.

return, somewhat decayed, for eventual disposal. We are going to have to put those some place and have somebody concerned about them for an extended period of time.

This focuses attention on the processes described earlier which may be characterized as "pulling the teeth" of these wastes. This refers to the selective and essentially quantitative removal of the Cesium 137 and the Strontium 90 isotopes. If and when the "teeth" can be removed, practically and economically, from the mixtures of fission products, two different problems are created. The first has been mentioned. The effective half-life of the mixed products obtained from fissioned uranium has been estimated to be of the order of hundreds of years. If strontium and cesium are removed, the effective half-life of the remaining mixture is reduced by perhaps a factor of ten; thus the remaining material might have an effective half-life figured only in tens of years but indiscriminate return to the environment of material with such radioactivity is, nevertheless, unthinkable.

The possibility of fixing these radioactive materials on an earth carrier is being studied. At Brookhaven the radioactive ions have been fixed on montmorillonite clay primarily by ion exchange; then, by heating the clay, the exchange reaction is macle irreversible. This "hot" clay could be stored in special locations that would prevent the radioactive material re-entering the human environment.

A.E.C. employees who labor daily with this problem are faced with the constant question, "When can we stop building tanks? or, When can we do something with these wastes other than putting them in tanks?" The chemical technologists, the physical chemists, the biologists, and many other disciplines have a part to plan in finding the solutions. What are the facts in the earth sciences field that bears on the possibility of putting these wastes in the ground? Then, just how do we go about deciding whether it is possible to put this stuff in the ground and at which locations? Then, just how do we go about putting these wastes in the ground? Specifically, the questions to be answered are as follows:

a. What are the problems, environmental and geological, associated with putting this material in the ground?

b. Assuming that underground disposal is feasible, where can we do this, and under what conditions? 
And then perhaps $c$ : If there are questions that are still unanswered, what do we have to do to get answers to them?

Because of the restrictions of classification and because of certain detailed technological data that have not yet been pinned down, there may be at the moment a lack of clear definition. This does not, however, make the problem any less real or less serious. It is not an academic problem.

CHAIRMAN HESS: Thank you.

Does anybody have a question he would like to ask?

DR. M. HAWKINS: I wonder if it would be possible to have a description of the cooling system in the tanks in Idaho which Dr. Lieberman refers to.

DR. LIEBERMAN: It is simply a cooling coil which is put into the tank. Mr. Culler can give a more detailed answer.

DR. F. L. CULLER: There are two systems. When the tanks were first built it was not known that aluminum nitrate would attack the weld in type 347 stainless steel, and it was supposed that the heat would be removed during boiling by refluxing the water. The tank was a standard API tank with a lower course going up to an umbrella type roof. Inside it was an octagonal concrete structure. After about a year and a half of exhaustive solution tests in the laboratory, it was tentatively concluded that a knife line would form along the center of the type 347 stainless steel, unless the temperature of the solution in the tank was kept below 150 degrees Fahrenheit. This meant that boiling cannot be tolerated and cooling must be accomplished with refluxers. Man-holes around the periphery of the tank provide access for dropping type 3472 -inch coils into the tank. Water was circulated through the coils, pumped through an external cooling structure, down the umbrella, and then allowed to trickle down the outside of the tank. This kept the walls cool even if the center of the tank was hot. There was a recirculating water system to pump extra water into the cooling system if a leak occurred. There was no connection with the water supply. So, it is a plain secondary heating circuit, somewhat unfortunately designed, but effective and operating.

QUESTION: How thick are the concrete walls? 
DR. CULLER: About two feet; they are uniformly 18 inches in some places.

DR. W. B. HEROY: What is going to be the life of that tank?

DR. CULLER: It is at least five years, and probably longer.

DR. HEROY: What is the rate of corrosion of the tank by the nitrate solution?

DR. CULLER: The loss is all in the welds. If you average out the coils, or if you interpret inches per year to total area, it is a negligible loss.

DR. HEROY: In other words, if it were a seamless tank and cooling coils were provided, the tank might last indefinitely?

DR. CULLER: If you could get a tank with no welds you would have no serious trouble that we know of. Some new material we have received may have adequate resistance but it has not been tested yet. The press notices say it is pretty good.

CHAIRMAN HESS: Are there any further questions?

DR. H. C. THOMAS: As I understand it, one of the most successful ways of dealing with the moderately high level waste is by pumping to the ground. The reason it is successful at Hanford, is that you have a homogeneous soil with no peculiar structures, no direct or rapid discharge to the river, and favorable ion exchange properties. It would be nice to do this in other places. How difficult is it to survey the region immediately around the percolation crib and determine the nature and extent of the changes in the soil? If you pumped 100,000 gallons of active material would you get uniform and predictable expansion of waste in the hole? It is possible to decide that such would take place?

MR. LIEBERMAN: The wastes being put to the ground at Hanford are not moderately high level; I would say they are relatively low level wastes and the steps used in their disposal are being taken very slowly and cautiously.

Diagrammatically, the procedure is as follows: the wastes to to $\mathrm{a} 30$ by 30 -foot crib. The crib and associated piping is 300 to 400 
feet above the ground water table. The volume of waste that goes into this crib is cetermined by laboratory tests, and the tests are extrapolated, with adequate safety factors, to an actual field installation. There is an elaborate system of wells around the crib to detect the presence of radioactivity away from the crib installation.

\section{DR. JAMES GILLULY: What about under it?}

DR. LIEBERMAN: Well, they can tell what is getting in the ground water.

DR. GILLULY: I wouldn't expect anything to move laterally 300 feet above the water table. I would expect the changes to take place under the crib.

DR. LIEBERMAN: The monitor wells might be on the order of 30 or 50 feet away from the crib, and activity has been detected in these wells. When field installation is made, only the volume of soil in the 30 by 30 -foot column under the crib down to the water table is considered; the operators feel they are getting the benefit of a bigger volume as far as exchange capacity is concerned. It is known that an element like ruthenium will go right through the column, but if is also known that ruthenium has a half-life of one year and that the travel time of the water from the bottom of the crib to the Columbia River is of the order of magnitude of tens of years or hundreds of years. The rate of flow is the subject of debate among the ground water geologists, but in any case, they are sure that before this water which might be contaminated with ruthenium gets to a place where somebody can use it, it will have decayed to the point where it is no longer harmful.

I am sure that the people who are involved in this work at Hanford would be the first ones to say that we can't take the results that we are getting here and apply them to any other place. Obviously, it is a question of environment, every location on its own merits.

DR. H.C. THOMAS: It is true, then, that no spot other than Hanford has actually been investigated from this point of view?

DR. LIEBERMAN: That isn't quite true. This afternoon Dr. Struness and Mr. Morton will summarize the investigative work being done at Oak Ridge in connection with surface pits that Floyd Culler mentioned earlier. But on a routine production basis, shall I say, at 
40 .

no place within the Commission jurisdiction are high level wastes being discharged to the ground. Relatively low level wastes are going to cribs at Hanford.

DR. KOHMAN: I wonder if someone would please define a crib.

DR. LIEBERMAN: We call them cribs or caverns. They are simply excavations that might be 30 -foot squares in plan, and as much as 30 or 40 feet deep. They are filled with coarse broken rock.

DR. KOHMAN: Is it lined?

DR. LIEBERMAN: No. Previously there was a crib-like structure of timbers to hold the excavation. The purpose of the rock is to distribute the waste so as to take advantage of the full cross-section of the column when the waste is pumped in. The top of the pit is covered with some impervious membrane which is in turn covered with the natural soil; the piping into the pit may be covered so it is safe to walk over, and the membrane sheds what little precipitation there is in the area.

It is a very rough structure, but it is surprising how expensive it is to build a lot of these cribs. It costs from a tenth of a cent to one cent per gallon to discharge the relatively low level wastes into the ground at Hanford.

DR. GILLULY: The statement has been made several times that this is soil. It is difficult to persuade me that there are 350 or 400 feet of soil at Hanford: there is an abundance of Columbia River lava, there are gravels, and there are jointed rocks, all of which provide channels to carry the solution through or diffuse it. I would like to have Dr. Piper explain the hydrology.

Mr. A. M. Piper, Staff Scientist, Pacific Northwest

U. S. Geological Survey

Box 3418

Portland 8, Ore.

CHAIRMAN HESS: I was going to call on you later, Mr. Piper. Would you like to present your views now?

MR. PIPER: A crib is merely a shallow excavation supported 
by rough timbers into which selected end products are discharged Iproducts with only a low level of radioactivity $\bar{T}$. The water table is 250 or more feet below land surface, and over most of the Hanford area the unsaturated interval is occupied mainly by glacial outwash - silt, sand, and some gravel. A few areas adjacent to old cribs (where discharge of wastes has been terminated) have been tested by sinking holes at intervals around them, sampling the earth material, and analyzing it. This has delineated, beneath the cribs, roughly pear-shaped zones in which fission products have been adsorbed by the earth materials. I know of no case where the total quantity of fission products fixed in the pear-shaped zone can be shown to be a major part of the products that were in the total volume of fluid discharged into the overlying crib.

MR. M. HAWKINS: Where did the rest of it go?

DR. D. GRIGGS: Is that statement based on the water removed in the survey? You didn't find fission products in solution-- is that what you meant?

MR. PIPER: The earth material was not saturated when testdrilled. It was not dry in the sense that it contained no water. Except for a thin zone near the land surface, probably all this material naturally contains that amount of water which it can retain against the force of gravity, and essentially all the fluid added to the cribs must go on down and ultimately reach the water table. We can conclude that all the fission products put into a crib either are trapped in the underlying area or have gone down somewhere.

Before some of the later cribs were put into use, observation wells were drilled adjacent to them and some holes were angled beneath the axis of the crib.

DR. J. GILLULY: What sort of a drill did you use?

MR. PIPER: Cable tool. The mast was canted, a guide casing was set, and the hole was drilled carefully and with fair success in getting under the axis.

DR. T. P. KOHMAN: What kind of material?

MR. PIPER: Glacial outwash largely. Over most of the area no basalt highs were cut above the water table. 
DR. KOHMAN: How was the water table related to the Columbia River? river?

DR. L. F. CURTISS: Is it different from the level of the

MR. PIPER: If you wish to defer that for a moment, I would like to come to it later. I would like to caution against any interpretation that we can show conclusively in wells of this sort what happens to the fluid: it passes down largely in an unsaturated state and a test hole may penetrate the zone of percolation and not collect a single drop of fluid. Similarly with well sampling of the water at the ground water table: contaminated water may be caught or it may go by undetected.

I doubt that the present practice of discharging low-level wastes could be continued over the centuries, and wouldn't for a moment consider adopting this practice in a populous area. I feel the problem of waste-product disposal is far from solved.

There is another aspect to disposal in cribs at Hanford. Most of the waste cribs are roughly in the center of the area bounded by a large bend of the Columbia River. The diagonal across this area measures about 40 miles. The water table does not slope uniformly across the area. A couple of intermittent streams discharge into the area from the hills to the west, and have formed a natural ground water ridge. The ridge merges with a rather gentle ground-water slope and induces a general radial movement of ground water in the central area, toward the river. This natural pattern has been complicated by disposal of cooling water in the plant area, which has built a couple of rude ground-water mounds, possibly several tens of feet higher than the natural water table. These two mounds act essentially as dams to the movement of water and, for the moment, they hold back the water that is beneath the cribjed area. We can't say definitely what the condition may be 25 years from now.

DR. CURTISS: What is the nature of the ground? Can you give us a cross-section or rough sketch.

MR. PIPER: On the west side of the area there is a ridge of basalt, 1500 or 2000 feet high. From its base, a rudely terraced plain descends to the river. The water table is relatively steep at the west side, then flattens beneath the central plain. 
DR. M. HANKINS: Do materials forming the terraced plain rest on basalt?

MR. PIPER: The basalt passes underneath, and there are some irregularities in its upper surface. We haven't the data to plot the rock profile. The overburden is outwash and some material that may be non-glacial.

DR. HAWKINS: What would be the normal rate of water movement toward the river if the mounds were not present?

MR. PIPER: That is the sort of question a ground-water man never answers. (Laughter) Regardless of the average rate of movement, we know that in other areas contaminating (but non-radioactive) fluid moves largely by displacement, as though floating. The great uncertainty is that there is no indication of impending trouble until the contaminant suddenly appears. The average rate of movement is no measure of the movement in the most permeable threads.

DR. GILLULY: In a laboratory test of the soil column, solutions can be passed through samples in a beaker or diffusion column without duplicating the conditions in nature; in nature there are going to be high permeable channels through which the flow will be concentrated. The natural conditions are far from homogeneous and very different from the conditions and results one is apt to get in a test in a laboratory.

MR. PIPER: That is very true. Any test in a cylinder of restricted size is difficult to extrapolate to natural conditions. For one reason there is a boundary effect in any cylinder of laboratory size that may greatly distort the results. The lack of homogeneity is shown by the tests made around some of the cribs: I sketched a smoothly bounded zone /of fission-product adsorption/ but they are not all that way by any means. In the ideal case the solutions moved down through uniformly permeable material; where the permeability is discontinuous there is considerable irregular lateral spreading. You can get all sorts of queer details reflecting local inhomogeneity. Yet, on the whole, the material is permeable throughout.

MR. S. G. LASKY: Why do you say that the test holes at the ground water table may not pick up any radioactive material?

MR. PIPER: A well is drilled to the water table for the purpose of detecting the passage of a contaminated fluid. There is water in 
44.

the bottom of the well. How much pumping is necessary to be sure that you exhaust the fluid in the bore hole of the well and that you do get a sample of what is going by? It is not nearly as simple as it seems to be.

DR. HUBBERT. How are you going to get a sample in the wells around the cribs?

MR. PIPER: There may or may not be some seepage from the percolating waste. But you can have fluid go right by the end of a well and not collect a drop. It is the hardest thing in the world to sample fluid moving in unsaturated material.

DR. GILLULY: You said this pear-shaped area of poisoned soil doesn't contain anywhere near a major fraction of the material that was fed into it. What happened to the rest of it? Where did it go?

MR. PIPER: Some of the missing material may be tied up in sludge in the bottom of the crib, and it is physically impossible to drill and sample the crib bottom to get a good quantitative measurement of that sludge. But even making allowance for that, we haven't demonstrated at Hanford that there is anything like complete interception by adsorption.

DR. E. W. ROEDDER: Could you have relatively uncontaminated material underneath the pear-shaped mass?

MR. PIPER: Yes. The bottom of the mass is substantially above the water table.

DR. ROEDDER: Completely uncontaminated?

MR. PIPER: Yes.

DR. GRIGGS: I asked a question as to whether contamination occurs in the ground water.

MR. PIPER: Not directly under the areas of absorption that have been tested by drilling. Contamination has been found in a few ground-water samples.

DR. HAWKINS: Where were they located? 
MR. PIPER: Those that I am familiar with go back to war-time operation that was not well documented. Just where it came from I hesitate to say.

QUESTION: Is there a pattern in the amount of radioactive material you found in the hole?

MR. PIPER: You mean areas of absorption. They are quite unlike. I sketched a pear-shaped mass, but actually each one is rather irregular.

DR. A. B. JOSEPH: Is the sampling adequate?

MR. PIPER: Not entirely, no. These masses aren't too large. A 200-foot cylinder would probably enclose one. Near its margins you get into material of so low concentration that analytical methods are not sufficiently delicate to be sure of the total quantity of adsorbed fission products.

DR. R. H. WILHELM: Can one get activity by putting an absorber over the hole?

MR. PIPER: An effort was made to assemble apparatus that would rementer some of the drill holes, and take samples through the casings. I am not familiar with the results.

DR. GRIGGS: I don't know if anybody mentioned it, but somebody may have gotten the impression that some / waste products $\overline{\text { / may }}$ have gotten down to the ground water. How do you reconcile the fact that there is no contamination beneath this pear-shaped area?

MR. PIPER: I am not sure that any reached the ground-water level immediately beneath any of the absorption zones that were drilled out. I don't think we could prove so from /the existing/ sampling.

DR. GILLULY: What happened to the stuff then?

MR. PIPER: Some could have gone down to the water table. We can't prove that it didn't.

QUESTION: Were any samples taken below the surface of the ground-water table?

MR. PIPER: I don't recall. Can you answer, C.V.? 
DR. C. V. THEIS: There were samples taken in wells going down below the water table in this area and they haven't shown any radioactive contamination. I believe I am right.

QUESTION: How far below the water table?

DR. THEIS: Not deep enough, as far as I am concerned. These waste materials at Hanford are not shown to be of any higher specific gravity than water. So you have more opportunity near the water table. And I might add to what Mr. Piper said that they have taken soil samples below these cribs, and one of my difficulties has been that they have gotten too much activity in a small zone.

DR. S. LASKY: I would like to know, once strontium and cesium have been removed, how long it takes for the remaining stuff to get within tolerable limits.

DR. J.A. LIEBERMAN: Tens of years, I think, would be the order of magnitude.

DR. HAWKINS: Is there any concern of possibly wanting to get at these materials once they are put in the ground? Is anybody concerned over that?

DR. LIEBERMAN: I think the only basis on which one could answer at this time is that strontium and cesium can be extracted readily. They are sources of radio energy which may have value in the future. But the problem is not whether we can get the stuff back but what can we do with it now that we have it.

MR. RALPH HUNTER: I wonder if the acid material going down into the crib might be precipitating in the alkaline soil some strontium carbonate or some of the other carbonates or phosphates which are holding fission products. Has that been aswered?

MR. PIPER: I don't know that it has been answered.

DR. HUBBERT: Mr. Chairman, the question just asked is one that several of us have been discussing between sessions. Mr. Culler this afternoon mentioned that all of these wastes could be put into a liquid form by the various methods of extraction. When the possibility is considered of taking the liquid waste and putting it underground, the question arises of whether or not a reaction between the material injected and the minerals in the ground might immediately block all the 
pores. Of course, the injection of liquids in the ground is quite common and one of the practices that is quite essential in oil work is to put up a plant so that the water is chemically treated in advance of injection. However, in the disposal of brines from oil wells, the whole object is to get the stuff in the ground. One of the most recent developments in underground mechanics is the deliberate fracturing of rocks by pressure and the injection of sand in the fractures to hold them open. Instead of having just the well bore, you have perhaps hundreds of square feet of exposed surface. Plugged pores can be dealth with by using enough pressure in a properly designed and executed maneuver to give controlled fracturing. Would it be necessary to reprocess the waste fluids to remove the constituents that might subsequently precipitate on contact with the rock material to form plugs in the pores?

I think we have to dilute the materials enough to avoid forming "hot spots." To obtain dilution and at the same time keep the density high, we can use natural brines. If the waste is placed in the bottom of the basin, diluted to disperse the hot stuff, and the density is kept higher than the surrounding water, we then have mechanical stability. Culler?

CHAIRMAN HESS: Would you like to make a comment, Dr.

DR. CULLER: It is going to be difficult to define a typical kind of waste. The kind of waste you get is high in aluminum nitrate, or in neutralized aluminum nitrate and contains as much as 40 per cent by weight of dissolved solids. Certain conditions in the rock might precipitate the aluminum nitrate as a heavy sludge and plug up the bore hole. If you dissolve stainless steel in nitric acid and inject it into an alkaline layer, the bed will plug with ferrous oxide, which would be hard to unplug. However, I susject the chemical processing people could remove certain materials or the conditions of the systems adjusted so the waste could be injected. It is a matter of deciding where the material is to be injected, what the conditions are, and what would be detrimental to the process, and then having the solutions prepared to fit the requirements.

It is really difficult. Precipitation will be ?. problem. Heat will be a problem. It might be necessary to cool for periods of three or four years, especially in the case of wastes from the processing of stainless steel which otherwise would require very expensive neutralization. If there is concentration along restricted bands in the rock or soil the heat concentration might be very serious; montmorillonite clay may act as a trap and prevent distribution. Removal of 
48.

cesium and strontium will help reduce the problem.

DR. HUBBERT: In these remarks I am thinking about putting wastes down in a well which may be 10,000 feet deep. It will be structurally a basin in shape. The rocks at that depth are always full of water. If we inject into a sandstone at this depth, all the injected fluid will do is flow out radially from the well. It is quite important it does not block the pores of the sandstone. Now, in a dilute form as. far as the hot constituents are concerned, many of them won't accumulate to form concentrations.

DR. CULLER: But if the soil through which it passes has the capacity for an ion exchange it will solidify. You will have solids.

DR. HUBBERT: At a depth of ten thousand feet, we do not have soil; we have rocks, and it is rocks I am thinking about. There may be rocks composed of montmorillonite clay. We don't inject into those. But we may have sandstones that have a percentage of clays which may have important ion exchange properties. We might possibly be injecting into a limestone. The most desirable rock would be sandstone; the clays we would avoid. The rocks occur in layers. The sandstone is probably bounded above and below by clay stone, and the sandstone may be several hundred feet thick. If we inject into the thick, clean sandstone, there will be comparatively little ion exchange. So, a part of the chemistry would be to get the waste ready for that kind of an injection.

DR. A. R. DENISON: I should like to inquire if there has been any plugging in these cribs. Have any of these cribs at Hanford been abandoned?

MR. PIPER: One or two of the earlier ones have been discontinued because of probable sludge in the base of the crib that may have been suspended in the fluid when it entered the crib. Escape of fluid was considered hazardous and the cribs were abandoned for that reason. I am not familiar with the operation of some of the later cribs.

DR. DENISON: Is there a plugging effect in the cribs?

MR. PIPER: There definitely was in one or two of the earlier ones.

DR. DENISON: Of something not going into the present cribs? 
MR. PIPER: Yes.

DR. 'THEIS: Tanks collect most of the sludge, so the experience you may have with these cribs would not be a very good indication of what might happen in the wells. The Hanford low level wastes are not typical of the wastes we are talking about.

DR. J. W. WATKINS: In the petroleum industry we have a half-million barrels of brine to dispose of this year. There are disposal wells in western states taking thousands of barrels per day without treatment at all. So it depends on the location-- whether there is permeable rock or not.

DR. DENISON: I think in east Texas they put back one barrel of water for each barrel of oil they take out. It all goes by gravity. No fracturing is needed.

DR. HUBBERT: This still depends on the fluid not blocking the holes in the sand.

DR. DENISON: You have to be sure not to let the algae grow; they will block it up quickly. But keep the water clean and keep the air from it and it goes back in any quantity you want to put in.

DR. HUBBERT: Another thing, Dr. Culler mentioned colloidal solids suspended in this material. That is not tolerable if you are going to inject it in the ground. It has to go in as a pure liquid, no solids.

CHAIRMAN HESS: Are there any other questions:

We have two more speakers that we would like to get in in the next forty minutes.

MR. F. A. HEDMAN: I would like to get a comment from Dr. Lieberman. From the distribution of Hanford wastes, is it likely to be practical to put up a plant that will generate high level wastes at some place where you would have to transport the waste?

DR. LIEBERMAN: I think it is very likely that problems would confront us, and the feasibility of putting the waste in the ground might well determine the type of process we would plan to use. 
50.

DR. HUBBERT: It may ultimately determine where you put the reactors.

DR. LIEBERMAN: We have had experience in transporting solid fuel elements to a chemical processing plant, but the handling of the liquid waste from the chemical processing plant, assuming we want to put the waste in the ground, might determine the location of the process.

MR. HEDMAN: Millions of gallons of waste is something I wouldn't want to handle.

DR. LIEBERMAN: Neither would I.

CHAIRMAN HESS: If there are no other questions, I would like to ask Mr. Morton, of Oak Ridge, to talk to us.

Mr. Roy J. Morton

Health Physics Division

Oak Ridge National Laboratory

P. O. Box P

Oak Ridge, Tennessee

MR. MORTON: Dr. Lieberman asked that Mr. Struxness and I discuss our experience and our study program at Oak Ridge. As background information for Mr. Struxness's discussion of high level waste problems, I will give a brief resume of past activities and developments, and a summary of the present studies.

At Oak Ridge National Laboratory the waste studies are carried on in the Health Physics Division and were organized in 1948. Until 1953 we were concerned principally with low level wastes, with water decontamination problems, with stream surveys, and the needs, criteria, and techniques of laboratory analysis. Those problems have not been solved completely but they have been given considerable attention and reported. The high level waste disposal problem became urgent, and in early 1954 the section was reorganized as the Sanitary Engineering Research Section. Since that time our efforts have been devoted almost entirely to this problem in anticipation of the peacetime uses of nuclear energy, particularly by the power industry.

The early studies had to do with the wastes which could be discharged from the Laboratory into White Oak Creek and thence into 
Clinch River, and be disposed of by dilution. There are several types of wastes. The principal types are: sanitary sewage which is treated separately; cooling water which has no opportunity for being contaminated with radioactivity and can be discharged directly to White Oak Creek; the slightly-contaminated process water from laboratory sinks, and the like, which, aftex brief retention, is discharged into White Oak Creek; chemical wastes; and metal wastes. Chemical wastes, which we call intermediate, containing $1 / 300$ th to $1 / 30$ th of a curie per gallon, have to be disposed of with care; and metal wastes have to be stored in tanks until reprocessed for recovery of the fuel materials.

About 1951 the intermediate radiochemical wastes were filling up the available concrete storage tanks, despite the use of the waste evaporator, and the construction of new tanks had to be considered. Prior to that a survey by a geologist had indicated that a nearby bed of Conasauga shale had a thickness of at least 1500 feet. The shale is relatively impervious and laboratory tests showed that it might be suitable for containing wastes of this kind. We first excavated an experimental pit with a capacity of 200,000 gallons (Pit No. 1). After introducing 130,000 gallons of evaporator concentrate a break-through to the surface occurred because it was on a steep hillside. Subsequent excavations have been located more carefully. Two additional pits have been dug, and another is to be started in October 1955, each having one million gallons capacity (Pit No. 2, No. 3, and No.4). The use of Pit 1 was discontinued after a few months.

Pit 2 and Pit 3 are still in operation. Pit 3 is nearly full, Pit 2 is two-thirds full, and Pit 4 will be in operation in time to relieve these when they are full. We are trying to evolve a safe but economical design to get the maximum possible efficiency from pits. Since June 1952, we have put two and a quarter million gallons of intermediate level waste containing nearly 30,000 curies of activity into the se pits. About 75 per cent of the activity is due to ruthenium, and about 20 to 22 per cent is due to cesium. Three or four monitoring wells were installed around each pit for making radiologs and taking samples in an effort to detect the underground movement of the waste. Sampling at a distance of 80 to 85 feet showed, after about a month and a half, ruthenium and nitrates in the well. In the highest concentration, the activity was about 70,000 counts per minute per milliliter and the nitrates about 3,000 parts per million. The activity of the waste as originally put into the pit was about a million counts per minute per milliliter, at 10 per cent counting efficiency, or about $10^{7}$ disintegrations per minute per milliliter. 
After about a year and a half there was some breakthrough of ruthenium and nitrates to the surface and into a small stream at a distance of 500 feet. This was detected by the monitoring program which included an occasional scanning of the ground surface and the vegetation. Only ruthenium activity was found in any of the wells or seeps despite the fact that cesium and small amounts of other radioisotopes were present in the waste. During a very dry period when the stream was being fed solely by ground water seepage, 15,000 parts per million of nitrates were found in the creek. During that summer of 1954 turtles were found dead or in distress in this creek apparently affected by the nitrates. It was known from the beginning that investigations of the problems of sanitation would have to include studies of both the radioactive constituents and the chemical constituents because the wastes are salted and the nitrates, and perhaps other chemicals, may be toxic.

The construction costs was about $\$ 15,000$ per million gallons of pit capacity, including the monitoring wells. This does not include the expense of the special studies, the time of the health physicists, the monitoring program, the collection of samples, and the analytical cost. The monitoring cost is a continuing expense not related to the cost of construction. It has been estimated conservatively that the discontinuance of the evaporator and the other economies, made possible by the use of pits, have saved the laboratory approximately $\$ 63,000$ a year. The contribution of waste fluids to the natural drainage has not caused local hazards nor an appreciable increase in the content of radioactive material in the river.

DR. KOHMAN: What is the size of the pit?

MR. MORTON: Each pit is approximately 200 feet long, 100 feet wide, and 15 feet deep, with a slope from the outside edges to the bottom.

QUESTION: They will be above the water level?

MR. MORTON: For the most part they are above the water table which varies in depth with the location and may fluctuate 5 or 6 feet. In dry seasons the water level is below the pit but the bottom of the pit may be in the water some of the time. The surcharge up to 15 feet of liquid in the pit has to be considered, of course, because of its effect upon the water level. 
DR. C. V. THEIS: Do you keep putting liquids in the pits?

MR. MORTON: Yes. They were transferred formerly by tank truck, but a pipeline has been built and about 75,000 gallons are pumped to the pits every two weeks. The chemistry of the wastes is different from those described by previous speakers. These wastes contain 25 to 35 per cent of dissolved solids by weight. The principal bulk constituents are sodium and ammonium nitrate. The principal radioisotopes are ruthenium and cesium. There is only a small percentage of aluminum.

DR. GILLULY: What happens to the stuff? Is it diffused?

MR. MORTON: It appears to diffuse gradually through the soil, the nitrates preceding everything else. The ruthenium diffuses, but none of the other isotopes have been found in wells 50 to 75 feet from the pit. We have not detected strontium as yet, although strontium has been present in the waste going into Pit No. 3 since January 1955.

DR. KOHMAN: What fraction of what you put in has seeped out?

MR. MORTON: The total input to the pits has been over two and a quarter million gallons, and there are about one and a half million gallons in them now. There has been loss by seepage but the exact amount is not known. In connection with these pits we have tried to collect data which will be of value in studies on high level waste disposal and on further use of pits for intermediate level wastes. One subject for investigation is the amount of seepage in this particular formation. Detailed explorations have been made by the Geological Survey of the character of the formation, the structure, and the hydrology in this area to help determine the amount of seepage. A carefully planned series of observations will be made during the next year to determine the evaporation from a pit of this configuration. If we know the waste input and the rainfall contribution, and can estimate the loss by evaporation, then we have a measure of the seepage. An approximate estimate is that the evaporation loss is about 30 to 35 inches a year and that rainfall contributes about 50 to 55 inches a year. The liquid wastes added are about 35,000 gallons per week into the two pits.

DR. KOHMAN: The original intention was to have no seepage?

MR. MORTON: No. These pits were intended primarily to provide increased storage volume. It was assumed there would be some 
seepage and the plan was to study it carefully to determine whether the seepage created a hazard. So far we think it has not. The

Operations Division is considering the use of, say, a total of five pits, the idea being that an operating seepage system would contribute fluids continuously to the soil over a large area and that the seepage of fluid would balance the production of waste. That is the general concept. If we find that it creates a hazard, we can put liners in the new pits to minimize seepage, or again start building storage tanks. Some people in the more arid areas are quite interested in this concept because they do not have the unfavorable balance between rainfall and evaporation which we have. We have more rainfall than evaporation but in many places it is the reverse.

DR. KOHMAN: Why not build shed roofs over the pits?

MR. MORTON: That is a possibility that has been discussed with the Weather Bureau, but a roof will restrict evaporation as well as the entrance of rainwater and we might not gain much.

The work of estimating the evaporation loss is being done with the collaboration of the Weather Bureau, the U. S. Geological Survey, and others. It includes measuring liquid temperatures at the surface and below the surface, air temperatures and wind velocities, the chemical content of the waste liquid, and other measurements that the Weather Bureau people tell us are necessary in order to calculate evaporation losses. it hot?

DR. HUBBERT: What is the temperature of this material? Is

MR. MORTON: No, it is not hot? Ii may be above ordinary tap water temperatures, but not much.

Waste disposal research at ORNL is a cooperative program involving several agencies: the Public Health Service, the U. S. Weather Bureau, the U.S. Geological Survey, the Tennessee Valley Authority, and the U.S. Engineers. The program takes into consideration the interests of many agencies besides our own. For example, the U. S. Geological Survey and our own workers are studying in detail the geologic structures and the hydrology at the sites which we propose to use for high level wastes disposal facilities. The objective is to see whether or not the behavior of wastes below ground can be correlated with the movement of underground water. The evidence 
gathered to date inclicates that it may be possible to correlate the data on waste with the data on water. If this proves valid, a reliable picture of the ground water movement may make it possible to predict in a given situation whether or not a hazard would be created by the release or escape of wastes into the ground.

DR. DENISON: Did you say your first two pits were built on a knoll and you had a breakthrough at the base?

MR. MORTON: Yes.

DR. DENISON: And you are now building one which won't have that hazard?

MR. MORTON: No, that is also being built on somewhat of a knoll in order to keep the pit above the water table as much as possible. We plan to put fresh water into this pit and make observations on seepage into the ground. The water can be pumped out and the waste put in later. We suspect that it will break out but we feel that in dealing with intermediate or low level waste we should take acivantage of the capacity of the soil so long as we don't get a breakout that is excessive of hazarclous.

CHAIRMAN HESS: We will now hear from Mr. Struxness.

Mr.E.G. Struxness, Director

Waste Disposal Project

Health Physics Division

Oak Ridge National Laboratory

P. O. Box P

Oak Ridge, Tennessee

MR. STRUXNESS: In late 1954, after extensive discussions, we set out to formulate a practical concept of the reactor waste disposal problem. Calculations based on the Putnam predictions of power development in the next forty years yielded figures that were invariably large. After a year of study, we decided to let others worry about the U.S. problem and we would be content to develop a method of disposing of ORNL wastes. Highly-radioactive powerreactor waste may be disposed of in pits, provided there is complete retention and immobilization of radionuclides in the pits. For the disposal of low-level and intermediate-level waste, some combination of retention plus seepage might be useful. 
56.

The disposal of high-level wastes includes pre-treatment to make them suitable for ground disposal. This may be considered chemical processing in the sense that fission products having indus trial and medical use may be of sufficient interest to recover. The critical isotopes are: $\mathrm{Sr}^{90}, \mathrm{Y}^{90}, \mathrm{Sr}^{89}, \mathrm{Y}^{91} \mathrm{Cs}^{137}, \mathrm{Ba}^{137}, \mathrm{Ce}^{144}$, $\mathrm{Pr}^{144}, \mathrm{Zr}^{95}, \mathrm{Nb} 95, \mathrm{Ba}{ }^{140}$, La ${ }^{140}$, and $\mathrm{Pm}^{147}$. If these can be removed the problem of heat will largely disappear. Chemical precipitation and solvent extraction methods for removing some of these isoto pes are being developed and the value of one or two isotopes might pay for the removal of the rest of them.

To increase the effective use of pits, the geologic and hydrologic conditions that seem to be most favorable for the location of the pits are being studied. In addition, the possibility of developing impervious liners is being explored: this includes mineral liuers and asphalt liners, and also possible self-sealing as the result of interaction between the wastes and the soil. In searching for a suitable liner, we have studied concrete, limestone and asphalt in the containment of acid waste; high temperatures and radiation have a deleterious effect on asphalt, but the concrete seems as though it might hold up long enough once we have developed a method of permanently fixing and fusing the waste. Asphalt has been tested with highly alkaline waste and it has been in the pit for over a year without showing any leakage. Even though an impervious liner is developed, it will be necessary to immobilize the waste in the pit. The ceramists have ideas which may prove helpful in permanently fixing and fusing the material in the pit after the water has evaporated and the nitrogen oxides have been driven off.

Even if we have an impervious liner, and the material is permanently fixed and fused in the pit, it is important for purposes of monitoring to understand the exchange properties of the soil in which you locate the pit. The surface disposal of wastes is as much a problem of geochemistry as it is geology. We are concerned also about the techniques of monitoring in wells and in the soil to determine the underground movement.

The acid aluminum nitrate wastes have been studied in the past year to devise means of fixing the isotopes permanently. This is acid-deficient waste which might form a gel or slurry when mixed with cheap and readily available materials such as clay silicates, phoshate tailings, and soda ash. The volumes added should be kept as low as possible and should aid in fusion. To avoid creating a hazard from 
airborne radioactivity during the evaporation and fusion processes, it may be feasible to use river sand as an entrainment bed and shield. It may be possible to sinter the dried mass into a ceramic body, from which, we hope, the radioisotopes will not escape. There may be enough heat generated in the residue to bring about self -fusion or selfsintering but ceramists and others feel that the amount of heat energy available is on its borderline. It might be necessary to use a calcining or sintering machine. It is important to keep the sintering temperature low in order to minimize the volatilization of the radio isotopes. Something like twelve or fifteen clay flux mixtures containing synthetic waste and tracers were prepared by Dr. McVay. One mixture consisted of the following:- 250 milliliters of acid waste solution, 30 grams of soda ash, 30 grams of about 200-mesh limestone, and 100 grams of 16-mesh calcareous shale from the Volunteer Cement Co.

The mixture sinters at 1,050 degrees Fahrenheit; after 50 days, leach tests in tap and salt water showed that only Cesium 137 is leached. This was unusual in our experience, because the wastes in the present pits contain cesium, ruthenium, and strontium, but only ruthenium has moved through the shale.

DR. GRIGGS: You listed a group of critical nuclides that you are going to get rid of but you include one of them in your tests of fusion fixation?

MR. STRUXNESS: The idealized concept supposes that cesium will be removed from the waste, but Dr. McVay is including Cesium in his synthetic wastes because the cesium separation process has not been worked out.

CHAIRMAN HESS: We will have to limit the questions because the Steering Committee has to work after this meeting. I propose that we have the questions the first thing in the morning.

MR. STRUXNESS: Would you like for me to continue? I am afraid I have a half-hour more.

CHAIRMAN HESS: We don't want to rush. I think we will close this session now and start off at this point at nine o'clock tomorrow morning.

... The meeting adjourned at 10:15 o'clock... 
58.

SUNDAY MORNING SESSION

September 11, 1955

The meeting reconvened at 9:15 o'clock, Dr. Hess presiding.

CHAIRMAN HESS: Mr. Struxness will continue.

MR. STRUXNESS: We have made four "hot pot" experiments that are clesigned to tell us whether or not self-fusion is possible. The calculations of heat capacity and heat dissipation of various wastes and different containers were tested empirically. The pot is built as follows: the innermost container holds clay that had been calcined previously at 600 degrees, with a heater in the center; the heater is a pressed mica sheet wound with nichrome wire; surrounding the clay container is an insulating container of 4 inches of lamp black, and this, in turn, is surrounded by 8 inches of vermiculite. In the three experiments depicted in the table the dimensions of the inner container were changed. We tried to maintain the same insulation surroundin the inner container. $\mathrm{T}_{1}$ represents the temperature at the center of the inner container. $\mathrm{T}_{2}$ represents the temperature of the clay at the exterior of the inner container. $\mathrm{T}_{3}$ is the temperature at the exterior wall of the lamp black container. The outside container is a galvanizea can, the dimensions of which are 4 feet in height and 3 feet in diameter. In "hot pot" No. 1 the inner container was 4 inches high and 12 inches in diameter. In experiment No. 2 the inner container was 6 inches in diameter and 2 inches high. In experiment 4 the inner container was 24 inches in diameter and 8 inches deep. At 40 watts input the temperature rose to about 385 degrees in approximately 4 days. With increased power, the temperature rose rapidly and stablized at about 560 degrees Centigrade on approximately the 9th day. With further increase in power, the temperature rose rapidly and stablized at approximately 730 degrees after the 14 th day. If we plot the input in watts as a function of temperature, the curve suggests to the ceramists that a reasonable temperature to attempt to achieve for fusion is 900 degrees $\bar{C}$.

Experiments 2 and 4 were performed to determine the effect of areas to volume ratio on the energy required to heat the clay mass. In experiment 1 this ratio is .8 , and the calculated power is midway between .01 and .02 watts per c.c. In experiment No. 2 this ratio is slightly over 1.5 , and the power input calculated is midway between .06 and .07 watts per c.c. In experiment No. 4, where the dimensions 
TABLE I

HEAT EXPERIMENT DATA

$\begin{array}{cccc}\text { Time Watts } & \mathrm{T}_{1} \text { (Center) } & \mathrm{T}_{2} \text { (Exterior) } & \mathrm{T}_{3} \text { (Carbon Insulation } \\ & & \text { oC } & \text { od }\end{array}$ (days)

EXPERIMENT 1

$\begin{array}{rrrrr}0 & 40 & 28 & 25 & 25 \\ 1 & 40 & 280 & 157 & 46 \\ 2 & 40 & 338 & 208 & 72 \\ 7 & 60 & 383 & 254 & 98 \\ 15 & 60 & 554 & 373 & 140 \\ 17 & 80 & 636 & 414 & 144 \\ 25 & 80 & 722 & 490 & 176\end{array}$

EXPERIMENT 2

$\begin{array}{rrrrr}0 & 10 & 25 & 25 & 25 \\ 2 & 10 & 226 & 176 & 54 \\ 7 & 20 & 414 & 324 & 86 \\ 9 & 49 & 764 & 616 & 143 \\ 10 & 60 & 884 & - & 152\end{array}$

(failed before equilibrium)

EXPERIMENT 4

\begin{tabular}{|c|c|c|c|}
\hline 0 & 400 & 25 & 25 \\
\hline 2 & 400 & 800 & 428 \\
\hline 3 & 400 & 876 & $(628)$ \\
\hline
\end{tabular}


60.

were increased to 8 inches deep and 24 inches in diameter, this ratio is slightly above .4, and the calculated input is slightly above .01 watts per c.c.

DR. KOHMAN: Is this the power necessary to get 900 degrees?

MR. STRUXNESS: This is the power required to fuse this clay mass.

MR. MORTON: You will get 900 degrees if you have enough insulation at the boundary.

MR. STRUXNESS. However, Dr. Johnson, who did these experiments, feels that these power requirements are conservative. He says that with reasonable insulation in the ground, and with a pit about 20 feet deep and 20 feet in diameter, one might be able to fuse this clay flux material.

DR. HUBBERT: Wouldn't it be more important if you stated how much energy was required to reach that level?

DR. CULLER: It would have to be energy-time, wouldn't it, to reduce that temperature?

DR. HUBBERT: In order to produce fusion the temperature must be raised the required amount. This, in turn, involves the addition of an amount of heat equal to the heat capacity of the material at the melting temperature with respect to that of the initial temperature, and then an additional amount of heat to product fusion. The power required, it seems to me, is fundamentally ambiguous because the heat produced by any given power is proportional to the time. Since there are heat losses by conduction, these can be kept small only by keeping the time as short as possible, which implies rapid heating at a high power level. The object, therefore, should be not to find the least power that would permit fusing temperature to be reached, but rather to produce fusion at the least energy cost. At low power levels the energy expenditure could be without limit because of heat leakage; at high power levels the energy required would approach that for fusion without leakage.

MR. STRUXNESS: Further work is needed to extend the points on the curve, and I will certainly talk to him about it. 
DR. LINDSEY: At Hanford most of the energy would be released in boiling and in the ground.

DR. HUBBERT: The primary concern is how much energy is needed to make these brickettes.

MR. STRUXNESS: Yes.

DR. HUBBERT: Is this heating element shaped like a doughnut, hollow inside?

\section{MR. STRUXNESS: Yes.}

In experiment No. 4 , the set up is as follows: in the inner container is acid aluminum nitrate waste plus the clay flux mixture, surrounded with foam glass, and with vermiculite in the outer container. The diameter of the inner container is 12 inches, the foam glass container is 20 inches, the hot pot outer container is 36 inches, the height is 48 inches, and the inner liquid is 24 inches. With an input of 40 watts the temperature rose to almost 100 degrees Centigrade in 3 days. Then the power was increased to 100 watts and the temperature rose rapidly, and at about the fifth day it was somewhere between 110 and 120 degrees. Beginning at about the third day, and extending to the tenth day, it bubbled and steamed. Beginning about the sixth day the temperature began to increase slowly and $\mathrm{NO}_{2}$ fumes began to appear. This continued until the nineteenth day, the temperature gradually increasing -- on the fifteenth day, the temperature had risen to about 250 .

By the twentieth day the temperature had risen to $300^{\circ} \mathrm{C}$., at which point practically all the nitrogen oxide had been released. Then the temperature began to rise more abruptly, so that by the thirtieth day the temperature had risen to $460^{\circ} \mathrm{C}$.; the reason for this was that after the liquid had been evaporated and the nitrogen oxide fumes had been evolved, an insulating material was added above the dry mass.

Now a word about what happens in the inner container: the level of the liquid was 24 inches, the diameter 12 inches. As the level dropped 10 inches nothing clung to the walls. Then dropping from 10 to 17 inches the material did cling to the walls. The reduction of the waste and clay flux mixture was from 24 inches to something on the order of 8 inches. The heater failed, so temperatures could not be raised further but the mass seemed to be fairly well fused. Dr. Johnson's description of the consolidation is as follows: 
"No violent bubbling, surging or 'burping' were observed and as the mass shrank it did not adhere to the container walls during the first 2/3 of its consolidation. Only small amounts of the cake adhered after that. The mass appeared to be fairly uniformly heated. Although the temperature finally attained was insufficient for good sintering, the mass was hard with relatively small bubbles trapped within."

The plans are to continue the experiments using a pit perhaps 6 feet in diameter and 6 feet deep, and possibly progressing to a pit approximately 20 feet in diameter, 20 feet deep. The final stage, presumably, would be to build another pit of this approximate size and add to our clay flux mixture hot reactor wastes to see if self-fusion can be obtained.

DR. HUBBERT: How large is the first pit going to be?

MR. STRUXNESS: The first will be 6 feet deep and 6 feet in diameter. The second will be 20 feet deep and 20 feet in diameter with an internally installed heater. The third step is the same size pit, approximately, adding our mixture to the hot waste.

DR. L. R. ZUMWALT: I take it that this aluminum nitrate waste that you used in this experiment did not have the fission products in it. It was merely the chemical equivalent of the bulk.

MR. STRUXNESS: Right.

DR. ZUMWALT: In other words, there has been no opportunity to take the solid mass and subject it to leaching tests.

MR. STRUXNESS: Right. Furthermore, we have learned in some of the experiments that the ruthenium comes off in the gases. Not all of it, but quantities enough to worry us, and we are building equipment to collect it.

DR. THEIS: Where are the heaters located? Are they actually in the radioactive liquid?

MR. STRUXNESS: It is simulated waste.

DR. THEIS: They are in the reactors, and actually to have overheating the mixture must entirely overlie the heater surface. 
MR. STRUXNESS: Well, I don't know. Dr. Johnson says that the dry mass was uniformly heated.

DR. BENSON: I suppose you suspected that you would be very closely simulating it when you have the heat released by ralioisotope decay.

MR. STRUXNESS: Yes. I suppose if the heat were not evenly distributed we would have gotten burping.

DR. HUBBERT: Coming back to power versus energy: if to reach an equilibrium based on the curve would take a long time, it will take a very large amount of energy. If, on the other hand, you put in larger power you produce that temperature in much shorter time and I suspect you would bring about much lower energy cost. I think the energy is important, not the power.

MR. STRUXNESS: I will have to get the information.

DR. KOHMAN: When you do this by self-fusing you won't get any power failure. Your heater won't burn out. You would be able to turn it off when you want to. But it is difficult to get it solidified if it is hot enough so it will liquify, and this brings up the general problem of the heat that will be produced by insoluble waste.

MR. STRUXNESS: There are other difficulties connected with this experiment. It requires wastes with an activity of the order of 500 curies per litre to produce enough heat.

DR. HUBBERT: The problem involved is the energy problem. You can melt anything with that amount of heat coming off continually at the center.

DR. P. H. ABELSON: What is the object of using self-heating or self-fusing as against using other sources of heat?

MR. STRUXNESS: At the moment we don't know whether selffusion will work or not. The heat is there.

DR. ABELSON: Obviously the self-fusion will work if you have enough heat per unit of volume and if you don't allow too much to escape. I mean, suppose that you can have self-fusion, why use it? 
64.

MEMBER: I think it would be a lot easier to handle this stuff. It is going to be awfully hot from the gamma radiation standpoint.

DR. ABELSON: Once you have got this red hot brick, what are you going to do with it?

DR. ZUMWALT: You can have a remote operation and let it heat itself.

MEMBER: I assume you are going to keep it right there. .

MR. STRUXNESS: Part of our answer is self-fusion and lowfiring temperature, and there is a feeling that uses will be found for some of these fission products, and it would be nice if we could immobilize them until then rather than pump them into an inaccessible place.

DR. HUBBERT: Isn't it probable the production of fission products is likely to keep pace with the development of the needs? Suppose we throw everything away right now. There is more coming along. The way this thing is promising to develop it looks to me like we are always going to have ample supplies of hot material for all current needs. If so, a little waste is not important.

CHAIRMAN HESS: Are there any other questions?

Thank you, Mr. Struxness.

\section{GENERAL DISCUSSION}

DR. LOOFBOUROW: Is it correct to say that reactors will generate moderate to low intensity wastes, and those reactors must be located for reasons of operating economy near where the power is required, but the problem of disposal at those sites is not a serious one because of the type of waste. But the highly concentrated wastes generated at chemical plants, which can only be shipped with serious costs or hazards, can be shipped farther, so that the site of those plants can be chosen where disposal is most simple?

DR. ABELSON: No. It would be most economical to process at the spot. The radiation hazard would be very great. 
DR. LIEBERMAN: I don't believe that question can be answered categorically. For example: if you have an aqueous type of reactor and process it at the spot you would have high level waste right at the reactor site. On the other hand, with the heterogenous reactors, fuel elements can be shipped to the chemical processing plant. The answer differs with the type of reactor decided upon.

DR. LOOFBOUROW: Are we limited in the consideration of the immediate problem to one or the other of these situations?

CHAIRMAN HESS: No. The committee debated whether to limit discussion to the possibility of establishing two disposal areas in the United States, or whether the disposal should be around every reactor. So many variables had to be considered that it was decided each committee should be allowed to work out its own course.

DR. CULLER: The processing of the homogeneous waste does occur right at the site, in the sense that the fission products are the fuel. But the plant that separates thorium from uranium does not have to be there. In fact, the economics of the processing and of the construction of processing plants indicates it would be desirable to operate at maximum capacity. It appears at the moment most economical to have 5 to 15 reactors served by one processing plant.

DR. H. C. THOMAS: Is it possible to remove the aluminum from waste solutions?

DR. CULLER: Yes, depending on the type of fuel element. It is impossible to get rid of the aluminum in an aluminum-uranium alloy. Aluminum may be dissolved in caustic, but the uranium is not soluble, so a caustic separation process may be developed. The alloys for high temperature elements are difficult to separate and are highly salted in some cases.

DR. KOHMAN: I would like to ask a question about the ratio of ten reactors to one processing plant. Isn't it possible that all these reactors might be in one area for a central power station?

DR. CULLER: Yes.

DR. KOHMAN: So you wouldn't necessarily need transportation.

DR. CULLER: There would be some transport, and that means building a carrier and getting equipment. If you transport two miles, 
66 .

it is almost as economical, considering all the loading and unloading, to transport it 200 miles. The transportation cost per mile is important, but it is not necessarily the major item.

DR. HEDMAN: It seems to me there is a great difference between transportation between points in your own installation and points in different installations. Some citizens object to having radioactive wastes hauled across their water supply.

DR. LINDSEY: The slugs are moved generally in large casks that have 9 to 11 inches of lead. The cask weighs approximately ten tons, and the slugs weigh one to two thousand pounds. We have to transport a tremendous amount of lead to carry a limited amount of the fuel element. The cost is less for the fuel element then for the shielding, particularly under the present regulations, where we almost always have an escrot guarding a shipment of this sort. There is an incentive to reduce the transportation if there is a way to do it.

DR. WATKINS: I want to ask whether it is feasible at all to transport ion-active liquid waste by common carrier, and if so, how much could you haul it for?

DR. R. J.RUSSELL: May I add something to that question. The transportation of radioactive material in this country by common carrier is controlled by the Interstate Commerce Commission, and they have very definite rules, and anybody can read them.

DR. HEDMAN: I might add one thing to that. I have recently looked over the I.C.C. regulations, and they specifically state that you must transport according to the I.C.C. regulations unless it is done by or for the A.E.C. under escort, in which case the I.C.C. doesn't seem to care.

DR. HAWKINS: It seems to me the proper design of a pipline has some possibility, and there has been some experience on pipelines. I wonder if somebody would say something about that.

DR. LINDSEY: The pipelines at Hanford consist generally of a concrete encasement in which are laid two or three stainless steel lines, and covered by a concrete cap. The encasement and space around the pipe is carefully constructed so it drains, and the drainage is monitored to be certain there is no leakage from the pipes. The installation is extremely expensive. 
We have given thought to making pipe of carbon steel, but the difficulties always seem to be resolved by using stainless steel. The lines are built of about 3 -inch pipe, but there is no reason they cannot be made larger.

DR. HUBBERT: How much does it cost per mile?

DR. LINDSEY: I don't know the accurate figure, but it is something on the order of one hundred thousand dollars.

DR. ROEDDER: If you have disposal at just a few places you have to transport either the waste to those sites or you have to set up your processing plants at disposal sites. I would imagine that the cost of transporting slugs would be far less than the cost of transporting waste. Is that not true?

DR. LINDSEY: We have not transported liquid wastes. We are afraid to. We have transported slugs on a large scale and for quite a while. There is no reason why we couldn't work out a way to trans port liquids. It just doesn't seem as safe as transporting the slugs.

DR. RUSSELL: May I remark that the A.E.C. can get away with a great many things in this country that a private corporation operating a power plant would not be permitted to do.

DR. KOHMAN: With regard to transportation I think one would have to consider the relative cost of transporting the materials and transporting the power. In other words, whether the power plant is to be near an area where the material is to be disposed of, or near the area where the power is to be used, or not near either one.

DR. HUBBERT: Mr. Chairman, I would like to make a further comment on that. It is a truism of sorts that with any technology development, you begin to tie on where you are now, but as time goes on you sometimes abandon the initial premise. It seems to me this is a strong possibility in the case at hand. At the moment, we are talking about building atomic power plants for industrial power where we already have coal power plants. The reason for that is perfectly obvious: we use 60 cycle $A C$ current and the economic transmission is about 400 miles. Many of you know that there have been theoretical discussions and a fair amount of experimental work that dates back thirty or forty years on high tension DC long distance transmission. It is physically possible but it has never been done. In principle, you generate $\mathrm{AC}$ to high voltage, rectify $D C$, and transmit it great distances; then convert 
to $\mathrm{AC}$ and step the voltage down to that of your power plants.

Initially we assume building atomic reactors in lieu of coal plants in consumer areas. But if this industry becomes as large as has been discussed there, I think we will have to re-examine the premise. It may be, because of transportation costs of the hot material, that we might eventually decide that it is better to put the power plants in an uninhabited area, and transmit the power to centers of consumption by methods that are considered unorthodox at the moment. That is not something that this committee is called upon to solve or to recommend. It is not within the premise of the contemplated power plant, but it is in the background.

DR. MORTON: I don't have any specific data with regard to transportation of high level wastes, but our experiments with low or intermediate level lead us to think that transportation in a container is going to be uneconomic and not feasible for more than very short dis tances. Our wastes were 1 to 30 curies per gallon, transported in 500gallon tanks on specially constructed trucks, hoisted with a lift some feet back of the driver, and with lead shields behind the cab. The exposure time for the driver was very short but exposure time created a bottleneck in getting waste out to the pit despite its low level. A pipeline 7000 feet long now does the work of the trucks.

Multiply the hazard by several hundred to a thousand curies per gallon, and it requires transportation in a container shielded with seven to nine inches of lead all around, weighing many tons, and carrying several gallons at a time. It is impractical.

DR. ZUMWALT: Dr. Culler mentioned that economics require one chemical plant for several reactors. But I wondered how about the economics of field transportation. Is that considered in there?

DR. CULLER: There have been several studies of the probable cost of transportation of various kinds of carriers, but I don't think it has been worked out and integrated into the economics of power. I am saying that a central chemical plant is necessary from the standpoint of the chemical plant alone, and within a DC structure it is economic to ship fuel certain distances to a plant that already has the capacity rather than building a new plant. An individual kind of analysis has to be made and it isn't very clear at the moment, because the specifications have not been written on the reactor, the processing, the locations, the power, etc. 
DR. HEDMAN: Could I get some idea of the volume that is transported between a power reactor and a plant?

DR. CULLER: Let's say the fuel elements are made out of a metal like zirconium, and zirconium slag or stainless steel built in a similar manner. It might be necessary to transport an element 15 feet long and 5 inches in diameter. In order to shield this after a reasonable cooling period it would require about 8 or 10 inches of lead.

DR. HEDMAN: That is within the realm of being practical. I thought maybe you would have to transport large volumes of liquid besides.

DR. CULLER: No. If you shipped the fuel element within thirty days after it comes out the reactor you would have to provide cooling water to take out the fission products. You can put a number of such fuel elements in the cask, and I suspect the size of the cask is determined by the limits of the carrier. If you have an 80,000 pound flat car you make the cask 80,000 pounds.

There is another factor that enters into it. If the fuel elements are highly enriched you have to limit the number that go into the cask. But I suspect if you have more cylinders of shielded lead on a flat car you could transport a reasonable number of fuel elements at one time.

The transportation is going to become a business like the power business, I suspect, and it has never been looked at in this light. Regulations may have to be changed to take care of it. Right now it is a big hazard and we are doing everything we can to make sure there is no danger.

DR. L. MacMURRAY: Dr. Morgan at Johns Hopkins has some specifications on this question of transporting liquid wastes. Would you like to have him present it?

\section{CHAIRMAN HESS: Yes.}

DR. J. N. MORGAN: After the first Woods Hole meeting, at Johns Hopkins we made a few observations based on Dr. Culler's paper concerning the transportation of liquid wastes. These figures are based upon the information concerning shipment of slugs throughout the United States. The cost of the cask, the transportation cost, the carrier cost, the salaries, and amortization of the cask, total 9 cents per ton mile to 
70 .

ship the lead, i.e., the shield that contains the slugs. Calculations were made for a hollow sphere about $41 / 2$ feet internal diameter with a capacity of about 500 gallons as envisioned at Oak Ridge for transporting liquid waste. With a 12 -inch wall, skids, base, and structural steel, the cask would probably weigh approximately 50 tons. Some of the weight was the waste itself. The liquid waste that presumably would go into this contained the maximum activity mentioned by Dr. Culler in his first discussion, namely, 2000 curies per gallon. At 9 cents per ton mile, it would cost about $\$ 14$ per gallon to ship 1000 miles.

Remember that these calculations were on data obtained from the shipment of slugs, which are the only data available. There has been no shipment of liquid waste; possibly on a modified basis of 200 gallons in a container of 4 inches of lead shielding it would appear more economical.

DR. LINDSEY: What about cooling for something as hot as that?

DR. MORGAN: It was not considered.

DR. HUBBERT: Is 2000 curies the maximum you can handle?

DR. MORGAN: That is the maximum Dr. Culler mentioned.

DR. HUBBERT: Well, those can be further concentrated.

DR. MORGAN: Yes. We took these from his initial work, based on 2000 curies per gallon.

DR. HUBBERT: None the less, if you are shipping that much lead we can fill the cask with more concentrated material if there are no reasons for not doing it. In other words, how many curies could you put in that container and stay short of critical?

DR. CULLER: There is no criticality on the waste.

DR. HUBBERT: Good. Then we could concentrate this to dryness.

DR. CULLER: As this gets more concentrated you have to provide cooling: 1000 curies per gallon is pretty hot and will boil itself without a little cooling. 
DR. HUBBERT: What I meant is that we are paying $\$ 14$ per yallon for hauling lead. Now, if we can hold 100 times as many curies with the same load of lead we can cut this $\$ 14$ per gallon. Even if we have to add a refrigerating unit we cut that down to a fraction of a dollar.

DR. CULLER: This particular waste is already saturated with aluminum, and the dry aluminum concentrate occupies the same volume as the wet solution.

DR. HUBBERT: The aluminum is not radioactive. Can we get rid of it?

DR. CULLER: Yes. That $\$ 14$ per gallon made us get rid of it. (Laughter)

DR. MacMURRAY: I would like to come to the rescue of Dr. Morgan: liquid reactor waste costs $\$ 14$ a gallon to ship. The discussion has moved on to talk of concentration and refrigeration, and to the removal of aluminum.

DR. MORGAN: To carry it further, this was based on a freight car 40 feet in length, and it would hold three of these units. So the freight car load was about 150 tons.

DR. ROEDDER: If you loaded that same freight car with slugs what would be the equivalent?

DR. MORGAN: I don't think you can make a comparison.

DR. ROEDDER: As to curies and slugs, I wondered the relative cost.

DR. MORGAN: I cannot give you that. Perhaps the answer lies along the lines of developing a specially constructed railroad car in the shape of an oil tanker, completely shielded, with a tube through the center and shielded at either end.

DR. RUSSELL: Have you ever considered what would happen to the car in a train wreck?

DR. MORGAN: I am sure that the possibility of an accident has been on Mr. Gorman's mind. 
DR. HEDMAN: What is the basis for your 50 tons?

DR. MORGAN: Conformity with the existing I.C.C. regulations.

DR. WATKINS: It seems probable that with a homogeneous reactor, the disposal facilities are to be at the site; with a heterogeneous reactor, the processing plant can be at some distance from the reactor.

DR. CULLER: I don't think that is true. The homogeneous reactor materials can be shipped just as can the heterogeneous elements. The processing on the heterogeneous system consists of drawing a small amount off the reactor, and shipping it as the reactor fuel element, I suspect. It has a higher potential of spillage than does a metal container, but you are not shipping thousands of gallons. In the homogeneous system you do not withdraw uranium; you withdraw fission products, and from the external core. The cycle or turnover time for the core is about 270 days, and the amount of material that we have to take out per day may be in the neighborhood of 100 to 200 litres. The liquid might be transported in relatively small volumes, or as a dry solid. It is necessary to boil off heavy water and return it to the homogeneous system before the stuff drawn off the reactor leaves the plant. We probably would be transporting dry sodium oxide.

DR. RUSSELL: That would be at high temperature?

DR. CULLER: At a high temperature in a cooling system.

DR. HUBBERT: It seems to me we have been very premature indeed if we come to any conclusion that the waste cannot be transported. The difficulties are great and the costs appear high but admittedly the estimates are subject to many modifications and are based on inadequate data. There are endless opportunities for corrections and improvements, therefore, the imposition of limiting suppositions may seriously jeopardize the usefulness of the committee.

DR. CLAUS: In our committee work should we consider primarily our immediate problem, and by immediate I mean the next ten to twenty years, or should we consider it in terms of the vast quantities that have been discussed in connection with possible production by the year 2000? Furthermore, should we think primarily in terms of problems in the United States, or should we take a wider view? England, for example, expects to have a large number of reactors and some are under construction. Their waste disposal plans are unknown to most 
of us at the conference, and it should be kept in mind that England's problems are world problems just as ours are, and any thoughts we might have on the disposal of waste from England will also be of benefit to us.

CHAIRMAN HESS: I think it would be difficult to consider construction outside the United States. Construction of reactors and disposal of waste in most countries will probably follow the pattern set by the originators. There is nobody here who knows enough of the geology of out-of-the-way places to give intelligent data. A lot of people here are familiar with many parts of the United States, so we can come to rather specific conclusions about many places, whereas I don't know that we are competent to tackle the geology of England from our professional experience, and whatever we do here, except for England, will probably be followed in other countries. We can find solutions for the conditions in the United States and we can work out analogous solutions for other areas in the future. I think we have sufficient diversity within the United States to meet any conditions any other country would face. I don't think we should discuss outside areas.

DR. LACEY: Such things as costs and amortization would be considerations in competitive industry or would be handled by fairly substantial government subsidy. I propose we omit these items and think of the technological feasibility of the solutions to the problems nearest to us. If solutions are found, the costs will be dealt with in the normal development of the industry.

CHAIRMAN HESS: I think that is right, for we will not have cost figures for the means of disposal that we suggest.

DR. ABELSON: On the other hand, if the cost of disposal is more than the cost of storage in tanks, it is not a good solution.

DR. G. F. JENKINS: I would like to add that the Union Carbide Company is deeply interested in these considerations as a private firm. We are working with practically all the power reactor groups in designs of chemical processing plants to purify reactor fuels. The variations are certainly complex: in the government reactor program there are about five kinds of reactors, and the A.E.C. is encouraging the development of new types of reactors. There is no advantage in building just one kind, so the physicists, the metallurgists, and the mechanical engineers are being encouraged to develop new reactor designs, new reactor arrangements, and new metallurgical alloys. For example, 
the Detroit Edison Company is interested in the fast breeder reactor using alloys containing only a small amount of fissionable material; in order to run the system at the maximum efficiency, that is, to breed, the fuel is to be purified at a high rate. The problem is not just to rid the fuel of the fission products, but also to process rapidly so as to minimize the inventory costs of fissionable uranium. It takes a lot of reactors to make it economical to run a chemical processing plant; but on the other hand, all of the different reactor plants must have some on-the-site purification in order to cut down the amount of idle uranium. Then the slags or the concentrated form of the fission products containing a minimum of uranium will be shipped to a central facility where it is economic to recover the remaining uranium.

The only reason we have the waste is because we are treating the fission products to recover the U 235 or the U 233 or the Plutonium 239. If none of these materials were in the fission products then there would be no interest in them at the present time. However, we are interested in the radioisotopes because they are potentially valuable raw materials. Throughout our corporation we are encouraging research in applications as a form of investigation distinct from research in separation and recovery. We want to encourage research in applications to such fields as alloys, gases, carbons, chemicals, plastics, and resins, and we are trying to build up within our corporation an appreciation of the need for the utilization of these materials, so that instead of a waste disposal problem we are converting it into a raw material problem. We are, therefore, in favor of disposal in such a way that the material is not lost but is retained somewhere so that in the next five or ten years it can be recovered and put to use; that is what I would like to suggest at the present time. We have given a lot of thought to the methods developed at Brookhaven and other laboratories where the materials are treated in not-too-dilute form so that the valuable components can be put to some future use.

DR. CLAUS: To what extent may we actually consider it feasible to remove strontium and cesium? I think this was discussed very enthusiastically yesterday as something that might be done easily, and yet I understand that we have not yet reached the stage where it can be extracted from waste streams in a reasonable useable manner. It makes a difference what kind of disposal can be applied to the remaining material. If these elements are not present, the degree of hazard is so much less, that you have a different way of thinking about the remaining wastes than if the cesium and strontium are present. I think this ought to be clarified before we think seriously about what to do with the remaining material. 
CHAIRMAN HESS: It seems to me from the discussion that you have a reasonable chance of taking these two elements out at some future time, say five years hence, so it won't be much of a problem after that period. But it certainly is a problem at present. I think we should consider both alternatives and have multiple solutions.

I think I would agree there certainly is a disposal problem. The waste we have on hand is not being disposed of, in any strict sense, and it is something to worry about. There also will be a waste problem with us until the chemical processing and reactor treatments have been stabilized on a product that can be clealt with easily. But for the immediate future, extending to many years, wastes will constitute a serious problem. It is an encouraging possibility that in the future people can produce wastes that can be gotten rid of more easily than the present material.

\section{APPOINTMENT OF COMMITTEES}

The Steering Committee wishes to study the waste problem from two points of view and, therefore, this group should be separated into subcommittees to consider each one. One approach involves disposal at great depth using techniques like those used in disposing of oil field brines; the other approach is relatively shallow disposal such as is being employed at Oak Ridge and Hanford. The goal is an evaluation of the efficiency, the hazards, and the practical methods of resolvin the individual problems. Dr. Hubbert has agreed to be the Chairman of the Committee on deep disposal, and the Committee on near-surface disposal will be headed by Dr. Joh Frye. From the long List of Participants, each committee chairman has selected a few names to make up a nucleus; the remaining members on this list will be left to divide themselves as they see fit, in keeping with their individual interests and specializations.

Those selected for the Surface Committee are as follows: Benson, Claus, Frye, Goldich, Hunt, Ingerson, Jenkins, Latta, Loofbourow, Theis, Thomas.

Those selected for the Deep Committee are as follows: Culler, Denison, Ferris, Garrels, Gilluly, Hubbert, Hunter, Thurston, and Watkins.

The committees will meet and proceed immediately.

... Whereupon, at 10:50 o'clock, the meeting adjourned ... 
76.

\section{MONDAY MORNING SESSION}

September 12,1955

The meeting convened at 9:15 o'clock, Dr. Hess presiding.

CHAIRMAN HESS: This will probably be our final session of this conference. We will hear the reports of the work done and conclusions reached yesterday by the two committees. At the end of the reports we will have a general discussion, and then adjourn.

The first report will be by Dr. Hubbert.

Dr. M. King Hubbert

Chief Consultant, General Geology

Shell Oil Company

Box 2099

Houston 1, Texas

DR. HUBBERT: Mr. Chairman and Gentlemen: The committee to look into the possibility of deep waste disposal in permeable rocks met yesterday afternoon and reviewed the problem. We decided on two premises for our discussions: one, that the disposal should be safe; and, two, that we would formulate basic principles governing disposal during what we hope will be orderly and rational development of the industry in the future.

In order to obtain a clearer idea of the magnitude of the wastedisposal problem, the following calculation was made:

Suppose that beginning in 1960 , nuclear power were produced at a rate equal to the present entire power output of the United States, and the waste products diluted to the extent of 50 gallons of water per gram of fission products, were injected underground into a sandstone 100 feet thick, having 20 percent porosity, what would be the area of the sand that would be filled with waste products by the year 2000 ? At the meeting an approximate calculation was made, and the following are the slightly revised results: The present power output of the United States is about $4.8 \times 10^{11} \mathrm{kw}-\mathrm{hr} / \mathrm{yr}\left(10^{8} \mathrm{kw}\right.$ at a load factor of 0.54$)$. The quantity of U-235 required would be 84 metric tons per year, and the diluted wastes would amount to 100 million $(42-$ gal) barrels per year. By the year 2000 the area occupied by the wastes would be 40 
square miles, or a square of 6.3 miles to the side -- the size of a large oil field.

For comparison, in the East Texas oil field, 100 million barrels of water per year are currently being injected through 58 wells with 7 -inch casings. Eight wells take over 10,000 barrels per day each without pumping.

Since structural basins this size, or much larger, are abundant, it is concluded that the deep underground disposal of wastes for a long time to come would involve operations which are small as compared with those of the petroleum industry.

The various other phases of the deep disposal question were discussed in considerable detail by the committee, and finally a subcommittee drew up a summary of the conclusions which were approved and read as follows:

The committee has accepted as premises the following:

A. That the nuclear waste, if stored underground, should be isolated as permanently as possible from contact with living organisms;

B. That the nuclear waste may be stored under conditions where it need not be recovered;

C. That the disposal of waste is a special problem for each particular installation.

However, it is concluded that certain general principles should guide the selection of methods of disposal:

1. That the liquids containing the nuclear waste shall have a greater specific gravity when introduced into the reservoir than the liquids already present in the reservoir;

2. That the liquids shall be stored underground preferably where they will remain under essentially static conditions;

3. That the introduction of the fluids into the bottom of structural basins is one means of satisfying effectively this condition;

4. That adequate monitoring of the distribution of nuclear waste within the reservoir be provided by appropriate observation wells, 
78.

which could also serve as sources of diluent;

5. That prior to the introduction of nuclear waste liquids into the reservoir, the problems of heat dissipation, clogging of reservoir space, and chemical reaction with the reservoir rock and fluids be evaluated.

CHAIRMAN HESS: Does anyone wish to discuss this report or offer any amendments?

If not, I will call on Dr. John Frye to present the report of the committee on surface disposal.

Dr. John C. Frye

Chief, State Geological Survey

Urbana, Illinois

DR. FRYE: The committee on the study of shallow disposal recommends:

1. Disposal of waste materials in solid form is preferable to any suggested methods of disposal of liquids. The most desirable form appears to be a sinter or brick in which the fission products are fixed. In this form the material can be disposed of in shallow covered trenches in many places. Second choice would be waste materials evaporated to dryness, solids but soluble. Such materials could be packaged in metal containers and stored in shallow mines or underground vaults that are relatively dry. If feasible, different elements should be packaged separately. It seems highly desirable that research along both of these lines be pursued as rapidly as possible.

2. Until concentration in solid form becomes feasible, disposal of liquid wastes at relatively shallow depths may be possible under certain conditions.

"Shallow" proved to be a slight misnomer, because in considering mines, depths as great as 6,000-7,000 feet were contemplated. However, most of the excavations are relatively shallow in comparison to deep disposal methods considered by the other group.

The work of the committee was concentrated on item 2, and a large range of geologic environments were studied. Many of these geologic environments were discarded by the committee as unsuited for the disposal of liquids, but in order to record the possibilities that were 
discussed, it seems advisable to outline the various environments considered.

1. Excavations

a. In crystalline rocks

b. In permeable sedimentary rocks

c. In argillaceous rocks, such as shale and clay pits.

2. Infiltration in permeable, near-surface beds

a. Above the water table

b. Below the water table.

3. Underground openings

a. Natural caverns

b. Abandoned ore mines

c. Specially prepared workings .

4. Salt beds, salt domes, abandoned salt mines, and related geologic structures.

The consensus of the committee was that several of these envionments might be feasible but more information was needed.

The order of feasibility in which the committee arranged these various environments was as follows: (in determining this order we did not get a unanimous vote and the consensus of the committee was estimated)

First: salt domes, salt beds, abandoned salt mines, and storage in cavities excavated in salt below the surface but not necessarily near the base of the local stratigraphic section. This would use an environment that has relatively wide distribution in the United States, both in coastal areas and at many places in the interior. It was pointed out that the development of cavities in salt is very cheap. The figure ranges from three to six dollars per barrel for cavities for the storage of hydrocarbons. How these figures can be translated into specially prepared cavities for this type of waste disposal is another question. For this general type of disposal several lines of research are indicated: (a) laboratory study of salt under conditions of heat and pressure in contact with these liquids; and (b) heat-transfer considerations. 
The second priority was storage in especially prepared excavations in shale at depth. The experience record comes from cavities that have been prepared at a number of places for storage of hydrocarbons in very recent years. Some of the advantages are that relatively thick shale beds are scattered widely over the United States; there are sites that probably could be obtained for this use near several of the existing installations as well as potential future sites. Furthermore, the cost is low. When we use as a basis of cost evaluation the operations now under way for the storage of hydrocarbons, figures ranging from $\$ 3$ to $\$ 7$ per barrel were cited as representative of the cost for the preparation of this type of underground cavity. The research needed here is study of the stability of shale in the presence of these particular aqueous solutions.

The third order of preference -- and on this particular item there was considerable diversity of opinion -- was infiltration into particular low-permeable beds with a suitable high clay content for the fixing of these materials in place. This infiltration above the water table bears some similarity to the Hanford operation as it was des cribed, but with certain modifications. The needed research indicated here was (a) study of the hydrodynamic profile of the system; (b) development of proper tracer for water; (c) study of behavior of a suitably simulated solution to determine exchange characteristics; and, of course, (d) highly detailed investigations of water-table fluctuations in any area that might be considered for this type of disposal. It should be pointed out that only those areas with low water table, which would largely limit this matter to some of the western areas, would be usable.

The fourth order of preference was deep, abandoned dry mines. It was the consensus of opinion that if a proper dry mine could be located it might be a very feasible method of disposal, but that such mines would be extremely difficult to come by and might very well not be in the vicinity of any site where they would be needed. If such a structure could be located, it was indicated that some research would be needed on heat-dissipation problems under the particular conditions obtaining in that mine.

The fifth and last category that was judged to be worthy of consideration was disposal in properly covered shale and clay pits on the surface. The consensus was that at the present state of knowledge, it is nnt a desirable means of disposing of high level wastes, but that it would be desirable to have continued research on base exchange and self-sealing characters in the hope that this method might become feasible for high-level waste in the future. Research on self-sealing 
possibilities indicated in this area might also have applicability in several other areas or methods of relatively shallow disposal.

CHAIRMAN HESS: Thank you, Dr. Frye.

Does anyone wish to comment on this report?

You will notice that the tasks as given out were changed somewhat after the committees got to work. "Deep" and "shallow" do not apply any more.

Someone wanted to know what we meant by deep and shallow. The first committee did not comment on how deep they considered deep, but I would think it would mean 1000 to 10,000 feet for the dis posal of materials underground.

DR. HUBBERT: I think the consensus was that deep means asdeep-as-possible. (Laughter)

CHAIRMAN HESS: What is deep to a geologist may seem very deep to a non-geologist or not deep at all.

DR. HUBBERT: We can say ten or fifteen thousand feet is thoroughly practical, although in many cases depths of 5,000 to 10,000 feet, or even less, may be satisfactory.

The conference was adjourned at $11: 30 \mathrm{a} . \mathrm{m}$. 
82.

\author{
APPENDIX C \\ COMMITTEE ON DEEP DISPOSAL
}

SUMMARY MINUTES OF MEETING OF SEPTEMBER 11, 1955

Called to order at 11:00 a.m. by Dr. M. King Hubbert, Chairman of Committee.

\title{
ATTENDANCE
}

For full names and affiliations consult List of Participants.

Full-time attendance

$\begin{array}{lll}\text { Christy } & \text { Hedman } & \text { Russell } \\ \text { Culler } & \text { Heroy } & \text { Seal } \\ \text { Denison } & \text { Hess } & \text { Thurston } \\ \text { Ferris } & \text { Holland } & \text { Triplett } \\ \text { Garrels } & \text { Hubbert } & \text { Varnes } \\ \text { Gilluly } & \text { Joseph } & \text { Watkins } \\ \text { Gorman } & \text { Lindsey } & \text { Zumwalt } \\ \text { Hawkins } & \text { Morgan } & \end{array}$

Part-time attendance

Bass

B rown

Curtiss

Fuller

Griggs

Hunter

Lieberman

Piper

Renn

\section{PROCEEDINGS}

1. Dr. Hubbert started the discussion by diagramming two types of geologic structures mentioned in previous conferences:

a. A synclinal basin of sedimentary rocks, the lower porous strata containing brine.

b. Sedimentary rocks of uniform, low regional dip, in which the water might be static or might be in motion, e.g. , sedimentary rock sequence of a continental shelf.

1.1 Discussion of hazards lead to conclusion that safety was to be primary concern, taking precedence over cost.

2. Mr. Ralph Hunter described the geology of that portion of the Michigan Basin with which the Dow Chemical Company is concerned. One of the producing horizons contains saturated brine in the center of the basin but the margins near the outcrop area 
yield potable waters. Another producing horizon is the Sylvania limestone at a depth of 5,000 feet; 40 feet of the limestone has 10 percent porosity and the remaining 80 feet is very dense. The bromine-bearing brine is pumped out and waste brine pumped back at a rate of 350 gallons per minute; it took 30 years for the activities at one well to affect those at another well one and one-quarter miles away. Brines are also extracted from a deep bed of salt. The salt is dissolved by circulating water; after a cavern estimated to be 750 to 800 feet in size is formed, there is a strong likelihood that the roof will fracture and brines will be drained in from overlying beds.

3. Salient points of the general discussion.

Specific gravity of radioactive wastes ranges from 1.1 to 1.3 , and the more general types are about 1.20-1.25. (Lindsey)

A bed of sedimentary rock having the depth and structural configuration deemed acceptable for waste storage is very likely to be below the zone of potable water - - to be filled with brine - - the flow of deep waters (whether potable or salty) is probably very slow -- diffusion is probably slow. All these characteristics need to be determined before waste is injected into a particular horizon.

Heat derived from fission in the waste can be dissipated by dilution. The volume of waste is small enough so that dilution ratios ranging from $1: 1$ to $1,000: 1$ are feasible.

The boiling point for the given solution at the storage depth should not be exceeded so as to avoid fracturing the roof.

Heating would be local and the rate of brine circulation would be accelerated, thereby dissipating the heat - - a self-defeating cycle. The gentle evolution of vapor would also speed up the transfer of heat.

Permeability of a storage bed can be increased by standard operating procedures of the oil fields, e.g., fracturing and sand injection. The contact surface between "aquifer" and waste solution can be enormously increased, and plugged well-bottoms reopened by this means.

Pressures used in fracturing are commonly less than that due to the weight of the overburden, so that it seems hardly possible, 
84.

mechanically, that the overburden is being lifted. A far more likely result is that vertical or high-angle fractures are formed.

Might an oil pool have to be sacrificed at some place, some time, to provide a disposal site? This is most unlikely if the disposal fluids are made more dense than the displaced ground waters. In that case the wastes will remain in the lowest places, whereas oil or gas, being lighter than water, are trapped in the high places.

Many unproductive structures are known already.

In many fields operators are working on different strata at the same time; it is conceivable that oil might be withdrawn from one or more horizons while waste was being injected into deeper horizons in the structure.

\section{- - Lunch recess - -}

Meeting reconvened at 2:00 p.m.

4. Possible geologic structural basins in the United States.

4.1 Inspection of "Tectonic Map of the United States" disclosed that there are numerous large basins scattered across the country, many of which are known to contain brine-bearing strata at depth; some are not sufficiently well known to be sure of the nature of the deep waters but they may be freshwater bearing.

Major brine-bearing basins

Michigan Basin

various Appalachian synclines

Northeastern Louisiana

Southcentral Oklahoma

Illinois Basin

various West Texas basins
Basins of uncertain potability

Denver Basin, Colo. Powder River Basin, Wyo. Bighorn Basin, Wyo.

4.2 Coastal plain areas offer an alternative method: introduction of wastes into brine-bearing permeable sedimentary formations that dip gently seaward, and pass beneath the continental 
shelf; the contained waters are not static but move slowly down dip.

The Atlantic Coastal Plain appears generally unfavorable at this time because the known sedimentary section on land is thin, and much potable water is involved.

In the Cape Hatteras region a sequence as much as 10,000 feet thick is known which includes brine-bearing sandstone formations. The formations of the shelf slope seaward and thicken seaward, and are potentially useful for the disposition of waste. (Denison)

The Gulf Coastal Plain appears less unfavorable than the Atlantic: here there are tens of thousands of feet of brinebearing sediments dipping Gulfward. However, in many of these very high abnormal pressures (as much as 10,000 feet of anomalous head) prevail. Such wells are always in danger of blowing out. Very careful investigations would therefore be necessary in this area. Moreover, the oil fields here, both on land and in the Gulf, are quite closely spaced.

4.3 The Great Basin Province contains many potential disposal sites in the form of deep gravel-filled topographic basins as well as structural basins in deformed sedimentary rock. The geology of this vast area is so little known, however, that each possible site will have to be investigated extensively. The chances appear high that a number of sites can be found.

4.4 The Columbia Plateau, a section over 5,000 feet thick of basalts with many porous zones, appears to be an unlikely place to find suitable disposal sites; in that area there is a rapid discharge of enormous quantities of potable water.

5. Salient points of the general discussion.

When the iso-salinity lines are parallel to the structural contour lines, the brine is static.

In west-central Kansas the stupendous quantities of brine from petroleum operations are disposed of by allowing them to flow (without need of pumping) into "granite wash" at base of stratigraphic section. The brines are not static but flowing through this 
highly permeable layer, and are below any possible productive zone of oil or potable water.

A similar "granite wash" at Amarillo Ridge is below all potable water and drains northward. It is uncertain whether or not the fresh water farther to the north might be affected if radioactive wastes were introduced into this particular "granite wash".

"Granite wash" or analogous permeable basal layers may well exist in grabens of the Great Basin region.

6. Mr. Gorman reminded the group of the immediately urgent problems at the existing AEC installations.

It was recognized that the existing AEC installations, as well as the first series of proposed power reactors, present special problems since these seem to have been located without much regard for the waste-disposal problem. In each instance a competent geological review will have to be made to find the least inconvenient waste-disposal site available. In all future installations the accessibility to a safe disposal site should be a major consideration in determining the plant location.

7. The motion was made

That waste be disposed of without concern for its recovery, Seconded and passed.

8. Mr. John G. Ferris described some conditions obtaining in the Michigan Basin and elsewhere, and posed several questions, summarized as follows:

Experience with two permeable zones between confining beds shows that long-term withdrawal of brine can draw water from confining beds, as evidenced by changes in salinity, hardness, and other data in industrial records.

In a submarine aquifer the contact between fresh and salt water may be far off shore, as shown by fresh water wells and springs; might radioactive wastes escape to ocean from leaks in the aquifer? 
Contact of fresh and salt water in aquifer is in dynamic balance; man captures fresh water on surface so recharge is impeded and the contact migrates upward.

Injection of liquid into permeable formation raises pressure. Cracks, faults, unplugged or poorly plugged drill holes (locations in many cases unknown) would permit wastes to leak out of formation intended for storage and enter formations containing valuable oil or water. Pressure increases might induce fracturing and leakage.

Deliberate hydro-fracturing and sand-fracturing might break the confining beds relied on to contain the waste.

Waste may move out slowly but the pressure wave would move out rapidly: what effect would this have on the contact of fresh and salt water? And on existing industrial and domestic users?

To measure, minimize, and possibly control the pressure effects, the brine to be used as diluent could be pumped from the same formation the waste is to be injected into; the "diluent wells" could be spaced around the "injection well" so as to create a closed system.

9. Crossbed leakage might be monitored and controlled by rings of wells around injection well. (Holland)

10. If the waste solutions are heavy, the leaks will be downward, out of environment; using basins means that the disposal of waste would not be taking place in structures of present or potential interest for petroleum; enormous basins are available and small ones will suffice. Waste solutions could be made light for sequestering in anticlines but there are important objections: leaks would be upward, toward the biologic environment, and toward zones of potable water and possible oil; anticlines are generally small; the oil industry already occupies a great number of anticlines making for competition with disposal installations, an added difficulty for $A E C$ which is unnecessary in view of the abundance of basins. (Hubbert)

11. After numerous attempts to formulate basic principles and recommendations of policy, the motion was made, seconded, and passed, 
88.

that a small group make the formulation and present it to the Committee for discussion and action. Messrs. W. B. Heroy, D. J. Varnes, and H. D. Holland were appointed the Subcommittee on Resolutions. See item 14.

12. In orier to obtain a clearer idea of the magnitude of the wastedisposal problem, the following calculation was made:

Suppose that beginning in 1960, nuclear power were produced at a rate equal to the present entire power output of the United States, and the waste products, diluted to the extent of 50 gallons of water per gram of fission products, were injected underground into a sandstone 100 feet thick, having 20 percent porosity, what would be the area of the sand that would be filled with waste products by the year 2000? At the meeting an approximate calculation was made, and the following are the slightly revised results: the present power output of the United States is about $4.8 \times 10^{11} \mathrm{kw}$ $\mathrm{hr} / \mathrm{yr}\left(10^{8} \mathrm{kw}\right.$ at a load factor of 0.54$)$. The quantity of U-235 required would be 84 metric tons per year, and the diluted wastes would amount to 100 million (42-gal) barrels per year. By the year 2000 the area occupied by the wastes would be 40 square miles, or a square of 6.3 miles to the side -- the size of a large oil field.

For comparison, in the East Texas oil field, 100 million barrels of water per year are currently being injected through 58 wells with 7 -inch casings. Eight wells take over 10,000 barrels per day each without pumping.

Since structural basins this size, or much larger are abundant, it is concluded that the deep underground disposal of wastes for a long time to come would involve operations which are small as compared with those of the petroleum industry.

13. Salient points of the general discussion.

If the waste solution were to interact with either the rock constituents or the contained brines, precipitates might form which would clog the pores of the reservoir rock. Compatibility of the waste with the rock and water would have to be determined in advance; it will be necessary to treat the waste so it will be compatible. 
The possibility should be considered that some or all of the fission products may tend to be captured by the clays and other mineral components of the reservoir rock near the well bore and hence create an unciesirable local "hot-spot." This contingency needs prior investigation in orcier that it may be avoided.

The total volume of waste, at ten-fold dilution, produced by a 100,000 megawatt power economy (assuming $5 \mathrm{gal} / \mathrm{gmU}^{235}$ ) is $1 \%$ or less of the annual extraction of petroleum in the United States.

Most of the fission heat is generated in the first 100 days to one year, and tank cooling is feasible. Strontium and cesium produce $99+\%$ of the heat, and the calculations in item 12 allow for $\mathrm{Sr}$ and $\mathrm{Cs}$ so the figures are realistic and conservative. Strontium and cesium can be removed from the waste, concentrated to small volume, and given special handling and storage, if necessary, such as sequestering in a deep, dry mine.

There undoubtedly will be problems in designing the injection well equipment but there is no reason to fear that they will be beyond the realm of established engineering sciences. (Gilluly)

- Dinner recess - -

Meeting reconvened at 3:15 p.m.

14. Mr. Heroy read the formulation of the Subcommittee on Resolutions; after discussion and modification, the motion was made, seconded, and passed that the formulation be adopted as the conclusions and recommendations of this Committee, as follows:

The committee has accepted as premises the following:

A. That the nuclear waste, if stored underground, should be isolated as permanently as possible from contact with living organisms;

B. That the nuclear waste may be stored under conditions where it need not be recovered;

C. That the disposal of waste is a special problem for each particular installation. 
90.

It is concluded that these general principles should guide the selection of methocis of disposal:

1. That the liquids containing the nuclear waste, shall have a greater specific gravity when introduced into the reservoir than the liquids already present in the reservoir;

2. That the liquids shall be stored underground preferably where they will remain under essentially static conditions;

3. That the introduction of the fluids into the bottom of structural basins is one means of satisfying effectively this condition;

4. That adequate monitoring of the distribution of nuclear waste within the reservoir be provided by appropriate observation wells, which could also serve as sources of siluent;

5. That, prior to the introduction of nuclear waste liquids into the reservoir, the problems of heat dissipation, clogging of reservoir space, and chemical reaction with the reservoir rock and fluids be evaluated. 


\section{APPENDIX D}

COMMITTEE ON SHALLOW DISPOSAL

SUMMARY MINUTES OF MEETING OF SEPTEMBER 11, 1955

Called to order at 11:00 A.M. by Dr. John C. Frye, Chairman of Committee.

ATTENDANCE

For full names and affiliations consult List of Participants.

$\begin{array}{lll}\text { Abelson } & \text { Frye } & \text { MacMurray } \\ \text { Benson } & \text { Goldich } & \text { Morton } \\ \text { Branson } & \text { Hunt } & \text { Newell } \\ \text { Brown } & \text { Ingerson } & \text { Piper } \\ \text { Bryant } & \text { Jenkins } & \text { Prescott } \\ \text { Clark } & \text { Kohman } & \text { Riley } \\ \text { Claus } & \text { Lasky } & \text { Roedder } \\ \text { Cramer } & \text { Latta } & \text { Struxness } \\ \text { Curtis } & \text { Lieberman } & \text { Theis } \\ \text { Curtiss } & \text { Loofbourow } & \text { Thomas, Harold A., Jr. } \\ & & \text { Thomas, Henry C. }\end{array}$

\section{PROCEEDINGS}

1. It was agreed that the subject would be broken down into categories based on geologic environment, and the following four general categories were set up:
a. Surface excavations
b. Infiltration into shallow permeable beds
c. Natural and artificial excavations, including mines
d. Artificial solution cavities (principally in salt)

During the proceedings it was decided to include the cavities in salt (category D) in category $C$.

2. Surface excavations. The estimate of 1,000 gallons of waste per day for a one megawatt reactor was used as a yardstick for all the following discussions. 
A. Quarries in granite and other crystalline rocks.

(1) Advantages

Availability. There are numerous abandoned granite quarries in many parts of the country (e.g. ,

Texas, Minnesota, etc.).

Low cost of acquiring and preparing disposal site.

Recoverability of material if it is wanted.

If the quarry is tight, the material will not move.

(2) Hazards

Contamination of ground water or of atmosphere by leakage or by sucking up of material in tornadoes. Vulnerability to bombing.

(3) Problems and unknown factors

a. Effectiveness of a grout curtain to prevent seepage into ground water. It was doubted by the engineering geologists present that any grout curtain is 100 percent effective.

b. How could such a site be effectively monitored, an apparent necessity in any jointed crystalline rock?

c. Can the wastes be made self-sealing and thus provide their own "grout" curtain? Apparently this cannot be answered at the present time. Current wastes are high in aluminum salts, which might be useful in selfsealing, but power reactors will undoubtedly have wastes high in zirconium or stainless steel. More research is needed on self-sealing possibilities.

(4) Conclusions

It was the opinion of the majority that both grouting and self-sealing are probably unreliable. Granite quarries are feasible only if the wastes can be permanently immobilized.

(5) Significant parts of discussion leading to above summary.

Goldich: There are a number of granite quarries which might be used, especially in Texas or Minnesota. You could combine surface disposal with self-sealing. I favor surface disposal because you know where it is. A pit $100 \times 200 \times 50$ feet could hold a million gallons. 
I never saw a quarry that was water tight.

I know where it is and that it isn't going to move around. It doesn't have to be granite, it can be any firm rock.

The health agencies are going to insist on some specifications. It cannot leak into ground water which will be used for drinking or irrigation. It cannot be a source of contamination of the atmosphere. Winds have a way of whipping up a lot of surface water into the atmosphere. A tornado could suck up the total contents and spread them over the landscape. A cover would be indicated. (AEC)

What would be needed would be a test of the pit with tracers, over a period of time equivalent to the length of storage time.

Monitoring in jointed rock would be difficult. Some method should be used to immobilize the wastes - grouting, self-sealing, etc.

One of the first properties to be determined is the leaching qualities of the sintered wastes.

Hatch at Brookhaven has information on leaching from montmorillonite clay.

When we talk about self-sealing, we have to remember that aluminum is in the picture because all reactors now are research reactors; with the high temperatures involved in the power field, the wastes will be zirconium or stainless steel. (Union Carbide and Carbon).

Anything on the surface is going to make an attractive military target.

The current system of storing in tanks presents the same hazard.

Another surface bas in might be a lake, or a large depression like Death Valley. 
Death Valley is an active seismic area. There has been a movement of about 350 feet in front of the Funeral Range in the last thousand years.

Granite quarries seem to be open to the objection that you never know whether it is actually tight.

How about grouting granite?

No grouting or facing job is perfect. If grouting were the factor on which we were going to rely, I'd hate to be the one to approve it. I have had lots of experience and have no faith in it, beyond its specific capabilities. (Prescott)

Chairman: Is the consensus on crystalline rock quarries that the wastes should be self-sealing or immobilized?

If grouting isn't satisfactory, how can you rely on selfsealing as satisfactory? (Prescott)

Consensus: Self-sealing and grouting are unreliable, and granite quarries would be acceptable only if the waste is permanently immobilized.

B. Excavations in permeable non-crystalline rocks such as sandstone, limestone, coal, etc. These sites appear to have all the disadvantages of granite quarries in a magnified form. It would be virtually impossible to seal them so that liquid wastes would not contaminate ground water supplies. They are not worth considering unless the waste can be permanently immobilized in a solid form.

C. Excavations in non-permeable materials -- clays and shales.

(1) Shale pits appear to have all the advantages of granite quarries plus the possibility that they might be made "tight" more easily by self-sealing, adsorption, etc. It was also suggested that a non-radioactive sealing material might be found for clay or shale, thus producing a membrane or lining for the pit.

(2) Hazards and Problems. All rocks, including shales, are so variable that it would be difficult to guarantee the 
sealing of any pit. Adsorption by the clay minerals seems to show signs of promise, but in the ground this reaction is reversible and therefore not reliable as a "sealing" method. Long monitoring of low-level wastes may give valuable data on these problems.

(3) Conclusions. Disposal in shale pits is too risky in our present state of knowledge. The method, however, may have promise, and continued research on adsorption and sealers is recommended.

(4) Significant parts of the discussion leading to above summary.

If the material is placed in shale pits, deposition of solids will occur at the bottom and produce sealing there. The clear supernatant with some high radioactivity will pass out the sides.

Can we assume pH control?

Only at great cost and increase in volume. (ORNL)

The question has been raised of the effect of zirconium and the possibility of zirconium recovery.

Zirconium is tetravalent and has a high replacement value for other adsorbed ions and would displace the strontium.

Couldn't we use nonradioactive material to seal and then place in it the radioactive material? Then the membrane would be self-sealing.

Ideal conditions are being assumed. There is a great variation in rocks in their cementing abilities to the extent that probably no one would place his stamp of approval on it.

If the shale is thick and stable it might be a good gamble, since it could be monitored.

Sealing depends on the interaction with the rock. Dilution may damage the gel. 
You may build up a concentration of radioactive material in the gel and get a high heat.

Does anybody have any ideas on what would happen by throwing some bentonite in this material to help it gel?

Bentonite loses its properties in acid solutions.

Is there a geologist present who knows of a clay deposit ten feet thick, without bedding planes and fractures? (No volunteers)

In propane storage we can take a slight loss but here we're talking about zero leakage. I don't trust any natural material not to leak.

Everyone seems to agree that for any processing that you do which depends on plugging pores, the period of testing would be so long that it ceases to be of interest.

Consensus: Without research, shale is not safe.

3. Infiltration into shallow permeable beds.

A. Beds below the water table.

(1) Aquifers below the water table could be considered only in isolated desert basin areas like those of Nevada, and even here they have no advantages over deep aquifers. In addition, they have more potential problems than the deep.strata, e.g.: (a) in closed basins the solutions might rise to the surface and evaporate; (b) even in desert areas, shallow aquifers are commonly used as water supplies: (c) we don't know enough about the movement of ground water in these basins.

(2) Current experiments on adsorption indicate that about 20 tons of montmorillonite clay may be enough to adsorb 1,000 gallons of waste, mostly by base exchange. The reaction, however, is reversible.

(3) Conclusions. Disposal in shallow aquifers below the water table is not recommended. It would be possible 
only if further tests on adsorption indicate that the radioactive ions will not migrate any great distance. Even in this event, disposal in deep aquifers would be safer.

(4) Significant parts of discussion leading to above summary.

Chairman: Infiltration of material close to the surface into permeable and semipermeable formations:

A good estimate of adsorption capacities would be twenty tons of clay for complete adsorption of one thousand gallons. How much clay is there in the desert basins? (Henry Thomas)

In deserts there are thousands of cubic miles of clay.

I would not trust desert basins which appear to have no natural drainage.

Even if the basin is not closed, if the time is long enough in getting over the rim, isn't this adequate?

In these basins there are gravel layers extending out from the mountains like tongues (illustrated by interlocking fingers pointing the tips downward). There are gravel and clay in about fifty-foot layers. Each gravel layer has perched water.

Has any estimate been made of the age of these waters?

There would be stratification and mixing from wells. If you are thinking of tritium measurements, the se would be very difficult.

Consensus: We consider disposal in permeable beds should not be done below the water table, unless subsequent information indicates that adsorption will protect the aquifer above.

B. Beds above the water table.

(1) Possibilities. A part of the committee was of the opinion that this might be worth trying in isolated desert areas 
where the test could be monitored effectively. Areas suggested were: an isolated mesa on the Colorado Plateau; the edge of a fanglomerate, where gravels interfinger with clays; and an area underlain by loess. During the discussion, it was apparent that the feasibility of these sites was predicated on the assumption that clay minerals would adsorb the radioactive ions. Yardstick for the discussion was: A cubic mile of semiconsolidated material contains about $10^{10}$ tons. If the material has 1 percent montmorillonite, it would adsorb 1,000 gallons a day for 1,000 years.

a. The Colorado Plateau was deemed a poor place for carrying on the experiment, because too little is known about the movement of ground water in the aquifers there. The material might find its way to surface springs too quickly.

b. The fanglomerate at the edge of a desert mountain range would be a suitable test site, if preliminary laboratory tests are favorable.

c. A loess-covered area would be good if it is sufficiently isolated, and if the preliminary tests are favorable.

(2) Recommendations for tests and requirements.

a. "Cool" the waste for a period of several years.

b. Conduct specific retention studies on loess and other materials.

c. Conduct research on tracers to determine rates of ground water movement through unsaturated materials and movement of cations in the water. Helium was suggested as a tracer.

d. Laboratory studies on cation movement as related to heat effect.

(3) Conclusions. This method of disposal is worth investigating, but cannot be recommended at the present time. Extensive research will be needed, with no guarantee of success. 
4. Natural caverns and artificial excavations, including artificial solution cavities.

A. Natural Caverns. Natural Caverns are in the zone of potable water and leak like sieves. They are totally unsuitable for disposal of liquid wastes. They would be usable for dry immobilized wastes. Also, a dry cavern above water table would be suitable for dry wastes that were not immobilized but that were suitably packaged.

B. Abandoned Mines.

(1) Shallow mines are similar to caverns in that most are wet and even the dry ones would probably leak if filled with liquid wastes. Evaporated solids in cans could be stored in shallow dry mines.

(2) Deep mines are commonly below the water table and are dry. A deep dry mine (not on a fissure vein deposit) would definitely be suitable for storage of dry wastes in containers and might be suitable for liquid wastes. Heat would be a problem, but could probably be solved. One difficulty would be to find a mine that the owners would be willing to abandon.

(3) Significant parts of discussion.

Abandoned mines are very close in structure to natural caverns.

Real deep mines are dry. Canned peaches have been taken from mines after twenty years' storage and the cans are still bright and shiny and free of rust.

Deep mines might be difficult to obtain because they are expensive and, even if unused, the owners might be reluctant to part with them.

There is a mine in Ontario in a pre-Cambrian formation in the middle of a lake. No water has ever been pumped from it.

If deep, dry, non-vein mines below the zone of ground water table can be found, they may be suitable. If the 
site is satisfactory this would be worth looking into for liquid wastes.

Mines are also very promising for solid storage.

C. Special Excavations, including solution cavities in salt.

(1) General statement. Special excavations have all the advantages of mines except for their higher cost. In addition, we can choose the location, geologic horizon, geometry, etc. The cost of special shafts would be about $\$ 200$ a foot for the main shaft with a 6 to 8 -foot diameter, $\$ 100 / \mathrm{ft}$. for cross cuts, and $\$ 100 / \mathrm{ft}$. for ventilation shafts. As in mines, heat dissipation would be a problem, but the excavation could be designed to aid this dissipation.

(2) Excavation of solid rock. Deep shafts in crystalline rocks might be practical -- they would have the same characteristics as deep abandoned mines. Also, it seems worth while investigating artificial excavations in shale. Although surface pits in the shale are probably not leakproof, excavations in thick shale beds in Illinois have remained bone-dry since they were made (Loofbourow). It was the opinion of several engineering geologists that dry chambers can be excavated at relatively shallow depths in thick shale formations. A great deal of testing would be necessary, however, before one of these cavities could be endorsed for the disposal of liquid wastes. Type of research needed is: mechanical strength tests of the particular formation involved, stability of the shale in the presence of the particular solutions, etc. The cost of propane storage in this type of cavity runs from 7 to 14 dollars a barrel.

(3) Dissolved cavities in salt. Solution cavities in salt are probably the most promising sites for relatively shallow disposal of liquid wastes. Both bedded salt and salt domes are possible, although bedded salt would have more problems, such as the greater difficulty of controlling the size and shape of the cavity and the additional testing of the roof and floor rocks.

a. Advantages of salt cavities. 
Availability. There are numerous beds of salt in the mid-continent area and hundreds of domes along the Gulf Coast. Acquisition cost would be low.

Physical characteristics. Salt will flow under pressure, and in the salt domes would be self-sealing around cavities. Its high conductivity (about twice that of most rocks) and relatively high melting point $\left(801^{\circ} \mathrm{C}\right.$ at pressure of $760 \mathrm{~mm} \mathrm{Hg}$ ) would help in heat dissipation. It was stated that this type of storage could be developed at a cost of $\$ 3.50$ per barrel.

b. Hazards and uncertainties. Cavities and mines in bedded salt might be subject to cave-ins; the strength of the roof rock would have to be carefully tested. Seismic activity might fracture salt of the domes and permit the escape of some waste before the salt resealed the fissure.

c. Research needed.

Extensive laboratory studies of salt under the heat and pressure conditions that would exist. Test also the idea of dissipating the heat by making the salt cavity act as a reflux condenser.

Determine size, shape, and spacing of cavities to allow heat dissipation.

Phase rule study of salt in presence of waste solutions.

Migration of cavity along lines of stress by differential solution.

d. Conclusion. Solution cavities in salt domes are probably the best potential sites for the disposal of liquid wastes at shallow depths. Cavities in salt beds are also good potential sites, but must be viewed with more caution. Rather extensive laboratory tests will be necessary before disposal in salt can be attempted, but this research is pretty straightforward, and is pointed toward the question of how to do it rather than whether it can be done.

e. Significant parts of discussion on salt. 
In Kansas six caverns were dissolved in bedded salt fifty feet thick for LP storage. These had a capacity of 25,000 barrels and were within 500 feet of each other, but not connected. A well for the disposal of the dissolved brine was drilled at a cost of $\$ 80,000$. The cost of the first cavern, including the well, was $\$ 7.00$ per barrel and for the remaining five, $\$ 3.00$ to $\$ 3.50$ per barrel.

I think if conditions were favorable the cost could go down to fifty cents to a dollar a barrel.

Do you have any idea of the shape of these caverns?

There's no way of knowing.

I don't think you can predict the shape because most beds are shot full of fracture galleries. In Texas we have dissolved two caverns in salt, not bedded, of 1.7 and 2 million cubic feet. The diameter is about 270 feet, as measured by sonar explorations. The depth is controlled using gas or oil cushion. I think you could probably get this for $\$ 20,000$. In Canada there is one which is eighteen feet deep, lens shaped, with a limestone roof.

Salt domes can be written off as economically worthless because of huge amounts of salt available. Salt has twice the heat conductivity of soil, and a melting point of $800^{\circ} \mathrm{C}$. The liquid can be saturated and probably would stay there for years.

Put holes down into a dome, say thirty feet in diameter and one thousand feet deep. Keep them at, fifty pounds' pressure and let them operate as reflux condensers.

Reflux action may take material from the top and place it at the bottom. Differential heating would remove material from the the sides.

Maybe the hole will crawl.

I think this will work and I'd sure look into it. 
Would there be an evolution of chlorine gas?

No calcium sulfate usually is present.

This can be tested in the laboratory.

I don't believe the reflux condenser idea is anything more than a wild dream. Use water or brine to dilute or any method to get the heat into the body of the salt. However, there is an enormous calculation on heat to be made.

I'm lukewarm on salt beds but not on salt domes. There are two hundred and forty-two domes from Alabama to Texas. Some may be fifteen thousand feet thick, or more.

Consensus: Salt storage is a preferred method for liquid disposal.

Chairman: Will someone summarize the research needed?

It would be nice to know how it can be done -- how many -- what spacing - - what control -- under what conditions and how fast it would burrow with difference in heat up, down, and sideways. 


\section{APPENDIX E}

\section{PARTICIPANTS IN THE CONFERENCE ON DISPOSAL OF RADIOACTIVE WASTE PRODUCTS}

Princeton, New Jersey - September 10-12, 1955

Abelson, Dr. Philip H., Director, Geophysical Laboratory, Carnegie Institution, 2801 Upton Street, Washington 8, D. C.

Benson, Dr. William E., Chief Geologist, Manidon Mining Corporation, 307 First Street, N. W ., Mandan, N. D.

Bliss, Mr. Lyman A., Vice-President, Union Carbide Nuclear Company, 30 East 42 nd Street, New York 17, N. Y.

Branson, Dr. Carl, Director, School of Geology, University of Oklahoma, Norman, Okla.

Brown, Mrs. Helen, Department of Sanitary Engineering \& Water Resources, Johns Hopkins University, Baltimore 18, $\mathrm{Md}$.

Bryant, Mr. George, Department of Sanitary Engineering \& Water Resources, Johns Hopkins University, Baltimore 18, $\mathrm{Md}$.

Burleigh, Miss Jean, Stenotype Reporting, 10 East 43d Street, New York 17, N. Y.

Christy, Dr. J. T., Atomic Energy Commission, Hanford Project, Richland, Washington

Clark, Mr. Joseph R., The DuPont Company, Savannah Project, Aiken, S. C.

Claus, Dr. Walter D., Chief, Biophysics Branch, Division of Biology \& Medicine, Atomic Energy Commission, Washington 25, D. C.

Cramer, Mr. T.M., U.S. Potash Company 30 Rockefeller Plaza, New York, N. Y.

Culler, Mr. Floyd L., Jr., Director, Chemical Technology Division, Oak Ridge National Laboratory, P.O. Box P, Oak Ridge, Tenn.

Curtis, Dr. Howard J., Chairman, Department of Biology, Brookhaven National Laboratory, Upton, Long Island, N. Y. (Repr. NAS-NRC Division of Biology \& Agriculture)

Curtiss, Dr. L. F., Consultant, National Bureau of Standards, Washington 25, D. C. (Representing NAS-NRC Division of Physical Sciences)

Denison, Dr. A. Rodger, Vice-President, Amerada Petroleum Corporation, Box 2040, Tulsa, Okla.

Ferris, Mr. John G., U. S. Geological Survey, 407 Capitol Savings \& Loan Bldg., Lansing 68, Mich. 
Frye, Dr. John C., Chief, State Geological Survey, Urbana, Ill.

Garrels, Dr. Robert M., Chief, Solid State Group, Geochemistry \& Petrology Branch, U. S. Geological Survey, Washington 25, D. C .

Gilluly, Dr. James, Chief, General Geology Branch, U. S. Geological Survey, Denver Federal Center, Denver 14, Colo.

Goldich, Dr. S. S., Department of Geology and Mineralogy, University of Minnesota, Minneapolis 14, Minn.

Gorman, Mr. A. E., Reactor Development Division, U. S. Atomic Energy Commission, Bldg. T5, 1901 Constitution Ave., Washington 25, D. C .

Griggs, Dr. David T., -Institute of Geophysics, University of California, Los Angeles 24, Calif.

Hawkins, Mr. Murray, Professor of Petroleum Engineering, School of

Geology, Louisiana State University, Baton Rouge 3, La.

Hedman, Mr. Fritz A., Radiological Division, Chemical \& Radiological Laboratory, Army Chemical Center, Edgewood, Md.

Heroy, Mr. William B., 3712 Haggar Drive, Box 7166, Dallas 9, Texas

Hess, Dr. H. H., Professor of Geology, Princeton University, Princeton, N. J. (Conference Chairman)

Holland, Dr. Heinrich D., Professor of Geology, Princeton University, Princeton, N. J.

Hubbert, Dr. M. King, Chief Consultant, General Geology, Shell Oil Company, Box 2099, Houston 1, Texas

Hunt, Mr. Chas. B., U. S. Geological Survey, Denver Federal Center, Denver 14, Colo.

Hunter, Mr. Ralph, Dow Chemical Laboratory, Midland, Michigan

Ingerson, Dr. Earl, Chief, Geochemistry and Petrology Branch, U. S. Geological Survey, Washington 25, D. C.

Jenkins, Mr. George F., Union Carbide \& Carbon Research Administration, 30 East 42nd Street, New York 17, N. Y.

Joseph, Mr. Arnold B., Department of Sanitary Engineering \& Water Resources, Johns Hopkins University, Baltimore 18, Md.

Kohman, Dr. Truman P., Department of Chemistry, Carnegie Institute of Technology, Pittsburgh 13, Pa. (Repr. NAS-NRC Division of Chemistry)

Lasky, Mr. S. G., Office of the Secretary, Department of the Interior, Washington 25, D.C.

Latta, Mr. B. F., District Geologist, Oil Field Section, Kansas State Board of Health, County Court House, Dodge City, Kansas

Lieberman, Dr. Joseph A., Sanitary Engineer, Atomic Energy Commission, Washington 25, D.C. 
106.

Lindsey, Mr. Wilton J., Production Division, Atomic Energy Commission, Washington 25, D. C.

Loofbourow, Mr. R. L., Professional Engineer, 4032 Queen Avenue, South Minneapolis 10 , Minn.

MacMurray, Mr. Lloyd, Department of Sanitary Engineering \& Water Resources, Johns Hopkins University, Baltimore 18, Md.

Maxwell, Dr. John C., Department of Geology, Princeton University, Princeton, N. J.

Melvin, Dr. John H., Chief, Division of Geological Survey, Orton Hall, Ohio State University, Columbus 10, Ohio

Morgan, Mr. James M., Department of Sanitary Engineering \& Water Resources, Johns Hopkins University, Baltimore 18, Md.

Morton, Mr. Roy J., Health Physics Division, Oak Ridge National Laboratory, P. O. Box P, Oak Ridge, Tenn.

Newell, Mr. J. F., Atomic Energy Commission, Washington 25, D. C.

Pecsok, Mr. Donald A., Senior Assistant Sanitary Engineer, U. S. Public Health Service, Cincinnati, Ohio

Piper, Mr. A. M., Staff Scientist, Pacific Northwest, U. S. Geological Survey, Box 3418, Portland 8, Ore.

Prescott, Mr. Gordon W., P. O. Box 259, Hot Springs, S. D.

Renn, Mr. Charles, Department of Sanitary Engineering \& Water Resources, Johns Hopkins University, Baltimore 18, Md.

Riley, Mr. Leonard B., Geochemistry \& Petrology Branch, U. S. Geological Survey, Denver Federal Center, Denver, Colo.

Roedder, Dr. Edwin W., Geochemical \& Petrology Branch, U.S. Geological Survey, Washington 25, D. C.

Russell, Dr. Richard J., Dean of the Graduate School, Louisiana State University, Baton Rouge 3, La.

Seal, Mr. Morgan S., U. S. Public Health Service, Department of Health, Education and Welfare, Washington 25, D. C.

Struxness, Mr.E. G., Director, Waste Disposal Project, Health Physics Division, Oak Ridge National Lab., P.O. Box P, Oak Ridge, Tenn.

Taylor, Mr. Ralph E., Production Department, Humble Oil \& Refining Company, Humble Building, Houston 1, Texas

Theis, Dr. Charles V., Staff Scientist; U. S. Geological Survey, Box 302, University Station, Albuquerque, N. M.

Thomas, Dr. Harold A., Jr., Associate Professor of Sanitary Engineering, Div. of Applied Science, 223 Pierce Hall, Harvard University, Cambridge 38, Mass. (Repr. NAS-NRC Div. Medical Sciences) 
Thomas, Dr. Henry C., Associate Professor of Chemistry, Yale University, Box $190 \mathrm{~A}$, Yale Station, New Haven, Conn.

Thurston, Dr. William R., Exec.Sec., Div. Earth Sciences, National Academy of Sciences-National Research Council, Washington 24, D. C.

Triplett, Dr. William C., 1807 Alameda Blvd., Suite 234, Corpus Christi, Texas

Varnes, Mr. David J., Engineering Geology Branch, U. S. Geological Survey, Denver Federal Center, Denver 15, Colo.

Watkins, Mr. J. W., Petroleum Experiment Station, U. S. Bureau of Mines, P. O. Box 1321, Bartlesville, Okla.

Wilhelm, Dr. R. H., Chairman, Department of Chemical Engineering, Princeton University, Princeton, N.J.

Zumwalt, Mr. L. R., Nuclear Science \& Engineering Corporation, P. O. Box 10961, Pittsburgh 36, Pa.

Members of the Steering Committee

H. H. Hess, Chairman

John N. Adkins *

William E. Benson

John C. Frye

* absent

Assistants at conference

M. N. Bass

A. O. Fuller
M. King Hubbert

Chester R. Longwell *

Charles V. Theis

Richard J. Russell, ex officio

Chairman, Division of Earth Sciences, NAS-NRC 
108.

APPENDIX F

DISPOSAL OF RADIOACTIVE WASTE IN SALT CAVITIES

Report prepared for the

Committee on Waste Disposal in Geologic Structures

by

William B. Heroy

March 11, 1957

3712 Haggar Drive

Dallas 9, Texas 


\section{CONTENTS}

$\underline{\text { Page }}$

1. Introduction 111

2. Characteristics of Salt Deposits 112

3. Distribution of Salt in the United States 113

4. Production of Salt in the United States 121

5. Mining of Rock Salt 123

6. Production of Radioactive Waste 128

7. Requirement for Nuclear Energy $\quad 129$

8. Characteristics of Radioactive Waste 132

9. Waste Production in Nuclear Power'Plants 133

10. Transportation of Nuclear Waste 134

11. Accessibility of Salt Space for Waste Disposal 134

12. Utilization of Salt Space for Waste Disposal 135

13. Problems of Utilization of Mined-out Space 136

14. Recommended Studies 138 


\section{ILLUSTRATIONS}

$\underline{\text { Page }}$

FIGURE 1 - Location of the Principal Deposits of Rock Salt in the United States

FIGURE 2 - Area in New York Underlain by Salt

FIGURE 3 - Area in Pennsylvania Underlain by Salt

FIGURE 4 - Area in Ohio Underlain by Salt

FIGURE 5 - Area in Michigan Underlain by Salt

FIGURE 6 - Area in Texas and New Mexico Underlain by Salt

FIGURE 7 - Installed Capacity of Electric Utility

Generating Plants - United States - 1920-1954

TABLE I - Salt - Production by States - 1953 Short Tons

TABLE II - Rock Salt - Estimated Production by States 1953 - Short Tons 


\section{INTRODUCTION}

1.1 One of the possibilities for the disposal of radioactive waste products derived from the operation of nuclear power plants is its underground storage in space formed within deposits of rock salt. This report contains information concerning the characteristics of rock salt, its occurrence in the United States, and the underground space resulting from mining operations. Consideration is then given to the feasibility of using such space for waste disposal.

1.2 The Division of Earth Sciences, National Research Council, at the request of the Atomic Energy Commission, has undertaken a study of the underground disposal of atomic waste and the preparation of a report and recommendations on the subject. A conference for the discussion of the subject was held at Princeton University, September 10-12, 1955, and a Steering Committee was appointed to function in the preparation of a report.(1) During the period subsequent to the conference, as a member of the Steering Committee, the writer of this memorandum had an opportunity to investigate further the possibility of underground disposal particularly in cavities formed by the mining of salt. The information obtained has been compiled in this paper as a matter of record and for such value as it may have in further consideration of the disposal problem. The paper is preliminary in character, and is not a complete presentation of this phase of the problem.

1.3 Acknowledgment for information supplied concerning salt deposits is gratefully made to Dr. Frank C. Foley, State Geologist of Kansas; Dr. John H. Melvin, Chief, Division of Geological Survey, State of Ohio; Dr. William L. Daoust, State Geologist of Michigan; Dr. Kenneth K. Landes, Department of Geology, University of Michigan; to Messrs. L. E. Read, Manager, Detroit Mine, and C. H. Jacoby, Chief Geologist, International Salt Company, Detroit, Michigan; and to Mr. Tom M. Cramer, U. S. Potash Company, Carlsbad, New Mexico. The writer has also used freely information contained in various publications, references to which are made at the end of this paper, and wishes to acknowledge the assistance obtained therefrom. I am also grateful to Dr. E. G. Struxness of the Oak Ridge National Laboratory, and to Dr. L. P. Hatch of Brookhaven National Laboratory for courtesies extended during visits to these installations. 
1.4 This report was first circulated under date of July 20, 1956. It has since been reviewud by Dr. Floyd L. Culler, Oak Ridge National Laboratory, Oak Ridge, Tennessee, Dr. M. King Hubbert, Shell Oil Company, Inc., Houston, Texas, and Dr. C. V. Theis, U. S. Geological Survey, Albuquerque, New Mexico. I am greatly indebted to these associates on the Princeton Committee for their critical comments on the paper, which have generally been incorporated in the present revision of the report. Any responsibility for errors or other inadequacies and for opinions expressed in the report are, however, my own.

\section{CHARACTERISTICS OF SALT DEPOSITS}

2. 1 Rock salt in its crystalline form is the mineral halite ( $\mathrm{NaCl}$; sodium 39.4, chlorine $60.6 \%$ ). Halite is isometric and occurs in crystals with cubical cleavage, which are transparent or translucent.

Hardness is 2.5. Specific gravity of pure crystal salt is about 2.17 (136 lbs. per cu. ft.). Index of refraction is 1.5442 . It is highly nonconductive of electricity. The melting point of salt is $801^{\circ} \mathrm{C}$. and the boiling point, $1413^{\circ} \mathrm{C}$. Solubility in water in grams per $100 \mathrm{ml}$. is 35.7 at $0^{\circ} \mathrm{C}$. and 39.12 at $100^{\circ} \mathrm{C}$. (2) (3)

2.2 In its usual occurrence, rock salt contains impurities. As mined for commercial purposes, it is generally not less than $97 \%$ pure, with grades used in the chemical industry over $99 \%$ pure. As mined, the specific gravity ranges from 2.1 to 2.6 , depending upon the degree of purity. It has a coarse granular to compact structure. Its toughness makes it resistant to mining with power machines and explosives are used in its production in solid form. Its solubility in water permits its solution and extraction as brine.

2.3 From the geological standpoint, salt is plastic and flows under pressure. In that respect it is similar to ice, but the pressure and time required to produce observable plastic flow in salt are very much greater. The pressure required for the rapid deformation of rock salt is very great but, over long periods of time, much lower pressure may be expected to result in flowage. Plastic movement of rock salt has apparently not been observed in the pillars left in salt mines in the United States, with the amount of overburden as much as 2,000 feet. In mining potash in New Mexico, where the depth of the deposit is about 900 feet, the sylvinite ore (a mixture of halite, $\mathrm{NaCl}$, and sylvite, $\mathrm{KCl}$ ) shows positive evidence of plastic flow. Horizontal drill holes in the sylvinite ore show vertical compression of about $25 \%$ in about ten years. Sylvite, the principal potash-bearing mineral in the ore, is apparently more plastic than halite. (4) 
2. 4 Salt deposits are of sedimentary origin and commonly occur interbedded with other rocks, such as limestone, dolomite, anhydrite and shale. Under conditions of temperature and pressure present at great depths and during geologic time, bedded salt has flowed along lines of weakness and risen into overlying beds in the form of plugs and domes.

\section{DISTRIBUTION OF SALT IN THE UNITED STATES}

3.1 The most commercially important deposits of bedded salt are found in New York, Michigan, Ohio and Kansas. They underlie many thousand square miles extending from the outcrop downward to depths of more than 5,000 feet. Figure 1 shows the location of the principal deposits of rock salt in the United States.

3.2 In New York, the salt occurs in the Salina formation of Silurian age. (5) It crops out along a band extending from the Mohawk Valley on the east to the Niagara River on the West. The salt is not present at the outcrop because it has been dissolved. The Salina beds dip southward at a low angle. The dip is variable, averaging from 50 to 100 feet per mile, depending on the local structural conditions. At its maximum, the Salina is about 1,000 feet in thickness. The salt may be present in several beds. Its total thickness is more than 300 feet in central New York, south of Syracuse. In the western part of the state, the salt becomes thinner and may be absent in the Buffalo area. It continues southward under the increasing thickness of younger beds into southern New York and northern Pennsylvania, where the thickness of salt is over 600 feet in some deep wells. The total area in New York underlain by salt is roughly 10,000 square miles, as shown on Figure 2 .

3.3 The entire northwestern part of Pennsylvania is underlain by the Salina formation and salt has been found in many wells drilled for oil and gas. (6) Throughout most of the area the aggregate thickness of the salt beds is at least 50 feet. In half the area the aggregate thickness is over 100 feet and the aggregate thickness reaches a maximum of over 500 feet. The salt beds are found at depths of from 1500 feet in northwestern Pennsylvania to more than 8000 feet in the deepest part of the syncline. Figure 3 shows the area in Pennsylvania underlain by salt and the depth below sea level of the top of the salt.

3. 4 The salina beds continue westward into eastern Ohio and underlie about one-third of the state. (7) (8) The salt occurs in beds of Silurian age, which probably represent the westward extension of the Salina formation of New York and Pennsylvania. This horizon is below the surface 


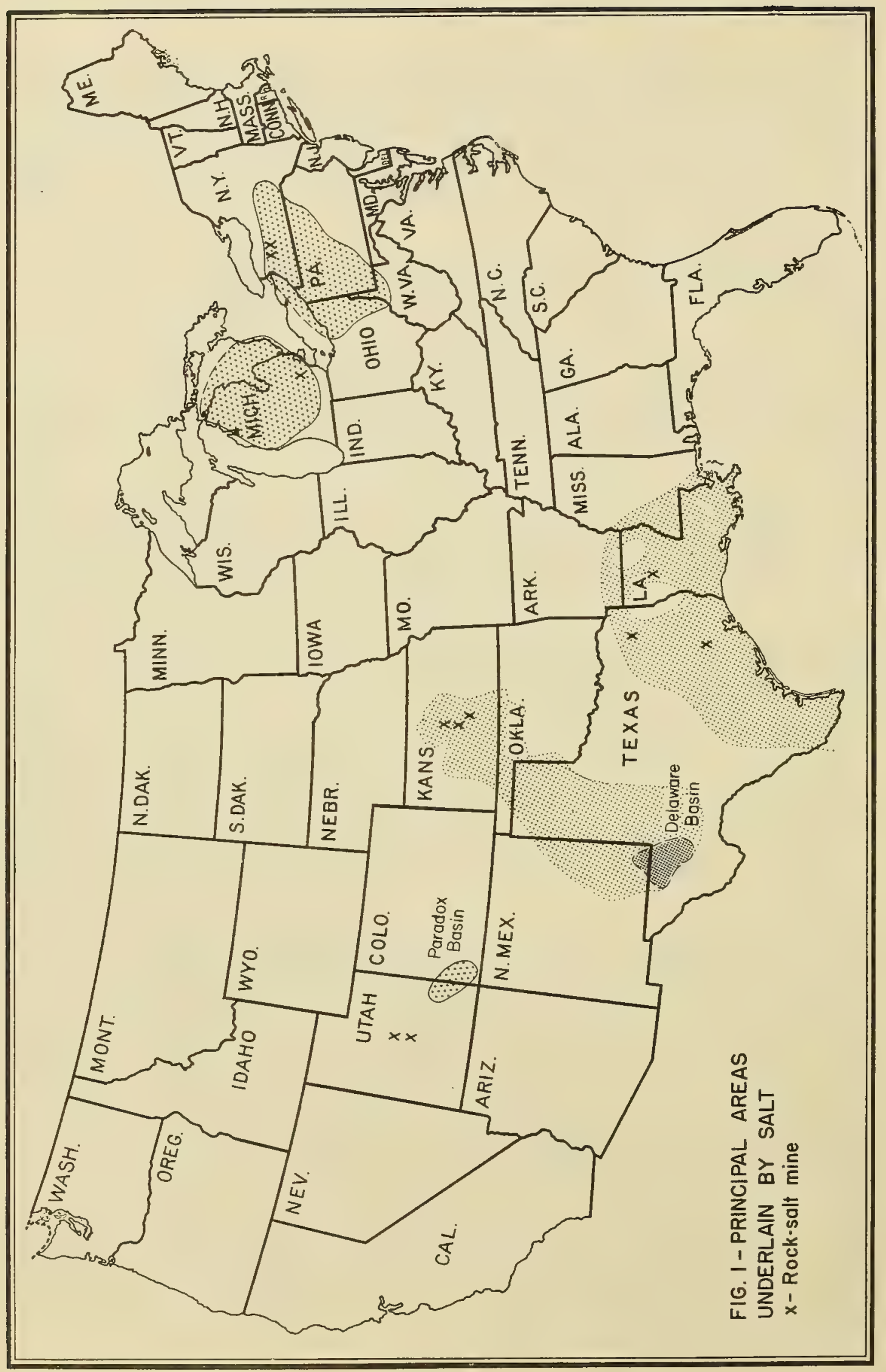




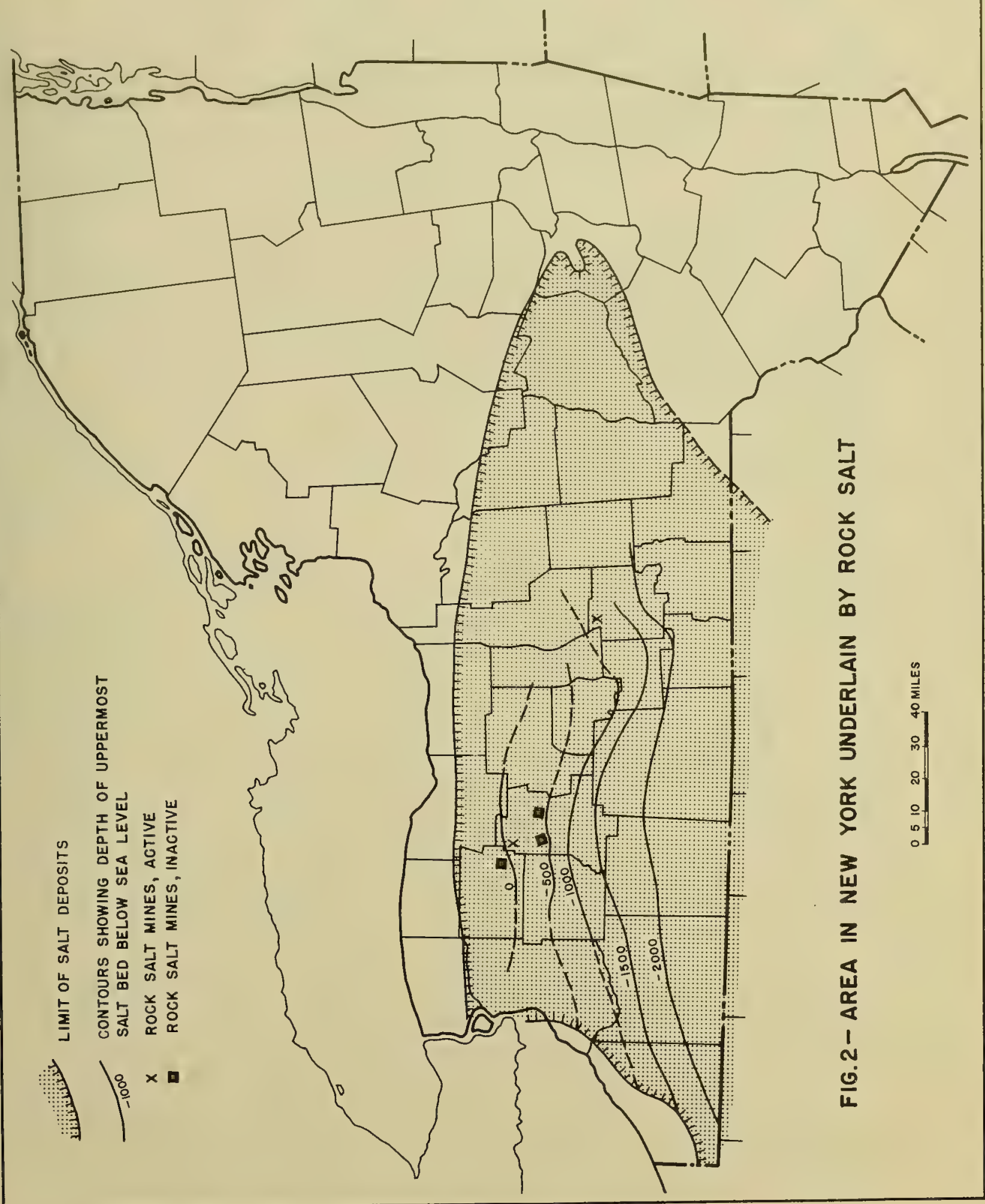




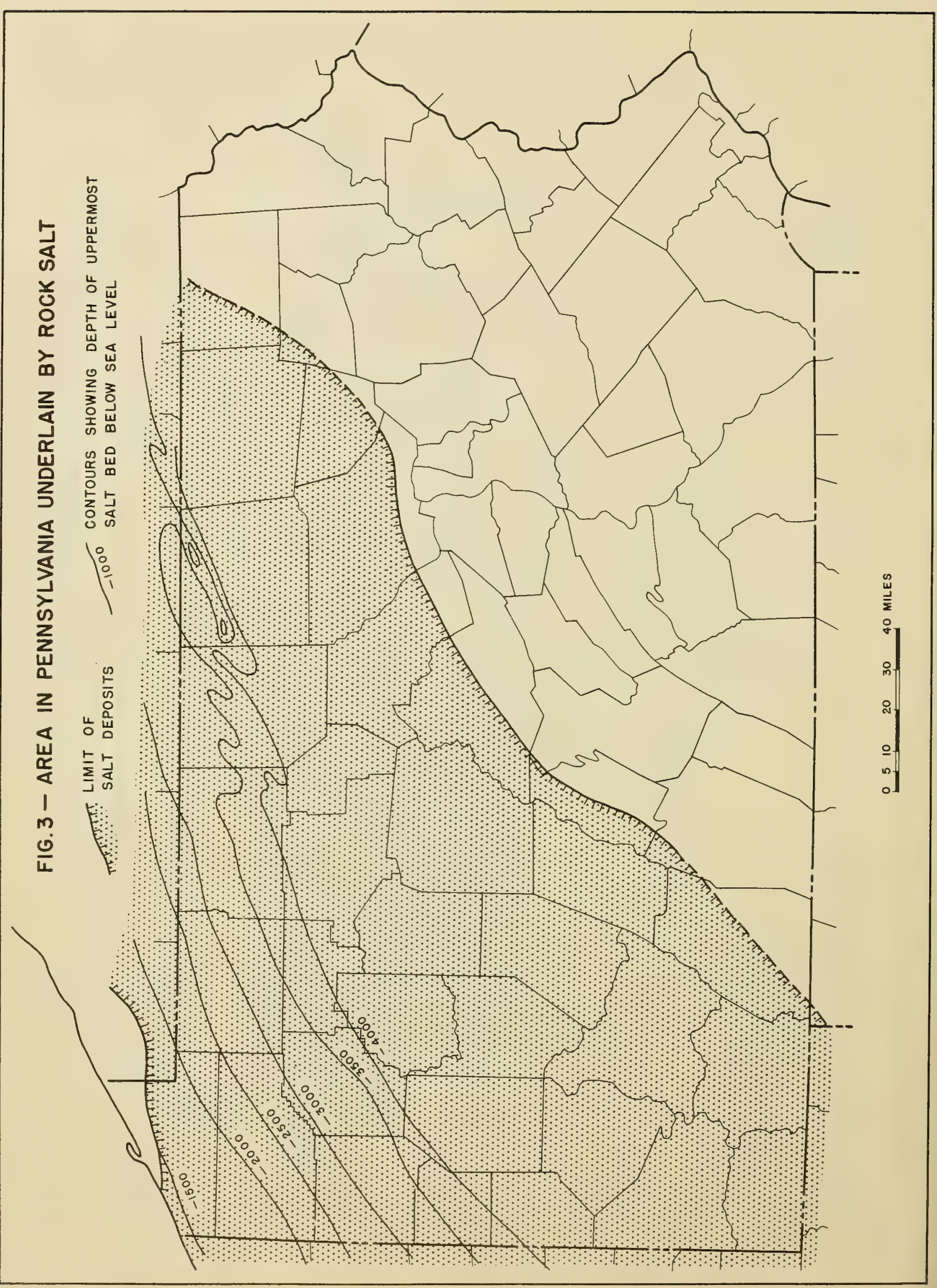


throughout Ohio and its character is known only from wells, of which more than 3,500 have been drilled through it. The salt thins westward and disappears beyond a line extending from Lorain, on Lake Erie, to Marietta, near the Ohio River. Over most of this area the salt beds have an aggregate thickness of more than 100 feet. The maximum is reached near Canton, Stark County, where well logs indicate the presence of several beds with an aggregate thickness estimated at more than 200 feet. Along Lake Erie, recent borings for the purpose of prospecting the salt beds indicate that their thicknesses total 60 to 70 feet in Cuyahoga, Lake and Ashtabula counties.

Near the Pennsylvania line, in Ashtabula County, the salt occurs at a depth of about 2,300 feet below the water level of Lake Erie. The depth decreases westward to a depth of about 1,300 feet near Lorain. From Lake Erie the beds dip gently southward. At Barberton, about 40 miles south of Cleveland, the uppermost salt is at a depth of 2750 feet. In Harrison County, 50 miles farther southeast, the salt was reached at over 4700 feet. The total area in Ohio underlain by salt deposits is over 15,000 square miles. Figure 4 shows the area in Ohio underlain by rock salt and the depth below sea level of the top of the salt.

3.5 Michigan has the largest reserves of salt of any state. Rock salt underlies most of the state, within the Michigan basin. It is found in the Salina formation, which is deposited in a saucer-like form, tapering toward the margins of the basin, where it is overlapped by younger formations and does not appear at the surface. Brine is found in several other formations. (9)

In the southeastern part of the state, along the Detroit River, the aggregate thickness of rock salt is from 200 to 500 feet. The thickness increases northwestward into the basin. In Bay County, about 90 miles northeast of Detroit, a maximum thickness of 1800 feet of salt was penetrated. Around the periphery of the basin, the salt thickness generally increases down dip from 0 at the edge of the Salina wedge to a thickness of 1000 feet in about 50 miles.

In Wayne County, near Detroit, the depth to the first salt bed ranges from 800 feet at Ecorse to 1150 feet at Oakwood (Detroit) and over 1600 feet at Port Huron. On the west sile of the basin, near Luaington and Manistee, the salt has been reached at depths of about 2000-2300 feet.

The total area of the southern peninsula of Michigan that is probably underlain by salt-bearing formations is 35,000 square miles. The 


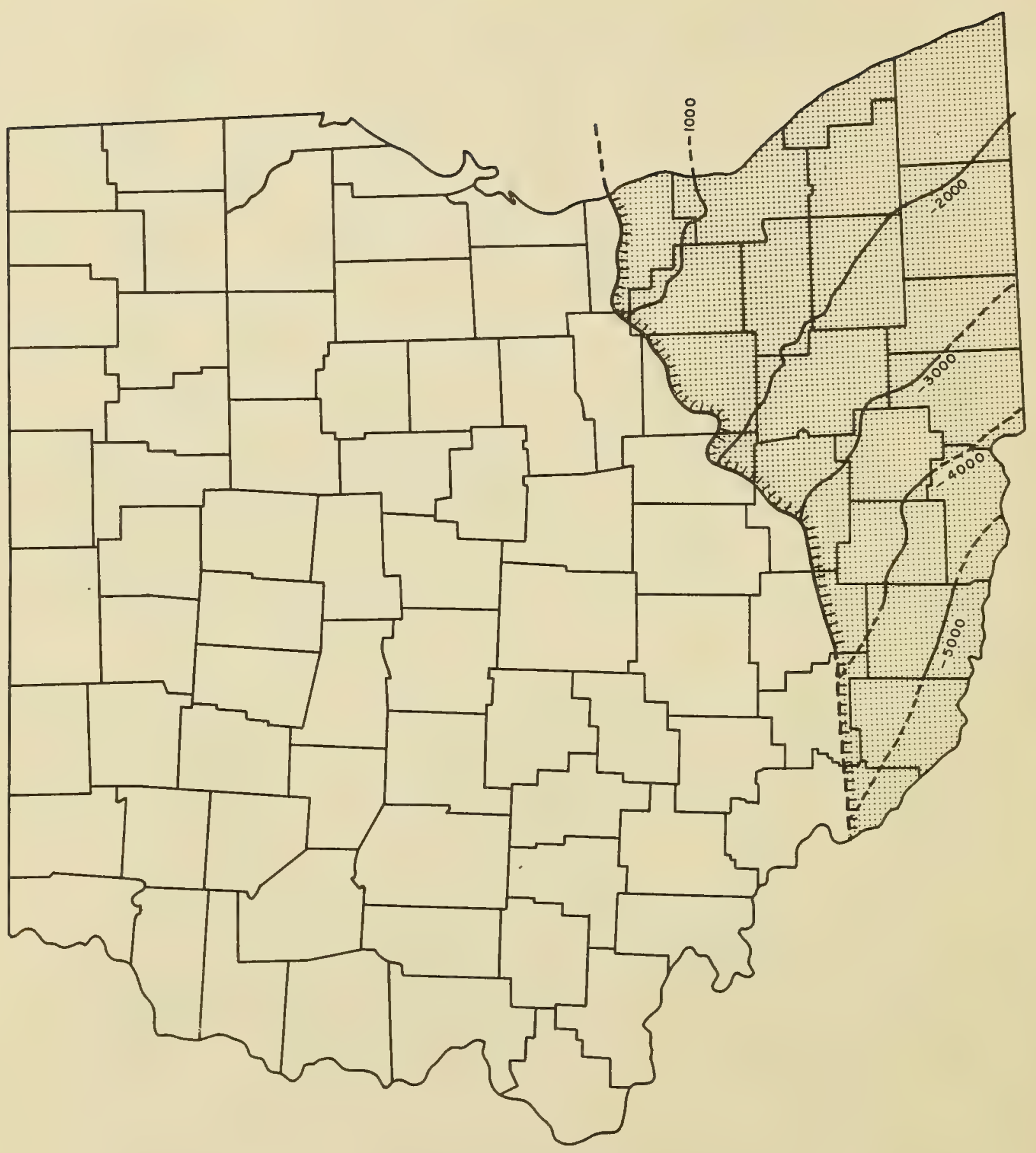

FIG. 4 - AREA IN OHIO UNDERLAIN BY ROCK SALT

W. WES WESTERN LIMIT OF SALT DEPOSITS

-2000 CONTOURS SHOWING DEPTH OF UPPERMOST SALT BED BELOW SEA LEVEL 
area underlain by rock salt is shown on Figure 5.

3.6 In Kansas, beds of rock salt occur in several formations of Permian age. (10) The Hutchison member of the Wellington formation and the Ninnescah shale (both of Middle Permian age) are the most important salt-bearing units, although salt is also found in the Harper, Salt Plain and Flowerpit formations higher in the Permian section. The eastern outcrop of the Hutchison salt member is along a line extending north and south from Saline to Sumner county. The salt at the outcrop is dissolved but dips westward under cover, and is about 650 feet below the surface at Hutchison; 1000 feet at Lyons; and 850 feet at Ellsworth. Farther west, the top of this salt is about 1700 feet in Kiowa County and 2000 feet in Clark County, and its thickness is usually from 200 to 300 feet.

The higher salt horizons underlie the southwestern part of the state. The Ninnescah salt is at a depth of about 1250 feet in Kiowa County, 1000-1500 feet in Clark County; and 1600 feet in Meade and Gray counties. The total thickness of salt in this part of the section ranges from 200 to 300 feet.

Altogether, about 30,000 square miles in the central and southeast parts of Kansas are underlain by salt-bearing formations.

3.7 A large area on the Gulf Coast contains numerous structural uplifts which are considered to have resulted from the flowage of salt. (11) In many of these uplifts the salt has flowed upward through the overlying beds to form salt domes. Exploratory drilling has proved the existence of a large number of salt domes and, on the basis of geophysical evidence, it is thought that salt forms the core of others. In northern Louisiana, southern Arkansas and east Texas, bedded rock salt of Jurassic (or Permian) age has been reached in widely separated wells . The Eagle Mills (Louann) salt is seldom fully penetrated in wells but thicknesses of 500 to 1500 feet are normal. It is estimated that this horizon underlies an area of 180,000 square miles on the Gulf Coast.

The known salt domes are over 200 in number. (12) In a few domes the salt is very near the surface but in many others it is below 5000 feet, and, in some instances, over 10,000 feet. The piercement-type domes that come nearest to the surface range in size from nearly circular domes a half-mile to two miles in diameter to elongated masses several miles in length. The best known group of salt domes is the Five Islands of southern Louisiana, characterized by surface uplifts overlying the 


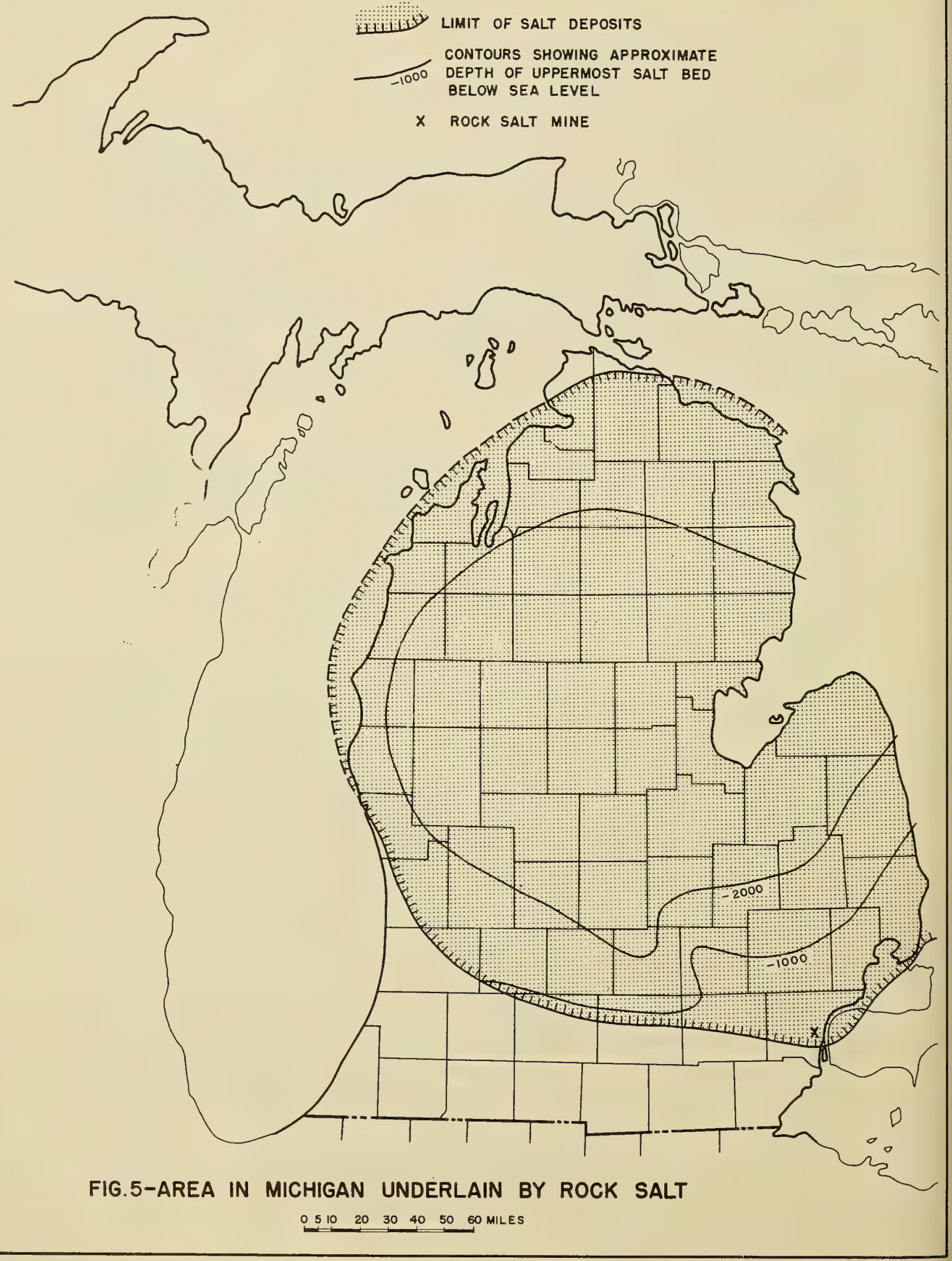


salt masses, and by the shallowness of the salt, less than 300 feet from the surface. At a depth of 1000 feet, these domes are a mile or more in diameter.

3.8 Rock salt occurs in the western states in several areas. Salt of Permian age is found in the Sevier Valley in Utah. Salt, believed to be of Pennsylvanian age, occurs in the Colorado River drainage in eastern Utah and western Colorado. The area is sometimes called the paradox salt basin. (13) The extent of the salt has not been fully determined but it apparently is not less than 10,000 square miles. The salt has intruded into a considerable number of anticlines and domes and has been penetrated in some test wells to a thickness of over 3,000 feet.

3.9 In the southwest, salt occurs in the Delaware Basin of New Mexico and Texas. The margins of the area are known only approximately but the total area underlain by salt may be as large as 70,000 square miles. (14) The probable extent of the area is shown on Figure 6. Rock salt is found in beds of Permian age belonging to the Upper Castile formation, with an evaporite section ranging in thickness from 0 to about 3500 feet. In part of the area a zone of potash salts is present which has been extensively developed near Carlsbad, New Mexico. The zone is about 250 feet thick and contains four workable beds of potash. The lowest bed is the thickest and averages about ten feet in thickness. A large area has been mined out since operations began about 25 years ago. Above the McNutt potash zone is a zone of halite about 500 feet thick, which has been named the Salado. The top of this zone in the Carlsbad district is about 500 feet below the surface, depending upon the topography. Below the potash zone is another bed of halite, about 900 feet thick, broken by anhydrite partings.

Rock salt is not mined in this region except as a byproduct of the potash ore, which contains $60 \%$ or more of halite. The salt extracted from the potash ore is marketed to only a small extent. No space in the halite beds is produced in the mining of the potash.

\section{PRODUCTION OF SALT IN THE UNITED STATES}

4.1 The total production of salt in the United States now exceeds 20 million tons per year, either as dry salt or in the form of brine. (15) This amount is about $35 \%$ of the world's total production. Because salt is widely distributed, the United States imports very little salt; it exports less than $2 \%$ of the production. 


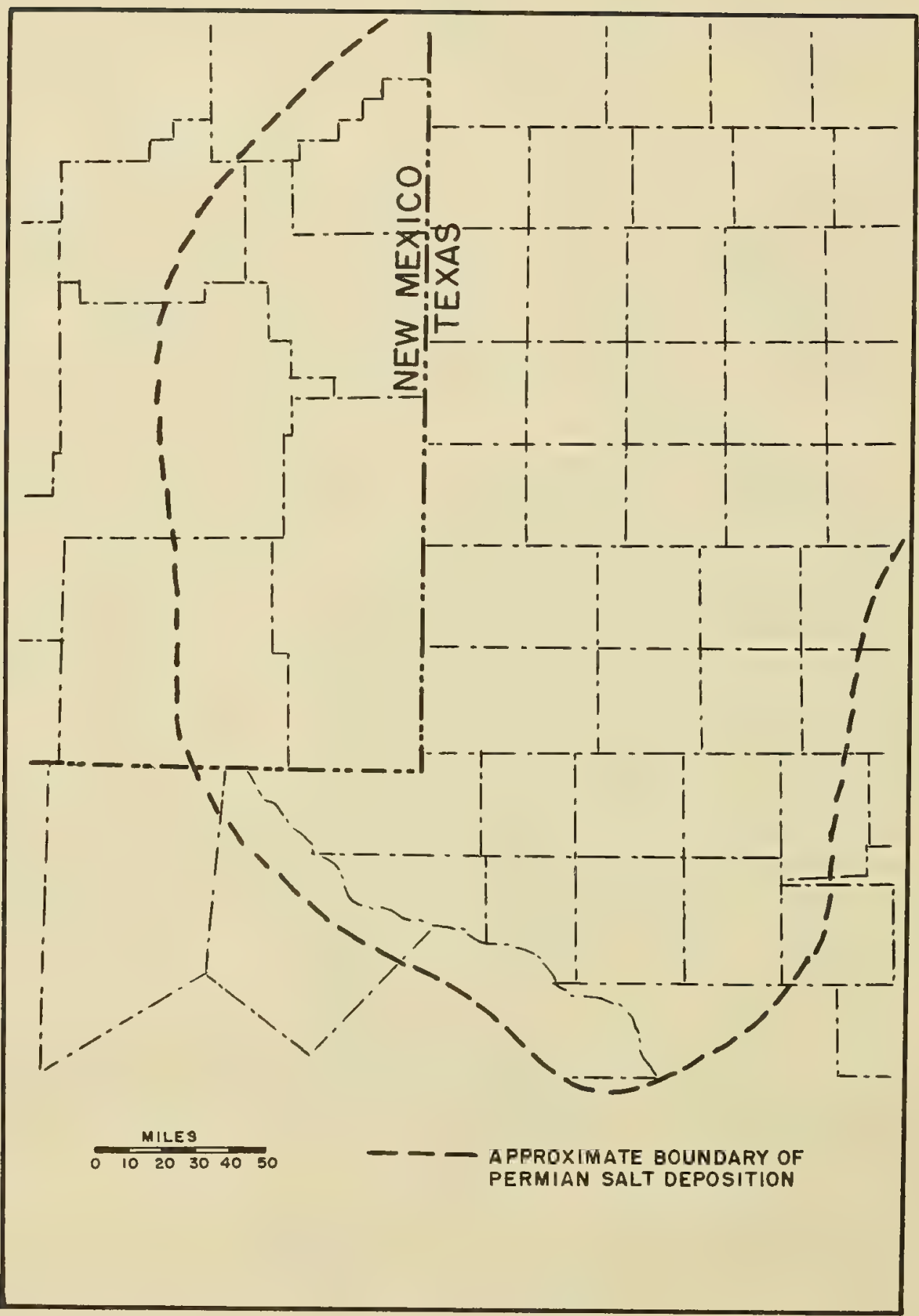

FIG.6-AREA IN NEW MEXICO AND WEST TEXAS UNDERLAIN BY SALT-BEARING FORMATIONS 
4.2 About $60 \%$ of the salt is produced as brine, natural and artificial. Natural brines, occurring in porous formations, are pumped to the surface ancl evaporated. Artificial brines are formed by drilling wells into beds of rock salt, pumping in water, which dissolves the salt, and then pumping the resulting solution to the surface. Salt is more economically produced by this method than by mining. But the process of solution eventually causes cavities to be formed beneath the surface. Where the salt is thick and underlies a large area, the overlying rocks may eventually be left without support and caving follows.

4.3 Most of the brine brought to the surface is supplied directly to chemical plants in which the sodium chloride is used as a raw material for the manufacture of other sodium compounds and chlorine, useful as reagents. A smaller part of the brine is evaporated to procluce refined salt for human consumption and for many industrial applications.

4. 4 About $20 \%$ of the salt production is obtained by underground mining of salt deposits. By careful selection of the source bed, salt of great chemical purity is obtained for use in chemical applications. Large amounts of rock salt are also used for highways, for stabilizing the surface, and, in winter, for ice removal.

4.5 The accompanying Table I gives the salt production of the United States in short tons, according to the form in which it is produced, and by state. Values are also given. The amounts of rock salt and salt in brine produced are estimated but are reasonably accurate approximations.

\section{MINING OF ROCK SALT}

5.1 Rock salt was mined at fourteen localities in the United States in 1953. The distribution of these mines by states is as follows: New York, 2; Michigan, 1; Kansas, 3; Louisiana, 4; Texas, 2; Utah, 2. The location of these mines is shown on Figure 1.

5.2 The principal operating mine in New York is that of the International Salt Company at Retsof, Livingston County.(16) The salt is produced from a bed in the upper part of the Salina formation that has a thickness of 9-10 feet. The mine shaft is $9^{\prime} \times 26^{\prime}$ and has a depth of 1063 feet from the collar to the bottom of the salt bed. The salt dips approximately $1 / 2^{\circ}$ to the south. The capacity is about 4,000 tons in 8 hours. The mine commenced operation in 1923. About $60 \%$ of the salt is extracted and $40 \%$ left as pillars. Assuming a production of $1,200,000$ tons per 
124.

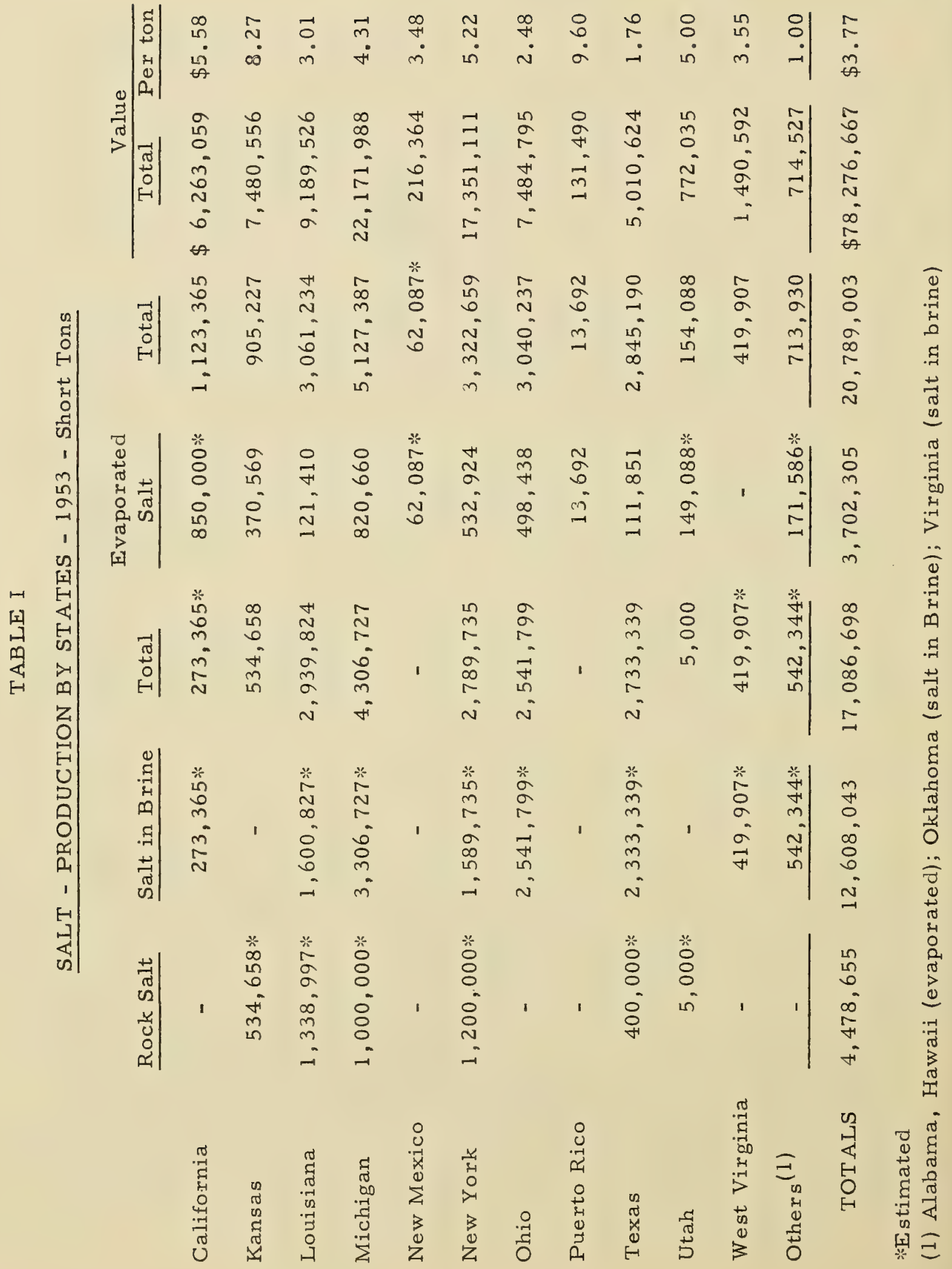


year and 15 cubic feet of salt per ton, the space mined out would be 414 acre-feet. With a thickness of salt of 10 feet and $60 \%$ recovery, about 68 acres would be mined out annually. The total production of the mine has not been published, but, with 30 years of operation, it is probably not less than 1500 acres.

At Portland Point, on the east side of Cayuga Lake, Tompkins County, a mine has been operated for about 20 years. Details of production, etc. are not known.

Several other rock-salt mines were formerly operated in New York but have been closed down. The oldest mine was at Livonia, Livingston County, and was operated from 1883 to 1890 . It was 1430 feet in depth. The mine is now filled with water and the condition of the shaft is now known. About 50 acres was mined out. Another mine at Lehigh, Genessee County, had a depth of 825 feet and was operated about 4 years. The quantity mined was about 15 acre-feet. The shaft is filled with water to the surface.

5.3 The mine of the International Salt Company, at Detroit, is the only producer of rock salt in Michigan. (17) It is operated through two shafts about 1100 feet deep and the uppermost bed of the Salina formation is worked. It varies in thickness throughout the mine from about $19^{\prime}$ to $40^{\prime}$. The greatest thickness mined is about 36', 4' being left for roof. About $60 \%$ of the area is mined, the remainder being left for pillars. The rooms are limited to a width of $60^{\prime}$. About 700 acres has been mined out. The mine is dry, except for an occasional seeping of a few cubic feet of bittern from the formation. The mine has been in opera tion since 1910 and, during that period, only one small roof-fall has occurred. The shaft is located about $11 / 2$ miles from the Detroit River and about $1 / 4$ mile from the River Rouge. The surface above the mine is chiefly property of the Pennsylvanian and Wabash railroads used for yards and shops. About $20^{\prime}$ below the bottom of the bed now mined and separated from it by a bed of dolomitic limestone, is a second bed of salt, much thicker than the one being worked. The top of this lower bed is exposed in one of the mine workings.

5.4 In Kansas, three rock salt mines are now operated. (18) The Carey Salt Company operates a mine near Hutchison through a shaft $645^{\prime}$ deep. The bed mined has a thickness of $10^{\prime}$. The total volume mined out is about 145 acre-feet, equivalent to about 14 acres. At Kanopolis, the Independent Salt Company has two shafts $846^{\prime}$ deep and is mining a bed 15-16' thick. The total mined-out space is about 4,000 acre-feet, equivalent to about 25 acres. The American Salt Corporation has a 
mine near Lyons 993' deep working a bed $81 / 2^{\prime}$ thick. The space mined out is about 100 acre-feet.

Several other mines are either closed down or have been abandoned. The largest is owned by the Morton Salt Company near Kanopolis and was closed in 1948. It is thought to be still dry. Depth to bottom is $810^{\prime}$ and the volume mined out is about 1500 acre-feet. The average ceiling is about $9^{\prime}$. The Carey Salt Company has a shut-down mine at Lyons closed in 1948. Its depth is 1024' average ceiling 10', and the volume mined out is about 1000 acre-feet.

The three producing mines produced 534,658 tons of rock salt in 1954 . This is equivalent to about 185 acre-feet. Assuming an average thickness mined of $10^{\prime}$ and $50 \%$ left for pillars, the area mined out would be about 37 acres.

5.5 Salt is produced in Louisiana from four mines. (19) The International Salt Company has a mine at the salt dome at Avery Island, Iberia Parish. The rock salt was first discovered at a depth of $18^{\prime}$ below the surface. The present mine was opened in 1898 with a shaft $518^{\prime}$ in depth.

At the Jefferson Island salt dome, where the mine is operated by the Morton Salt Company, a circular shaft has been sunk to a depth of 900'. Myles Salt Company produces salt at the Weeks Island salt dome from a shaft reported to be $645^{\prime}$ in depth. Carey Salt Company is mining salt from the Winfield salt dome, Union Parish, from a depth of 838'. The shallowest depth at which the salt has been found in this structure is $437^{\prime}$. Rooms are $50^{\prime}$ in width and 20 to $80^{\prime}$ in height. Mining began in 1931 and the production for several years averaged about 60,000 tons annually, increasing to 120,000 tons in 1941. Recent figures of the individual mines are not available.

5.6 In Texas, the Morton Salt Company, Grand Saline, Van Zandt County, has a shaft to a depth of $700^{\prime}$, which enters the salt at $213^{\prime}$. Rooms are $60^{\prime}$ wide by $80^{\prime}$ high. The production is about 1000 tons per day and 100 acres has been mined. (19)

The United Salt Corporation operates a mine on the Hockley dome, Harris County. The shaft is $1525^{\prime}$ deep.

5.7 The total estimated production of rock salt for 1953 by states is shown in the accompanying Table II. During that year, about 145 acres 
TABLE II

ROCK SALT

ESTIMATED PRODUCTION BY STATES - 1953 - Short Tons

\begin{tabular}{|c|c|c|c|c|c|c|c|}
\hline & Production. & Value & $\begin{array}{l}\text { Per } \\
\text { ton }\end{array}$ & $\begin{array}{l}\text { Equiva- } \\
\text { lent } \\
\text { space, } \\
\text { acre- } \\
\text { foot }^{(1)} \\
\end{array}$ & $\begin{array}{c}\text { Ave. } \\
\text { thick- } \\
\text { ness } \\
\text { mined } \\
\end{array}$ & $\begin{array}{l}\text { Acres } \\
\text { mined } \\
\text { out }(2)\end{array}$ & $\begin{array}{c}\text { Depth } \\
\text { to } \\
\text { salt }\end{array}$ \\
\hline Kansas & 534,658 & $2,194,751$ & $\$ 4.10$ & 185 & 10 & 37 & $\begin{array}{l}600- \\
1000\end{array}$ \\
\hline Louisiana & $1,338,997$ & & & 462 & 80 & 10 & $\begin{array}{l}600- \\
300\end{array}$ \\
\hline Michigan & $1,000,000$ & & & 346 & 30 & 25 & 1000 \\
\hline New York & $1,200,000$ & & & 414 & 10 & 68 & 1000 \\
\hline Texas & 400,000 & & & 138 & 60 & 5 & $\begin{array}{l}700 \\
1500\end{array}$ \\
\hline Utah & 5,000 & & & 2 & & 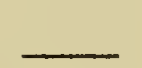 & \\
\hline TOTALS & $4,478,655$ & $23,777,527$ & $\$ 5.34$ & 1,547 & & 145 & \\
\hline
\end{tabular}

(1) Specific gravity, 2.15; 134 lbs. per cu. ft.; $15 \mathrm{cu}$. ft. per ton; 2900 tons per acre-foot.

(2) Assuming $50 \%$ or $60 \%$, according to locality, left as pillars. 
was mined out, producing an equivalent space estimated to be 1547 acre-feet. During the last twenty years (1934-53) the reported production of rock salt is $61,639,696$ tons, equivalent to 21,250 acrefeet. Assuming that the average thickness of salt mined was $10^{\prime}$, the area mined out would be 2125 acres. These figures give a general idea of the large amount of underground space that has resulted from the mining of the salt.

5.8 In the potash mines of New Mexico, a large volume of underground space is produced by the removal of the sylvanite ore. The total amount of ore mined in 1952 was approximately 7,850,000 short tons. Assuming 15 cubic feet of ore to the ton, the volume would be about 2700 acrefeet per year. If the average thickness mined is $8^{\prime}$, the total number of acres mined out annually would be about 335 acres. Pillars are left to support the roof during the mining operations but these are usually pulled after mining operations cease to recover the additional ore. Because of the plasticity of the sylvanite it is doubtful if the mined out space would be suitable for long-time storage of atomic waste. The subjacent salt would provide a more suitable potential storage space because of the greater resistance of the halite to pressure.

\section{PRODUCTION OF RADIOACTIVE WASTE}

6.1 Fission-product waste is produced when a nuclear fuel, such as $\mathrm{U}^{235}, \mathrm{U}^{233}$, or $\mathrm{Pu}^{239}$, is fissioned in a nuclear reactor. (20) In nuclear reactors, the fission of one gram of $\mathrm{U}^{235}$ produces about 1 gram of fission products. The fission products are, in part, gaseous and, in part, in liquid or solid form, depending upon the fuel used.

6.2 Fuel systems used or considered for power reactors may be grouped as follows:

6.2.1 Liquid-fuel systems, in which the fuel is dissolved in water or heavy water;

6.2.2 Solid-fuel systems, using metals such as uranium and plutonium, in which these metals are contained in corrosion- and temperatureresistant cans;

6.2.3 Liquid-metal systems, using sodium, bismuth, etc. as a solvent;

6.2.4 Fused-salt systems, in which the nuclear fuel is mixed, for example, with a fluoride or hydroxide of sodium, lithium, etc. 
6.3 Where the nuclear fuel is introduced in the reactor in aqueous solution the output of the reactor is directly processed to remove the waste. If the waste from the reactor is in solid form and included in the spent fuel elements, the waste is separated from the unconsumed uranium and plutonium in a chemical processing plant, in which the solids are dissolved and the waste thereafter separated by one of several methods. (2I)

6.4 Natural uranium contains one part of fissionable $\mathrm{U}^{235}$ in 139 parts of fertile $\mathrm{U}^{238}$. Thus, if natural uranium is used as a fuel, it is possible to consume $\mathrm{U}^{235}$ both to support the chain reaction and to give excess neutrons which, when captured in $\mathrm{U}^{238}$, will produce plutonium 239. Theoretically, in power breeders, it is possible to produce more $\mathrm{Pu}^{239}$ than the combined consumption of $\mathrm{U}^{235}$ and $\mathrm{Pu}$ in the reactor. In a system where highly enriched $\mathrm{U}^{235}$ is used, $\mathrm{Pu}$ is not produced because of the absence of fertile $\mathrm{U}^{238}$. If, in such a system, the reaction proceeded until $30 \%$ of the initial $\mathrm{U}^{235}$ were consumed, approximately 250 grams of fission products would be produced per kilogram of U235 charged. (22) Thus, from one metric ton of natural uranium irradiated to $30 \%$ burn up of $\mathrm{U}^{235}$, approximately $2 \mathrm{~kg}$ of fission products will be derived. If enriched $\mathrm{U}^{2} 38$ were used as fuel, the quantity of fission products per ton of charge would be increased, depending upon the extent of the enrichment.

\section{REQUIREMENT FOR NUCLEAR ENERGY}

7. I It has been calculated that the fission of 1 gram of $\mathrm{U}^{235}$ will produce approximately 24,000 kilowatt hours at 100\% thermal efficiency. The efficiency of production of electrical power from heat is usually taken as $25 \%$ for statistical calculations. (24)

7.2 The present installed capacity of electric utility generating stations in the United States is about $115,000,000 \mathrm{kw}(115,000$ megawatts). (25) The production of electrical energy for the year ended January 31, 1956 , was $553,568,952,000 \mathrm{kwh}$; equivalent to $63,000,000 \mathrm{kw}$-years. This represents an average load factor of about $55 \%$.

7.3 Estimates have recently been made that the installed capacity of electrical plants will increase 8 -fold during the next 50 years. (26) The installed capacity has in the past doubled as follows: (see Figure 7)

$$
\begin{array}{ll}
25,000-50,000 \mathrm{mw} & 1927-1946,18 \text { years; } \\
50,000-100,000 \mathrm{mw} & 1946-1954,8 \text { years }
\end{array}
$$




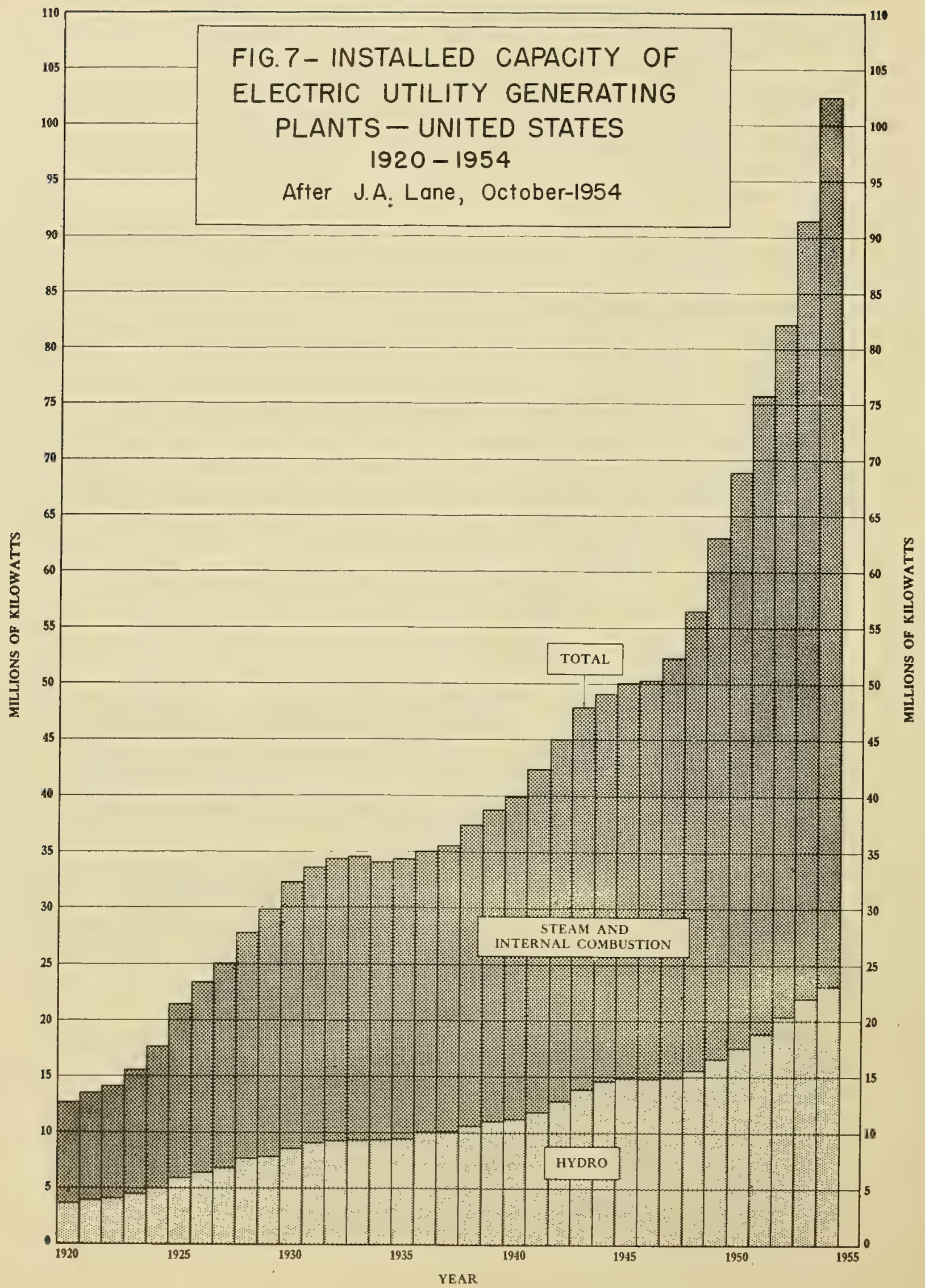


To increase 8-fold would require further growth as follows:

$$
\begin{array}{ll}
100,000-200,000 \mathrm{mw} & 1954-1970,16 \text { years; } \\
200,000-400,000 \mathrm{mw} & 1970-1985,16 \text { years; } \\
400,000-800,000 \mathrm{mw} & 1985-2000,15 \text { years. }
\end{array}
$$

7.4 It has also been estimated that $50 \%$ of the installed capacity in

\begin{tabular}{|c|c|c|c|c|c|c|}
\hline & $\begin{array}{c}\text { Thermal } \\
\text { capacity } \\
\text { utility } \\
\text { plants } \\
\text { mw } \\
\end{array}$ & $\begin{array}{c}\text { Electrical } \\
\text { capacity } \\
\text { utility } \\
\text { plants } \\
\text { mw } \\
\end{array}$ & $\begin{array}{l}\text { Electrical } \\
\text { production } \\
\text { kw years }\end{array}$ & $\begin{array}{c}\text { Electri- } \\
\text { cal pro- } \\
\text { duction } \\
\text { kw } \\
\text { hours } \\
\end{array}$ & $\begin{array}{l}\text { Thermal } \\
\text { capacity } \\
\text { nuclear } \\
\text { plants } \\
\text { mw } \\
\end{array}$ & $\begin{array}{c}\text { Electrical } \\
\text { capacity } \\
\text { nuclear } \\
\text { plants } \\
\mathrm{mw} \\
\end{array}$ \\
\hline 1956 & 460,000 & 115,000 & $6.3 \times 10^{7}$ & $5.5 \times 10^{11}$ & - & - \\
\hline 1960 & 568,000 & 142,000 & $7.8 \times 10^{7}$ & $6.8 \times 10^{11}$ & 2,000 & 500 \\
\hline 1970 & 800,000 & 200,000 & $10.9 \times 10^{7}$ & $9.5 \times 10^{11}$ & 24,000 & 6,000 \\
\hline 1980 & & & & & 100,000 & 25,000 \\
\hline 2000 & $4,000,000$ & $1,000,000$ & $54.5 \times 10^{7}$ & $47.5 \times 10^{11}$ & 700,000 & 175,000 \\
\hline
\end{tabular}
2000 will be nuclear plants. (27) Using these figures, the following table has been constructed:

Using a thermal capacity of $700,000 \mathrm{mw} \times 8,760,000$ (kwh per mw year) gives a total of $6.1 \times 10^{12} \mathrm{kwh}$ (heat) that would be produced by the operation of nuclear plants in the year 2000 .

7.5 If each metric ton of natural uranium is irradiated to 4000 megawatt days per ton as heat, approximately 63,500 tons of natural uranium would be required per year to produce $6.1 \times 10^{12}$ kilowatt hours of heat.

7.6 Plants now under construction or contemplated will have an installed electrical capacity of approximately 100 megawatts each. Assuming $25 \%$ thermal efficiency, such a plant would consume approximately 36 tons of natural uranium per year at 4000 megawatt days per metric ton. In the future it is quite probable that plants of 1000 megawatt electrical capacity could be built. At 4000 megawatt days per ton and $25 \%$ thermal efficiency, such a plant would require 365 tons of fuel per year, with a $100 \%$ load factor. If the capacity of the average nuclear plant were to be 500 megawatts electrical (or 2000 megawatts heat) 350 nuclear plants might be in operation in the United States by the year 2000. (28) 


\section{CHARACTERISTICS OF RADIOACTIVE WASTE}

8.1 If natural or enriched uranium is used in metallic form in a heterogeneous reactor, the fissioning process proceeds to some point limited by economics, corrosion or mechanical stability. It is probable that large quantities of fissionable and fertile material will remain in the irradiated fuel. Thus spent fuel elements are still very valuable since they contain part of the initial charge of fissionable and fertile material along with any new fissionable material produced. They are transported, usually in solid form, to a chemical processing plant for recovery and separation of fissionable and fertile material from fission products in diluent. This is accomplished by dissolving the elements in an acid such as nitric acid, followed by selective solvent extraction of valuable components from diluents and fission products. This leaves the fission products in the bulk of the depleted processing stream or raffinate. This raffinate stream is the high level waste and poses the principal disposal problem.

8.2 After irradiation in a reactor, the metallic elements in which unconsumed fuel and waste are mixed are highly radioactive and they are accordingly stored before processing for a period of time, during which further decay of fission products occurs. Cooling periods vary. However, the rate of decay of fission products is approximately the same; e.g., after 135 days the activity of the fission products is reduced by a factor $10^{-4}$ from their activity level at the time of discharge from the reactor. At the time of discharge from reactor, the gross fission product activity is 5.7 per cent of the rated power of the reactor.

8.3 If the fuel is fed to a reactor of homogeneous type in liquid form, the spent fuel must also be processed in liquid form. Because it is, under present conditions, more difficult to transport the waste in liquid than in solid form, the chemical processing for the removal of the waste from the fuel will presumably be accomplished at each reactor. Future developments may make it feasible to transport such liquid waste economically and safely.

8.4 In either case, the waste products of the reactor, except for those disposed of to the atmosphere in gaseous form, will be presented for disposal as liquids. The characteristics of the liquid waste are determined by the particular method of chemical processing used. Wastes resulting from the operation of nuclear reactors are classified as highlevel wastes. 
8.5 These high-level wastes, as produced by processing plants, have concentrations varying from 0.5 gals. to 20 gals. per gram of $\mathrm{U}^{235}$ burned. (29) One figure used for calculations of waste volumes resulting from solvent extraction is 820 gals. per metric ton of fuel charged to the reactor, which is equivalent, at $4000 \mathrm{mwd} /$ ton, to $2 \mathrm{gals}$. of waste per mwd of heat produced by a nuclear reactor. (30)

8.6 The principal problems in connection with the transportation and storage of radioactive waste arise from its chemical character, the energy given off as heat, and radioactivity. The waste is produced as an acid solution, and, unless neutralized by an alkali, such as sodium hydroxide, is corrosive to processing equipment. The corrosion is increased with high temperature and it may, therefore, be desirable that the temperature of waste in metallic storage be moderate; below $120-150^{\circ} \mathrm{F}$. is desirable.

8.7 Depending upon the concentration of fission products in the waste, the power produced per unit of fuel charged to the reactor, and the decay cooling time, fission products in the waste will produce heat at the rate of about 1 to $3 \mathrm{Btu} / \mathrm{gal} / \mathrm{hr}$. (31) This rate of heat production would be sufficient to raise high-level waste above the boiling point in a few days. In storage of waste underground in liquid form, it would therefore be necessary to provide means for cooling the waste and removing the heat, unless the waste were greatly diluted.

8.8 The radioactivity of liquid waste from natural uranium is from 20 to 400 curies per gallon depending upon its chemical character. (32) Adequate protection of personnel from this amount of energy requires heavy shielding. The weight of the shielding adds greatly to the cost of transportation.

\section{WASTE PRODUCTION IN NUCLEAR POWER PLANTS}

9.1 In a preceding paragraph it was assumed that the thermal capacity of nuclear power plants would reach $700,000 \mathrm{mw}$ by the year 2000 , requiring a feed of about 63,500 tons of natural uranium, or equivalent, per year. Using a figure of 820 gallons of high-activity waste per metric ton of fuel charged gives a total annual volume of waste of about 52 million gallons, equivalent to $7,000,000 \mathrm{cu}$. ft. or about 160 acre-feet. If this power were produced in 350 power plants, the amount of underground space required annually for each power plant would be about 0.5 acrefoot. 
9.2 This amount of total space is approximately $10 \%$ of the amount of space being produced annually in the mining of rock salt at the present time. By the year 2000 it is to be expected that the volume of salt production will increase several times, production having doubled in the last 15 years.

\section{TRANSPORTATION OF NUCLEAR WASTE}

10.1 The three methods in use for transportation of high-level nuclear waste, trucks on highways, barges and ships on waterways, and cars by railway, are all costly because of the necessity for shielding and other requirements for safety in transit. (33). Trucks are used for trans portation of waste for relatively short distances and generally in areas where safety is carefully controlled. The transportation of waste from processing plants to points of disposal is principally by rail or water. Estimates of cost indicate that rail transportation costs several times as much as water transportation for equivalent distances. The hazards of transportation of highly radioactive materials by rail through populated areas are also greater than is generally the case along water routes. For these reasons it may be advantageous to locate plants for the processing of spent fuel at points where the spent fuel can be transported by water from the reactor.

\section{ACCESSIBILITY OF SALT SPACE FOR WASTE DISPOSAL}

11.1 The principal areas in which salt deposits occur are those in the north central states and in the southern states along the Gulf Coast.

11.2 The salt deposits of the north central states, New York, Pennsylvania, Ohio and Michigan, are adjacent to the Great Lakes and lie in part beneath these bodies of water. It is possible in this region to use water transportation for the movement of spent fuel to a processing plant from points as far separated as New York City on the east to Chicago or Duluth on the west.

11.3 In southeastern Michigan or in northern Ohio a processing plant could be located on the shore of Lake Erie directly above salt deposits occurring at a depth of about 2,000 feet. Suitable facilities for unloading barges could be provided at the plant. Shafts could be driven to the underlying salt and the salt produced and marketed. The mined-out space could be so planned as to provide adequate roof support and safe routes for the transportation of waste to points of storage. The mining 
operations could be performed by an industrial contractor so that the net cost of the mined-out storage space might be very small. Detailed consideration should also be given to the suitability and availability of space in existing or abandoned salt mines in this area.

11.4 The area along the Gulf Coast in which salt domes occur is accessible to water transportation through the Mississippi River and its distributaries and the intercoastal canal. Numerous salt domes are present in the area but in many of them the salt is at uneconomic depths. Some of the salt domes are being mined and worked-out space now exists. The feasibility of utilizing such space for the storage of radioactive waste and at the same time continuing the operation of the salt mines would require detailed investigation. A few salt domes exist in the area in which mines have not been opened and which are favorable as to depth of salt and convenience of transportation.

\section{UTILIZATION OF SALT SPACE FOR WASTE DISPOSAL}

12. I The storage of radioactive waste in properly located space obtained by the mining out of rock salt has many advantages as compared with other methods of disposal. Some of these are the following:

a. The salt itself has considerable strength so that pillars left in mining may provide sufficient strength to support the roof. In bedded salt deposits the overlying strata such as limestone and dolomite provide truss-like support to the overburden. The possibility of roof collapse causing the release of radioactive materials stored under these conditions appears very small but merits verification.

b. The salt is impervious to the passage of water because of its plasticity and crystalline structure, so that the mined-out space is very dry. This dryness increases the life of metals by reducing rust and corrosion.

c. The salt deposits are quite level so that suitable vehicles can be used in transportation underground.

d. The two principal areas where deposits of rock salt occur in the United States have very low seismicity and the possibility of space in mined-out areas being collapsed by earth movements is extremely small. Geological examination of mined-out areas indicates that faults are not present, confirming a geological history of stability. 
e. The comparatively high thermal conductivity of salt and its sufficiently high melting point would permit the storage of wastes at moderate temperature without effect on the walls of the cavity, provided the plasticity of salt is not increased by long-continued exposure to elevated temperatures.

12.2 These advantages would not exist to the same extent if the salt cavities were produced by pumping water into the salt formations and the removal of the salt as brine. The large extent of cavities formed by this method, the absence of roof support, and the lack of control over the underground distribution of radioactive waste introduced into such cavities are disadvantages which make it inadvisable to consider the use of such space for disposal. The possibilities of collapse of such cavities are considerable and instances of surface subsistence from such collapse are known to the salt industry.

\section{PROBLEMS OF UTILIZATION OF MINED-OUT SPACE}

13.1 The storage of high-level radioactive waste in underground salt space presents several problems of an engineering character. These problems differ in some respects depending upon the physical form and characteristics of the waste as it would be produced by reactors or processing plants.

13.2 High - level waste now being produced from these sources is in liquid form. The liquid as produced is chemically active, radioactive, and produces heat through radioactive decay. It is therefore desirable that the waste be treated before storage to minimize these hazardous characteristics. It is also, in some cases, diluted in the course of the chemical separation process so that the volume is materially increased.

13.3 The activity of the waste is now chemically neutralized by treatment with alkaline solutions before it is placed in surface storage tanks for aging. This process results in an increase of about four times in the volume of the waste but this can be reduced by evaporation to a point where the slurry contains about $35 \%$ solids. (34) Waste so neutralized would apparently not have any chemical effect on the walls of a salt cavity with which it moves into direct contact but further study should be given to this problem.

13.4 The storage of the waste in surface tankage for a period of six months or more permits the decay of some of the fission products that 
have a short half-life, so that radioactivity and heat are both largely reduced. However, other fission products, such as $\mathrm{Cs}-137$, with a half-life of 33 years and $S r-90$, with a half-life of 25 years, are still present in the waste in important quantities after months of storage.

13.5 The transportation of such wastes to cooling tanks and its storage in such tanles, whether earth or metal, requires the exercise of much precaution. The piping and other vessels used in transportation must be chemically resistant to corrosion and the stainless steels and other metals required are costly. The building of metal tanks or the excavation of earth reservoirs for storage during the cooling period is also a serious economic burden. These costs must be balanced against costs of shielding and handling required to transport the waste to sites of disposal. It, therefore, becomes a problem in economics as to how long it is feasible to hold such wastes in temporary storage to reduce their activity before ultimate disposal. The engineering problems related to the transportation and storage during the cooling period have been solved but at high unit cost.

13.6 Perhaps the most difficult engineering problem connected with the underground storage of high-level waste is that of heating. The energy released from such waste as heat is, depending upon concentration, expected to be from 1 to $3 \mathrm{Btu}$ per hour per gallon. An acre-foot of such waste would, at the higher figure, produce about 1,000,000 Btu's per hour, equivalent to the combustion of about $700 \mathrm{lbs}$. of coal. From the standpoint of usable power, this is low-level heat and below the level of economic utilization. But, from the viewpoint of disposal, this amount of heat creates a problem that would be continuing for a period of 20-30 years.

13.7 It is feasible to excavate in underground salt deposits reservoirs that are adequate to contain the volumes of liquid waste that are contemplated in a program of development of nuclear power. However, the waste stored in such reservoirs would soon, from its own energy, rise in temperature to the boiling point, creating an additional hazard of production of radioactive vapor. The holding of the temperature in such underground reservoirs below the boiling point would require the removal of the heat by a cooling system installed in the reservoirs. The maintenance and operation of such a system presents problems of engineering design which, in themselves, appear to be manageable but only with substantial installation, maintenance and operating costs. An alternative method would be to let the temperature of the tanks exceed the boiling point and remove the heated air and vapor by a circulating system, filtering, and discharging the gases to the atmosphere. The 
underground storage of the liquid waste in barrels or other containers would present similar problems of heat removal and would probably, in comparison, be more costly than underground storage in bulk.

13.8 The fixation of the liquid waste in some solid form after cooling and prior to underground disposal would be advantageous as regards both transportation and storage. Various methods of conversion of waste to solid form have been suggested and some of these have been carried through the stage of pilot plant operations. Mixing with cement in the proportion of about $15 \mathrm{lbs}$. per gallon would result in a solid mixture of about 7 cubic feet, weighing about 80 lbs. per cubic foot. (36) On a large scale, at a processing plant, this material could be cast in molds into a form suitable for handling by automatic conveyors and shielded fork-lift trucks with very low hazards from irradiation. Other methods of solidification, such as incorporation in slag or ceramic products, have considerable merit. (37)

13.9 On the assumption that a disposal plant could be located in the immediate vicinity of underground storage in mined-out-salt space, the designing of a system of transportation from the plant to the point of disposal would seem to present no serious problems, using belt conveyors for movement and shielded fork-lift trucks for stacking or piling in the underground rooms. The solidified material would produce heat in storage but the problem of boiling would be eliminated and the air temperature could become high without effect on the surrounding salt. The cement blocks could be cast in such form that air could pass through them. A system of air circulation to remove the heat from storage rooms would be more feasible than the cooling of liquid waste in underground reservoirs.

\section{RECOMMENDED STUDIES}

In the light of present knowledge, no insurmountable obstacles to the storage of radioactive waste in solid form in underground cavities in salt appear to exist. Detailed studies should be carried out on the following engineering and economic phases of the problems related to salt:

a. The availability and cost of suitable space in underground salt deposits;

b. The most effective and economical methods of processing liquid waste in large quantities into solid form; 
c. The development of suitable conveyors and other devices for the underground transportation and disposal of waste in solid form;

d. The design of suitable ventilation facilities for the removal of excessive heat from underground storage chambers.

William B. Heroy

11 March 1957 


\section{REFERENCES}

1. Hess, Harry H., Chairman, Report of the Committee on Waste Disposal, Division of Earth Sciences, National Academy of Sciences - National Research Council, 1956.

2. Phalen, W. C., Salt resources of the United States: U. S. Geol. Surv. Bull. 609, p. 234, 1919.

3. Phalen, W. C., Salt: Chapter 37, Industrial minerals and rocks, Am. Inst. Min. Eng., p. 643-670, 1947.

4. Schaller, Waldemar T., and Edward P. Henderson, Mineralogy of drill cores from the potash field of New Mexico and Texas:

U. S. Geol. Surv. Bull. 833, p. 74, 1932 .

5. Alling, H. L., The geology and origin of the Silurian salt of New York State: New York State Mus. Bull. 275, p. 139, 1928.

6. Fettke, Chas. R., Occurrence of rock salt in Pennsylvania: Penn. Geol. Surv. Progress Rept. 145, 1 sheet, 1955.

7. Stout, Wilber, R. E. Lomborn and Downs Schaaf, Brines of Ohio: Ohio Geol. Surv. Bull. 37, 4th ser., p. 123, 1932.

8. Pepper, James F., Areal extent and thickness of the salt deposits of Ohio: Ohio Geol. Surv. Rept. Invest, no. 3, Ohio Jour. Sci., vol. 47 , no. 6, p. 225-239, 1947.

9. Cook, Charles W., The brine and salt deposits of Michigan: Mich. Geol. and Biol. Surv. Publ. 15, Geol. Series 12, p. 188, 1914.

10. Taft, Robert, Kansas and the nation's salt: Kansas Acad. Sci. Trans., vol. 49, no. 3, p. 223-272, Dec. 1946.

11. Barton, D. C., Mechanics of formation of salt domes with special reference to Gulf Coast salt domes of Texas and Louisiana: Am. Assoc. Petr. Geol. Bull., vol. 17, no. 9, p. 1025-1083, 1933.

12. Nettleton, L. L., History of concepts of Gulf Coast salt-dome formations: Am. Assoc. Petr. Geol. Bull., vol. 39, no. 12, p. 2373$2383,1955$. 
13. Shoemaker, E. M., Structural features of southeastern Utah and adjacent parts of Colorado, New Mexico and Arizona: Utah Geol. Society, Guidebook to the geology of Utah, no. 9, p. 48-69, 1954.

14. Hoots, H. W., Geology of a part of western Texas and southeastern New Mexico, with special reference to salt and potash: U. S. Geol. Surv. Bull. 780, p. 33-126, 1926.

15. U. S. Bureau of Mines, Salt in 1953: Mineral Market Report no. 2374, p. 7, March 29, 1955.

16. La Vigne, E. F., Mining and preparation of rock salt at the Retsof mine: Am. Inst. Min. Eng. Tech. Pub., no. 661, p. 21, 1936.

17. Jacoby, C. H., personal communication.

18. Foley, Frank C., personal communication.

19. Weigel, W. M., The salt industry of Louisiana and Texas: Am. Inst. Min. Eng. Tech. Pub., no. 620, p. 19, 1935.

20. Culler, F. L., Jr., Notes on fission product wastes from proposed power reactors: In Report of meeting on ocean disposal of reactor wastes held at Woods Hole, Mass., Aug. 5-6, 1954; Atomic Energy Comm., NYO, Waste Disposal, p. 79 (mimeo), May 15, 1955.

21. Glasstone, Samuel, Principles of nuclear reactor engineering: New York, D. Van Nostrand Co., p. 861, 1955.

22. Culler, F. L., Jr., op. cit., p. 15.

23. Joseph, Arnold B., and James M. Morgan, Jr., Radioactive wastes in the atomic energy industry; the problem of disposing of high level waste, Appendix 2, p. 24: The Johns Hopkins University, p. 32 (mimeo); under AEC Contract No. AT(30-1)-1477, March 31, 1955.

24. Ayres, Eugene, and Charles A. Scarlott, Energy sources - the wealth of the world, p. 102: New York, McGraw-Hill Book Co., p. 344,1952 .

25. U. S. Federal Power Commission, Electric Power Statistics, Report No. 55-12C, p. 15, December 1955. 
142.

26. Lane, J. A., Nuclear power requirements for large-scale industrial power: Nucleonics, p. 65, October 1954.

27. Zeitlin, H. R., E. D. Arnold and J. W. Ullman, Processing requirements, build-up of fission product activity, and liquid radiochemical waste volumes in a predicted nuclear power economy: Oak Ridge National Laboratory, January 30, 1956, File 56-1-162.

28. Culler, F. L., Jr., personal communication.

29. Culler, F. L., Jr., Notes on fission product wastes from proposed power reactors, Table 5, p. 22 .

30. Zeitlin, H. R., op. cit., Figure 4, p. 11 .

31. Joseph, A. B., op. cit., Table 1, p. 3.

32. Culler, F. L., Jr., op. cit., Table 7, p. 26.

33. Harrington, A. C., R. G. Shaver, and C. W. Sorenson, Permanent methods of radioactive waste disposal - an economic evaluation: U. S. Atomic Energy Comm., Report K-1005, Waste Disposal, p. 50, March 11, 1953.

34. Clark, Joseph R., Radioactive wastes at the Savannah River plant, p. 40: In Report of meeting on ocean disposal of reactor wastes held at Woods Hole, Mass., Aug. 5-6, 1954; Atomic Energy Comm., NYO, Waste Disposal, p. 79 (mimeo), May 15, 1955.

35. Culler, F. L., Jr., op. cit., Figures 2, 3, pp. 5, 6.

36. Vitro Corporation of America, Disposal of radioactive wastes in cement: U. S. Atomic Energy Comm., Report KXL-1377, p. 15, June 18,1952 .

37. Hatch, L. P., Ultimate disposal of radioactive wastes: American Scientist, vol. 41, no. 3, p. 410-421, July 1953. 


\section{THE NATIONAL ACADEMY OF SCIENCES - NATIONAL RESEARCH COUNCIL}

The National Academy of Sciences - National Research Council is a private non-profit organization of scientists, dedicated to the furtherance of science and to its use for the general welfare.

The Academy itself was established in 1863 under a Congressional charter signed by President Lincoln. Empowered to provide for all activities appropriate to academies of science, it was also required by its charter to act as an adviser to the Federal Government in scientific matters. This provision accounts for the close ties that have always existed between the Academy and the Government, although the Academy is not a governmental agency.

The National Research Council was established by the Academy in 1916, at the request of President Wilson, to enable scientists generally to associate their efforts with those of the limited membership of the Academy in service to the nation, to society, and to science at home and abroad. Members of the National Research Council receive their appointments from the President of the Academy. They include representatives nominated by the major scientific and technical societies, representatives of the Federal Government, and a number of members at-large. More than 3000 of the foremost scientists of the country cooperate in the work of the Academy-Research Council through service on its many boards and committees in the various fields of the natural sciences, including physics, astronomy, mathematics, chemistry, geology, engineering, biology, agriculture, the medical sciences, psychology, and anthropology.

Receiving funds from both public and private sourcesby contribution, grant, or contract, the Academy and its Research Council thus work to stimulate research and its applications, to survey the broad possibilities of science, to promote effective utilization of the scientific and technical resources of the country, to serve the Government, and to further the general interests of science. 
